\title{
Spatially-Dependent Measurements of Surface and Near-Surface Radioactive Material Using In situ Gamma Ray Spectrometry (ISGRS) For Final Status Surveys
}

\author{
Prepared by \\ J. A. Chapman, CHP, PE \\ A. J. Boerner, CHP \\ E. W. Abelquist, CHP
}

FINAL REPORT

November 15, 2006

Prepared for the United States Nuclear Regulatory Commission
in support of RFTA-06-010

This report is based on work performed under an Interagency Agreement (NRC Fin. No. J-5403) between the U.S. Nuclear Regulatory Commission and the U.S. Department of Energy. The Oak Ridge Institute for Science and Education performs complementary work under a contract with the U.S. Department of Energy. 


\section{TABLE OF CONTENTS}

$\underline{\text { PAGE }}$

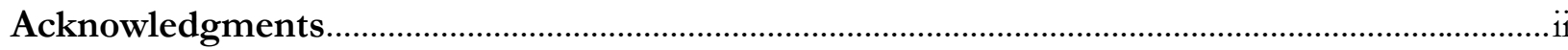

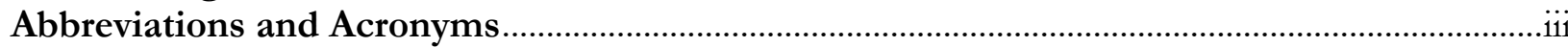

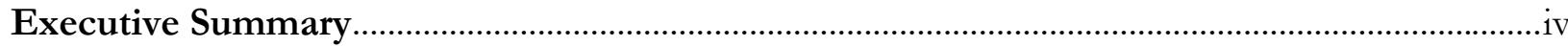

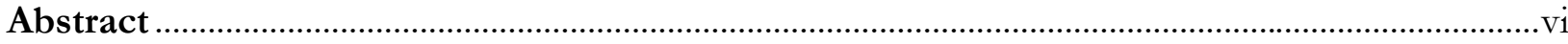

Scope

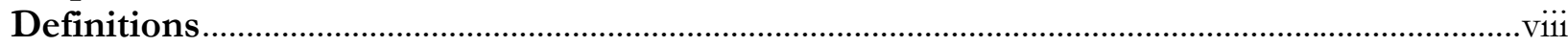

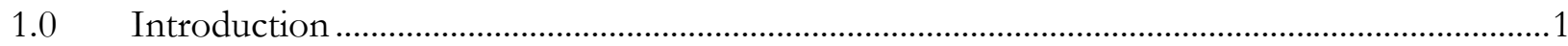

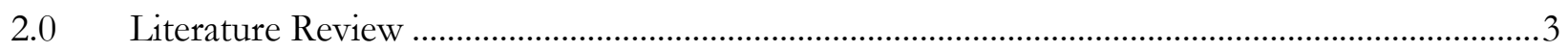

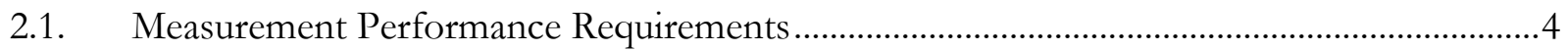

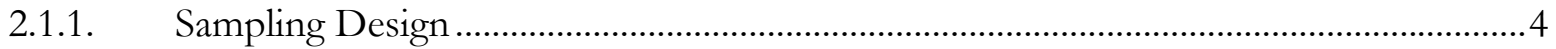

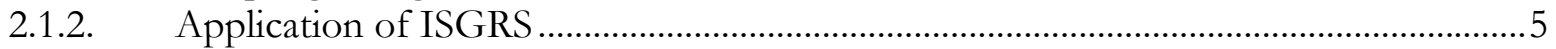

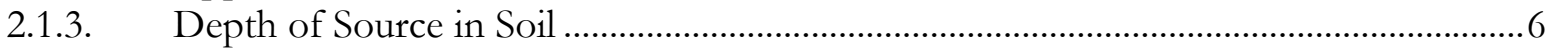

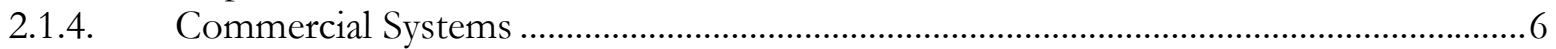

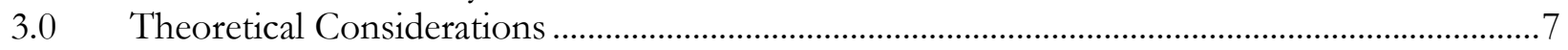

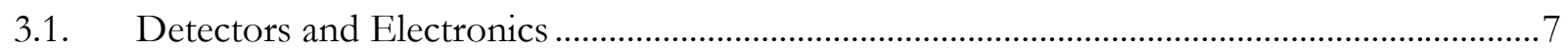

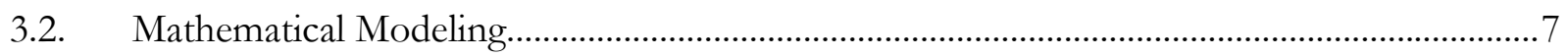

3.2.1. Detector Efficiency Model Assumptions for Uniform Distribution.............................10

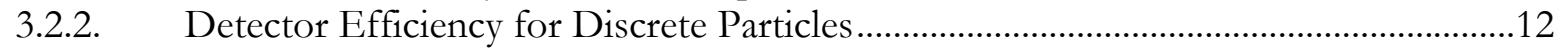

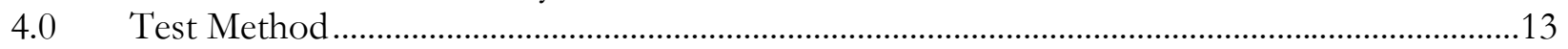

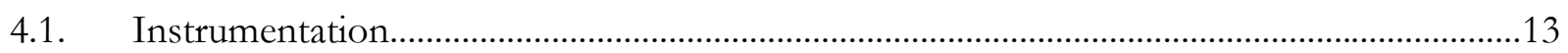

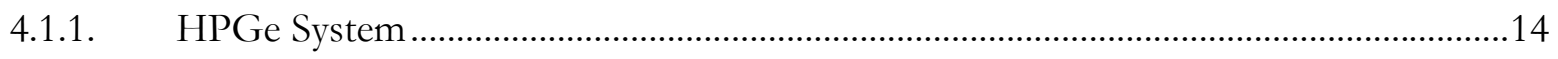

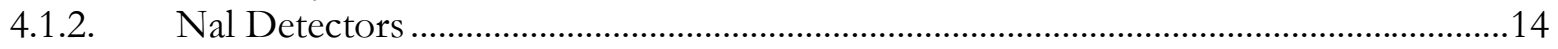

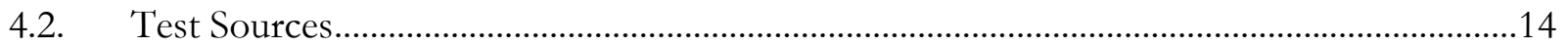

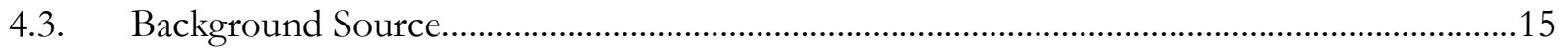

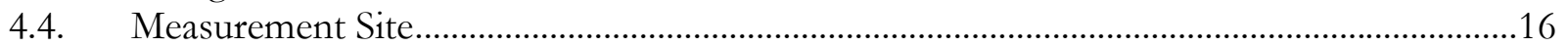

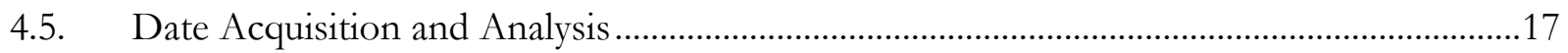

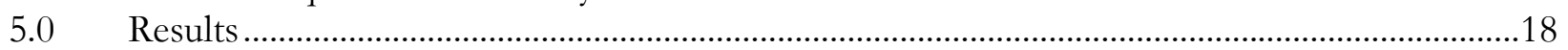

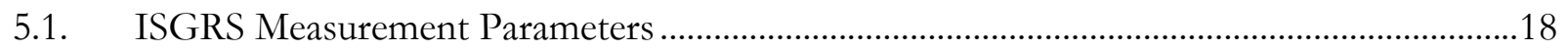

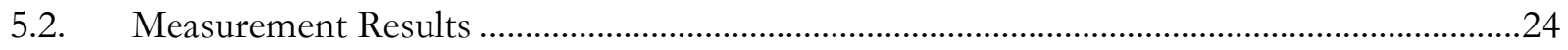

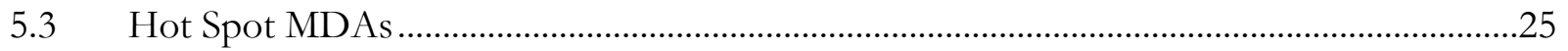

5.4. Minimum Detectable Concentration Using ISOCS Modeling of Hot Spots ........................31

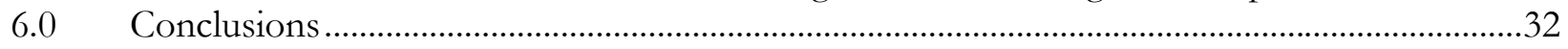

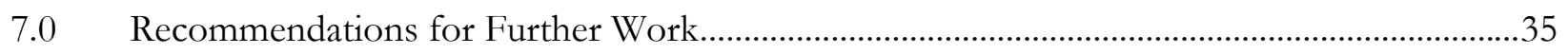

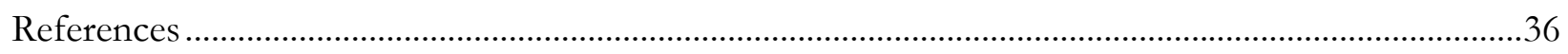

Appendix A. Primary Steps in the Field Measurements and Analysis Procedure ...............................38

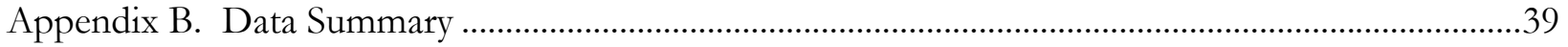

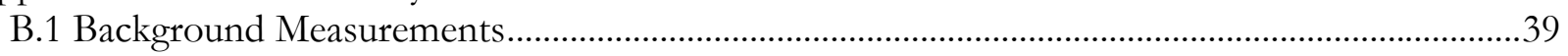

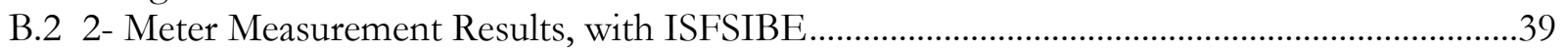

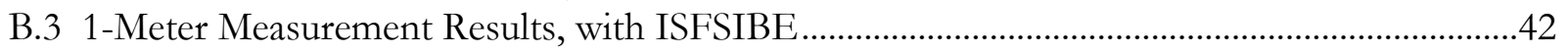

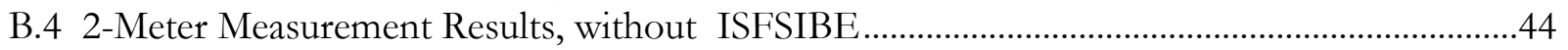

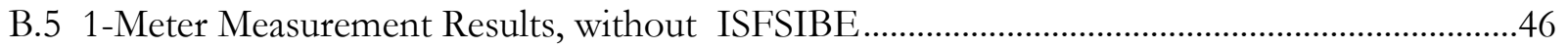

Appendix C. Spectral Data from the Experiments...............................................................................48

Appendix D. Adjustments to the Efficiency Model...................................................................................51 


\section{Acknowledgments}

Ben Estes and David Yancey, ORISE summer interns, were instrumental in setting up the ISGRS measurements, preparing the radioactive source standards, and preparing the measurement field laboratory. Ben is now in graduate school at Idaho State University, while David is completing his senior year in nuclear engineering at the University of Tennessee.

The ORISE radiochemistry laboratory performed the analytical measurements that qualified the test standards as secondary reference materials. Dale Condra and his staff are acknowledged for this effort.

Finally, a number of field engineers who supervise, direct, or teach MARSSIM methods, characterization surveys, or verification surveys were helpful in providing input and reviewing this report: Wade Adams, Tim Vitkus, Paul Frame, and Matthew Buchholz. 


\section{Abbreviations and Acronyms}

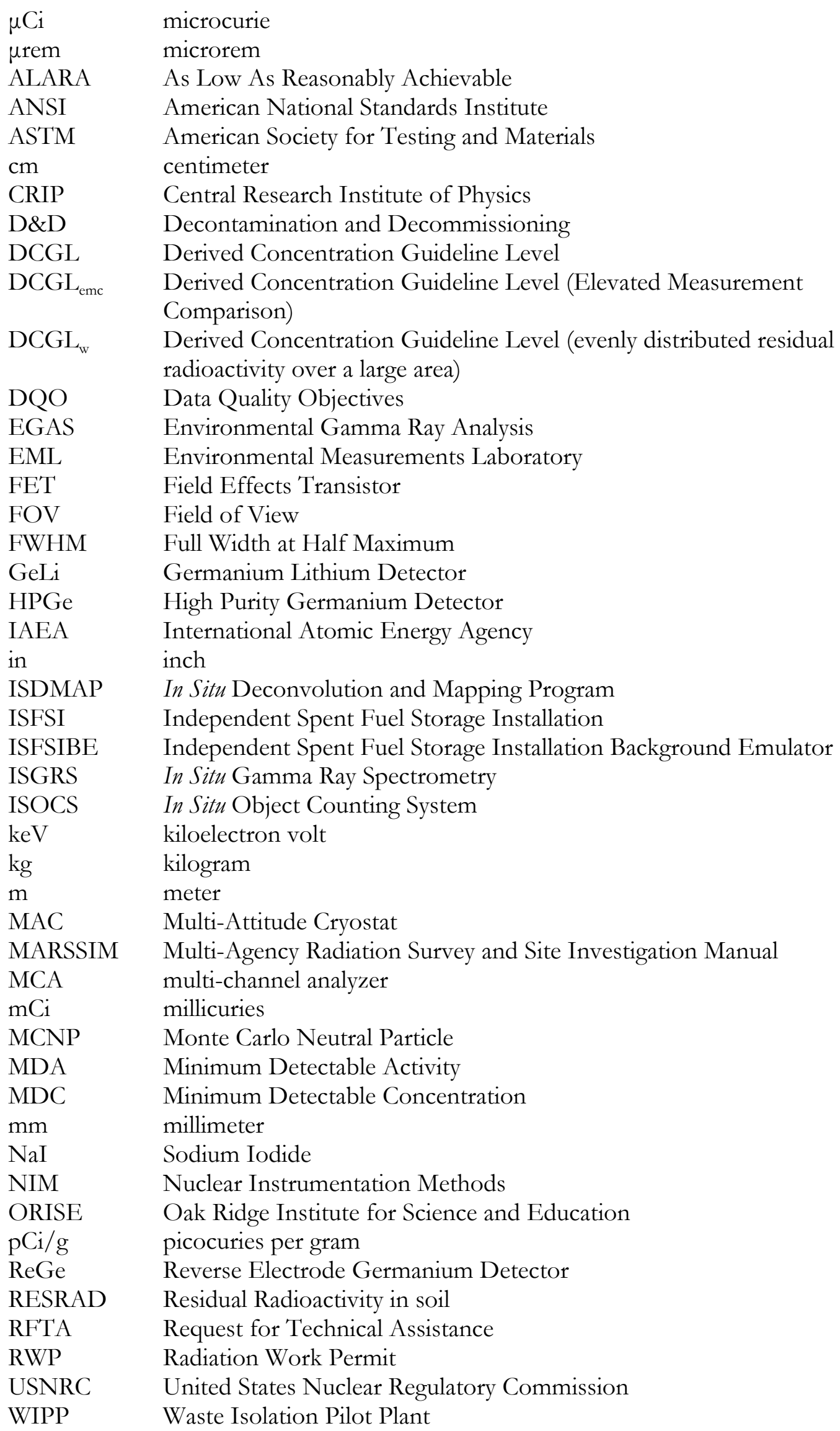




\section{Executive Summary}

In-situ, high-resolution gamma-ray spectrometry (ISGRS) measurements were conducted at the Oak Ridge Institute for Science and Education (ORISE) field laboratory in Oak Ridge Tennessee. The purpose of these tests was to provide analytical data assessing how "fit for use" this technology is for detecting discrete particles in soil. Results show that when small volumetric standards of ${ }^{137} \mathrm{Cs}$, ${ }^{60} \mathrm{Co}$, and $\mathrm{Th}_{\text {nat }}$ are prepared at nominal concentrations of a DCGL (Derived Concentration Guideline Level)-equivalent, and placed in subsurface locations at radii describing the field of view, the measurement system positively detects the tested quantity of radioactivity. The small test sources were detectable on-axis and at the periphery of the field of view, and from the surface and subsurface to 15 centimeters.

The measurement results confirm theoretical results commonly cited in the literature, that is, an ISGRS measurement is capable of detecting very small concentrations of radioactivity below a nominal $D C G L_{\text {emo }}$ and for many isotopes below a nominal DCGL $L_{w}$. For a few of the difficult to detect gammaray emitters, detection limits may be too large—all radionuclides of interest should be evaluated on a case by case basis.

Whether the device is "fit for use" then becomes a matter related to discrete particle detection from a "volume-averaged" response, similar to the arguments presented by the USNRC in concentration averaging for radioactive waste disposition. The matter of detecting localized hot spots using a farfield gamma-ray spectrometer was studied by the USDOE Environmental Measurements Laboratory (EML) (Reginatto, 1997; Reginatto, 2000). In Situ Deconvolution and Mapping Program (ISDMAP) uses the method of maximum entropy to deconvolve measurement data collected on a grid. Given input specifications for the field of view and the amount of overlap between adjacent measurement points, local areal maxima are estimated. This is a tool that should be considered in the future to help support measurement design requirements for center to center spacing, collimator selection, and mounting height. The ISDMAP code was not tested or evaluated for these measurements, though it could be in the future.

The measurement results presented in this report answer a fundamental question: for sources of ${ }^{137} \mathrm{Cs},{ }^{60} \mathrm{Co}$, and $\mathrm{Th}_{\text {nat }}$, what is the minimum detectable concentration/minimum detectable activity (MDC/MDA) for a reference soil-sample or discrete particle source placed on the fringe of the field of view and at various depths? An important distinction is that the ability of ISGRS to detect contamination does not extend to the ability to identify the precise location within the field of view.

On the one hand, a precise "far-field" ISGRS measurement provides, in less than 15 minutes, a complete radioisotopic summary of a large volume of soil (e.g. $800 \mathrm{~kg}$ ) that otherwise could only be obtained by taking hundreds of soil samples and returning all of them to a radioanalytical laboratory for analysis.

On the other hand, the averaging scheme when deploying ISGRS technology is such that the identification of a spatially-dependent radioisotopic distribution is lost. The analytical results are averaged over the volume defined by the field of view and the model assumption for contaminant depth. Of course, there is the question of what level of fine spatial information is relevant to the 
dose model; current dose models (e.g. RESRAD) are based on contamination averaged over relatively large areas and volumes. ${ }^{1}$

This report is unique in one important way. The advantage of most ISGRS methods is that the data quality objectives (DQO), including minimum detectable concentration, count time, and spatial grid estimation for point-to-point averaging, can all be derived computationally. From the original detector calibration and characterization, radiation transport codes are applied to establish boundary conditions and uncertainty estimates for the specific measurement endpoint of interest. Analytical calculations account for spatial variability, laminate source structure, surface activity, and multiple combinations of the source term $\mathrm{S}(\mathrm{r}, \theta, \mathrm{z})$. This work did not test the software or detector calibration methods --- this has already been satisfactorily completed. In fact, there is a draft American Society for Testing and Materials (ASTM) standard on how to implement proper "software calibration." This report represents a set of actual measurements that were performed under field laboratory conditions. Secondary reference standards were prepared. The standards were placed at various radii off the centerline, and at various depths in the soil. Actual detector response functions were generated from direct measurements. These measurement results can be used as representative estimates for achievable detection limits when the source term is located off axis and on the periphery of the field of view. The authors are not aware of any test standard measurements conducted below the surface.

Three distinct data reduction methods were utilized in this report employing measurement versus detection objectives. The first two methods both employed the ISOCS software to estimate an efficiency function for a 1) large volume disc source; and 2) discrete particle. The third method is an alternative approach to estimate the discrete particle measurement efficiency, but uses field (empirical) data rather than the software to estimate efficiency. This third method is detection-based and employed the calculation of a basic MDA based on a measured efficiency for a discrete particle determined by taking the results (in counts) and dividing by the known activity of the field sources. Method 3 is designed to determine how much activity in a discrete particle geometry can be potentially detected in the field at various distances and depths from the detector.

As required by USNRC RFTA 06-010, a test plan was developed to address the following issues (Chapman and Boerner, 2006): ISGRS calibration and operation; data management (specifically averaging issues); the ability to measure areas of elevated activity from discrete particles; the field of view and detecting radioactivity on the fringe; the effect of background; survey unit geometry; collimator use; soil sample depth; topographic issues; and practical guidelines for detecting spatial heterogeneities.

Because many of the questions of interest have been answered in the technical literature, a brief introduction is given that includes an extensive review of published performance reports. This review includes measurement objective requirements under MARSSIM guidance, methods for estimating the source term projection that would yield the measurement spectrum result, prior performance measurements, and mathematical methods for reconstructing a static, far-field measurement protocol into a map of elevated activity, and other relevant test data and application experience. The report continues with a description of the measurements performed at ORISE, followed by the measurement results. The ORISE test plan describes the measurement tests from which this report was written. (Chapman and Boerner, 2006)

${ }^{1}$ Private Communication, Eric Abelquist, Oak Ridge Institute for Science and Education (May 2006). 


\begin{abstract}
At the request of the NRC, ORISE performed In Situ Gamma Ray Spectrometry (ISGRS) measurements with reference source materials of ${ }^{137} \mathrm{Cs},{ }^{60} \mathrm{Co}$, and $\mathrm{Th}_{\text {nat }}$. An HPGe detector was placed 1 and 2 meters above the ground. Sources were placed on the surface and subsurface at 7.5 $\mathrm{cm}$ and $15 \mathrm{~cm}$ and in addition, at radii of 0 (on axis), $1 \mathrm{~m}$, and $2 \mathrm{~m}$. The radioactivity concentrations were equivalent to nominal DCGL $\mathrm{emc}_{\mathrm{e}}$ values selected beforehand so that actual measurement capability could be tested at these low concentrations. When placed under these measurement conditions, the sources were detectable in nearly all cases, given a 15 minute count, a 90-degree collimator, and a 38\% efficient HPGe detector. The same set of measurements was conducted in the presence of an enhanced background field, i.e., two times natural background. The purpose of the background tests was to demonstrate that collimated ISGRS measurements are insensitive to background radiation, for example, local background increases caused by Independent Spent Fuel Storage Installations (ISFSIs). The goal of the ORISE measurements is to evaluate the spatial dependence of the detector response so that future capability statements can be made regarding the detection of discrete particles in soil. For the measurements conducted, detection limits were significantly below nominal DCGL values, even for the sources placed in worst case locations.
\end{abstract}




\section{Scope}

A set of high-resolution gamma-spectrometry measurements was conducted at the ORISE laboratory in Oak Ridge, Tennessee to evaluate, by direct measurement, achievable sensitivities under field conditions. The measurements were conducted according to a test plan that was submitted to the USNRC in August of 2006. (Chapman and Boerner, 2006) The objective of this work was to provide measurement capability statements of the ISGRS technology for spatiallydependent source terms, as described in USNRC RFTA 06-010. To ORISE's knowledge, this is the first set of laboratory measurements made with ISGRS for sources placed in a number of various spatial combinations, at grade, below grade, and at various radii. It also is the first set of measurements to be conducted to evaluate the impact of background radiation. Several citations are reviewed where similar work has been reported. The authors recommend that a NUREG document similar to NUREG-1506 or NUREG-1507 should be written for the ISGRS technology applied to final status surveys. 


\section{Definitions}

Areal maxima

CAM file

Center to center spacing
Within a given field of view (or area), a smaller area (or volume) that is significantly greater than the average concentration. The areal maxima may be detectable by ISGRS, but in a far-field measurement, the specific location of the maxima cannot be known, without additional near-field measurements. For example, in the 1974 release of Regulatory Guide 1.86, average surface contamination values were provided per square meter. At the same time, an areal maximum was provided for a 100 square centimeter area within the square meter equal to three times the average. The term "hot spot" is sometimes used for areal maxima, and is defined by the USNRC as the region in a contamination area where the level of contamination is significantly greater than in neighboring regions in the area.

The high-resolution spectral data file of a measurement (for a Canberra system). The CAM file embodies all information about the measurement, including efficiency functions, energy calibration, general information, and gamma-ray libraries.

The distance between adjacent ISGRS measurements, from the center-line of the detector to the adjacent center-line measurement. For example, a 90-degree collimated detector, placed 1 meter above the surface, will measure a field of view with a radius of 1 meter. If a measurement grid is established at 2 meters, adjacent measurement locations will not overlap-the FOVs will "just touch." The diagram below shows two adjacent measurement areas, with radius, $r$, and center to center spacing $\mathrm{d}>2 \mathrm{r}$.

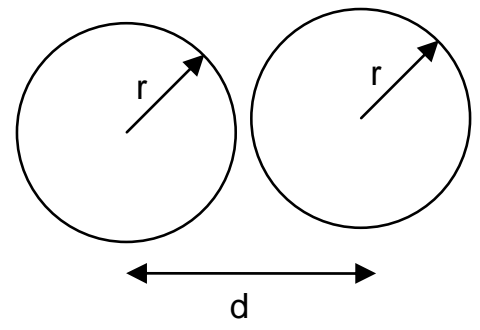

Deconvolve/deconvolute

A mathematical algorithm to reconstruct the independent (and dependent) variables of a physical process. For example, a 
measured photopeak in high resolution gamma ray

spectrometry may consist of an amalgam of closely-spaced

gamma-ray energies. The "multiplet" is then deconvolved into

its constituent components.

DCGL equivalent activity This is a new term created by ORISE to explain how the amount of radioactivity used in the test standards was determined. Experimental ISGRS measurements are made in a far-field geometry. A large cylinder of soil is measured, with radius of $1 \mathrm{~m}$ or $2 \mathrm{~m}$, uniformly distributed at depths of no greater than $15 \mathrm{~cm}$. The measurement estimates the average radioactivity concentration in the large volume element. When designing the experiments to be conducted, the amount of radioactivity determined for each of three test sources (Cs-137, Co-60, Th(nat)) was that quantity that if spread throughout the volume element of interest would yield an equivalent activity concentration near a "nominal" DCGL value. In this manner, the system is tested for whether an average DCGL concentration is detectable in various counting geometries. For example, consider the following from NUREG-1757, Volume 2, Appendix H: the NRC screening value for soil is $3.8 \mathrm{pCi} / \mathrm{g}$ Co-60. If this amount of activity was uniformly distributed in a disc volume element, radius of $1 \mathrm{~m}$, depth of 15 $\mathrm{cm}$, the total amount of radioactivity would be calculated as the product of the total mass of the volume element:

\section{$\pi(100 \mathrm{~cm})^{2} 15 \mathrm{~cm} 1.7 \mathrm{~g} \mathrm{~cm}^{-3}=8.01 E+05 \mathrm{~g}$}

and the activity concentration:

$$
A=(8.01 E+05 g)\left(3.8 p C i g^{-1}\right)=3 \mu C i
$$

Discrete Particle

Entropy (maximum)
A small localized volume of soil that contains one or several particles of radioactivity that is significantly more radioactive than the average low-level concentration of the surrounding soil. For the purposes of this study, the discrete particles significantly exceed the $\mathrm{DCGL}_{\mathrm{emc}}$ 's in areas typically less than 1 $\mathrm{cm}^{2}$. The discrete particles measured for this work were in the $1 \mu \mathrm{Ci}$ of radioactivity.

A mathematical method to deconvolve a set of point-wise measurements collected on a grid and estimate whether any localized hot spots were revealed on the basis of far-field measurements. The method of maximum entropy is used in data analysis software termed ISDMAP (In Situ Deconvolution and MAPping Program). 
Far-field

Field of View (FOV)

Intrinsic efficiency

(detector)

Laminate structure (of the source term)

Near-Field

Off-axis

On-axis

Power

Source Term

Spatially dependent
A measurement geometry made at a distance from the item of interest that is sufficiently large so as to neglect heterogeneities in the source term or sample matrix. The measurement result is calculated as an "average" response for the item of interest. A far-field measurement, given that it is an "average" measurement, cannot reveal the specific location of areal/volumetric maxima (e.g. hot spots, discrete particles).

The solid angle projection of the source at the detector. For example, a 90-degree collimator will cast a circular measurement area onto the surface of interest that is equal to the height of the detector from the plane. A 90-degree collimated detector placed one-meter above the surface will measure a circle with area of $\pi(1 \mathrm{~m})^{2}=3.14 \mathrm{~m}^{2}$. The FOV is $3.14 \mathrm{~m}^{2}$ or described as a fraction of a steradian, as $0.25 \mathrm{Sr}$.

The efficiency of a high-resolution gamma-ray detector, as a function of energy, per incident photon striking the detector.

In final status surveys, residual contamination is normally modeled as a uniform volumetric distribution of surface soil, with a depth of $15 \mathrm{~cm}$. ISGRS methods are capable of accounting for gamma-ray attenuation and scattering for sources that are laminate: a layer of clean soil, a zone of contaminated clay, a water table.

A measurement that is conducted on contact (or nearly on contact) with the source. Assumptions on source term averaging do not apply. Contact measurements are the most sensitive and also identify the position and extent of a localized and elevated contamination area.

A source located off the centerline of the detector.

A source located directly beneath the centerline of the detector.

As used in this document, the statistical power $(1-\beta)$ of the hypothesis test for whether residual radioactivity is present above the DCGL (or alternatively, not present).

The quantity and distribution of radionuclides in soil.

Measurements of surface activity conducted on a grid pattern where neighboring measurement locations are dependent on one another. Measurements down the length of a runoff ditch may be correlated, and hence spatially dependent. 
Spatially independent

Spatial grid estimation

Spatial resolution
Measurements of surface activity conducted on a grid pattern where neighboring measurement locations are independent from one another: the measurements are independent and identically distributed.

The process of determining spatial resolution for fixedposition, grid-style ISGRS measurements: the type of collimator, the height of the measurement, and the center to center spacing.

The percentage of a $100 \%$ survey required to meet detection objectives. The survey percentage can be greater than 100\% when the center to center spacing is less than the radius of the FOV. 


\subsection{Introduction}

High-resolution, gamma-ray spectrometric methods have been used in radioanalytical laboratories since the 1970s, first with the introduction of solid-state lithium-drifted germanium or "GeLi" detectors (pronounced jelly), and then by the late 1990s, high-purity germanium detectors (HPGe). These detectors revolutionized the manner in which pulseheight analysis could be performed, thereby increasing significantly the selectivity and identification of all gamma-emitting radionuclides. The early systems, including both the detector (germanium crystal, cryostat, and field-effect transistor) and the electronics (amplifier, analog to digital converter, multi-channel analyzer) were rarely deployed in the field. HPGe-based systems were analytical, laboratory-grade instruments. With the advancements in personal-computing technology and significant technological advancements in detector fabrication, mounting, cryostat design, and digital electronics, manufacturers made significant progress to miniaturize and ruggedize these systems.

Until the mid 1990s, even if precision field measurements could be made of high-resolution gamma-ray spectra, it was still a significant amount of effort to estimate source term efficiency functions. The authors of this report recall in the early 1990s taking "photon" photographs of objects "in place" (or the Latin term in situ). The difficulty then was quantifying the photopeaks and reporting, by radioisotope, the activity $(\mu \mathrm{Ci})$ or activity concentration $(\mathrm{pCi} / \mathrm{g}$ ) measured. At Oak Ridge National Laboratory, combinations of Monte Carlo Neutral Particle (MCNP) calculations were performed to iteratively solve the radiation transport equation such that the calculated spectrum was equivalent to the measured spectrum. The source term, in $\mathrm{pCi} / \mathrm{g}$, was determined as a result of the iterative computational exercise. This required a great deal of effort, as one might imagine, for just one number. Even estimating the concentration for a high energy gamma emitter would take a day or more effort.

As an industry relying heavily on numerical radiation transport codes to estimate shield design or in this case, detector response functions, a significant effort is required to convince designers and engineers that the application of the code is properly benchmarked, verified, and to some degree validated. Most QA programs require an elaborate system of checks and benchmarks before approving, carte blanch, a design result calculated by "rolling the dice" on a computer, vis-à-vis, Monte Carlo methods. While implementing Data Quality Objectives (DQO) for the Waste Isolation Pilot plant (WIPP), as an example, it was simply not good enough to run tens of MCNP calculations---it was required to mock up the "actual or most actual" measurement geometry and source term combination to confirm that the computational methods were valid (and benchmarked). This program, called the WIPP PDP (Waste Isolation Pilot Plant Performance Demonstration Program), required all national laboratories to pass blind measurement tests for plutonium-generated waste packaged in 55-gal drums. While these WIPP efforts were underway, the two manufacturers of high-purity germanium, ORTEC and Canberra, were planning to bundle the analysis software with the detector and electronics. At the same time, they were retooling to ruggedize the instrumentation. As a result, what was once thought of as an analytical laboratory device was engineered for field conditions, with software that allowed an engineer to rapidly generate detector efficiency functions in near real-time. Concurrent with the WIPP measurement protocols and analysis, scientists working through the International Atomic Energy Agency (IAEA) were studying In Situ Gamma Ray Spectrometry (ISGRS) for 
measuring ground contamination from the Chernobyl accident. In the late 1980s, the technology was really beginning to mature.

The Canberra system was introduced on the market before 1995 and named ISOCS ${ }^{\mathrm{TM}}$ (In situ Object Counting System). The system includes a characterized HPGe detector, cryostat, collimator, cart, signal conditioning electronics, a personal computer, and two pieces of software, one to analyze the spectra (GENIE-2K), and the other to generate the efficiency functions (ISOCS Calibration Software with Geometry Composer). The ORTEC system is bundled as ISO-CART ${ }^{\mathrm{TM}}$, which includes the specific HPGe detector, cart, cryostat, signal processing electronics; and the software, which may include the spectral analysis software and the count-to-activity-conversion efficiency software. Hundreds of both systems have been deployed for applications that require laboratory-grade measurements of radioisotopic constituents in radioactive products and materials, waste, process control systems, and environmental monitoring applications.

When compared to conventional survey scans, ISGRS is an invaluable tool for measuring radioactive material mixtures because it detects very reliably one isotope from another. When compared to conventional sampling and analysis, ISGRS has the added benefit of not having to collect samples, manage the samples including chain of custody, ship to laboratories, and wait for results a week later. ISGRS has been widely used for scoping studies and for managing decontamination and decommissioning (D\&D) activities in real time: answering questions about how much soil to remove, how much concrete to scabble, and so on.

ISGRS has not been widely applied to confirmation of less than background levels of residual radioactivity and ensuring that MARSSIM sampling, analysis, and measurement conditions are met. If the ISGRS technology was applied to a MARSSIM-type survey, there would be issues encompassing both the detection efficiency for volumetric contamination for comparison against $\mathrm{DCGL}_{\mathrm{emc}}$ or $\mathrm{DCGL}_{\mathrm{w}}$ values, and discrete particle detectability. This report investigates both the volumetrically averaged detection performance, and discrete particle detectability using ISGRS in field conditions.

To this end, three distinct data reduction methods were utilized employing measurement versus detection objectives. The first two methods both employed the ISOCS software to estimate an efficiency function for a 1) large volume disc source; and 2) discrete particle. These two methods are measurement-based approaches and provide MDCs in pCi/g. The third method is an alternative approach to estimate the discrete particle detection efficiency, but uses field (empirical) data rather than the software to estimate efficiency. This third method is detection-based and employed the calculation of a basic MDA (not MDC) based on a measured efficiency for a discrete particle determined by taking the results (in counts) and dividing by the known activity of the field sources. Method 3 is designed to determine how much activity in a discrete particle geometry can be potentially detected in the field at various distances and depths from the detector.

The detector response for a "discrete particle of interest" is assessed in this study assuming an otherwise non-contaminated land area. Specifically, what level of activity in an off-axis discrete particle will trigger a positive measurement result, discernable from background? At the licensee's discretion, this could then be used to trigger a follow-on investigation. One 
focus of the work herein is to establish discrete particle detectability using an ISGRS, as opposed to trying to measure or quantify the hot spot activity.

Additionally, there is the complicating issue of what the smallest allowable average volume should be for reliable detection and comparison to volumetric DCGL release criteria — matter which has been treated only partially in the MARSSIM approach. This issue is not addressed in this report. If the end-goal is discrete particle detection outside of the scope of a MARSSIM survey, then volume averaging is a non-issue.

In order to implement ISGRS under MARSSIM methodology, a number of NRC licensees have submitted plans for setting a MARSSIM investigation level, a measurement result that triggers further investigation. For example, one NRC licensee made the following case in its approach to setting investigation levels for an ISGRS measurement:

- $\quad$ Using a set height ( $2 \mathrm{~m}$ ), and a collimated viewing angle (90 degrees), perform a $100 \%$ scan looking at a $12.6 \mathrm{~m}^{2}$ field of view (FOV) for each measurement. Overlap the FOVs such that $100 \%$ coverage is achieved.

- Determine an effective investigation level that accounts for the possibility that, while looking at a $12.6 \mathrm{~m}^{2} \mathrm{FOV}$, the activity may actually be located (worst case) in a single $1 \mathrm{~m}^{2}$ at the edge of the FOV.

- The effective investigation level is an observed value that correlates to what $1 \mathrm{~m}^{2}$ at the edge of the FOV, containing activity at the $1 \mathrm{~m}^{2} \mathrm{DCGL}_{\mathrm{emc}}$, would "look like" while in fact measuring a $12.6 \mathrm{~m}^{2}$ area.

- The effective investigation level is thus calculated as the $\mathrm{DCGL}_{\mathrm{emc}}$ for a $1 \mathrm{~m}^{2}$ area, multiplied by the ratio of the $12.6 \mathrm{~m}^{2} \mathrm{MDC}$ to the $1 \mathrm{~m}^{2} \mathrm{MDC}$.

However, whether the potential application of ISGRS is intended for MARSSIM surveys or for simple detection of discrete particles outside of the MARSSIM context, the underlying issue is the instrument detection capability. This is the primary issue addressed in this report.

\subsection{Literature Review}

ISGRS measurement results are widely published for hundreds of applications. These methods have been studied, evaluated, and reviewed within subcommittees of ANSI, the IAEA, and ASTM. A standard within ASTM C26.12 is currently in draft, addressing specifically the use of the mathematical modeling software used to quantify radioactivity detected by a "high-resolution" gamma-ray detector. The U.S. Department of Homeland Security recently announced that ISGRS-like systems will be distributed throughout the country in essentially a portal monitor configuration. Manufacturers of the hardware and/or software for performing these measurements have published widely as well. The U.S. Department of Energy has used this technology for special nuclear material holdup measurements, safeguards and security, waste characterization to meet the Nevada Test Site low-level radioactive waste acceptance criteria, and characterization of materials during decontamination and decommissioning. It is a mature technology, having been deployed for 
nearly fifteen years. Only recently, however, have engineers been interested in applying it to meet MARSSIM or MARSSIM-like objectives for final status surveys. At least fifteen citations have been found with direct application to this question, and are summarized in this report.

\subsection{Measurement Performance Requirements}

Determination of the baseline measurement requirements for a final status survey is a primary issue. How well does the measurement method have to perform to meet detection objectives? For this question the baseline methods are evaluated and guidance is given in NUREG-1506 and NUREG-1507. Nominal detection limit methodologies are provided for walk-over surveys, NaI-scans, and to a lesser degree, spectrometry. A significant discussion is presented in NUREG-1507 concerning theoretical detection limits and practical detection limits to account for uncertainties brought about by "surveyor skill" and human performance. Gamma-ray spectrometry is discussed in chapter 6 of NUREG-1506, and chapter 7 of NUREG-1507. Both chapters describe general representations of the technology in the late 1990s. Neither of these references covers the effect of collimating the detector, detector standoff, modeling software, and intrinsic efficiency. Nevertheless, some generalized minimum detectable concentrations are given showing that in most cases the detectable concentration is less than $0.1 \mathrm{pCi} / \mathrm{g}$. It is important to recognize that the low activity concentration activities that can be derived are due in part to the fact that the "mass of the sample" (the denominator) is large (many kilograms). It is also pointed out, and is still true today, that when compared to NaI-scanning:

- $\quad$ "ISGRS is of value when the detector is used to verify the absence of contamination in the area;

- $\quad$ ISGRS offers the additional benefit of improved documentation over the scan survey;

- $\quad$ ISGRS measurements are generally more objective and less likely to be influenced by human factors than the conventional scan survey records obtained with $\mathrm{NaI}$ scintillation detectors, which require subjective interpretation of the detector response by the surveyor." (NUREG-1506, page 6-1)

\subsubsection{Sampling Design}

What sample spacing and measurement grid system is allowable under NUREG-1575 (MARSSIM)? Essentially, the question is how to establish a statistical survey design to ensure sampling and measurement protocols will satisfy the statistical proofs that residual radioactivity is less than the $\mathrm{DCGL}_{\mathrm{w}}$ and $\mathrm{DCGL}_{\mathrm{emc}}$. For far-field measurements such as ISGRS, it is relevant to consider whether elevated areas of radioactivity could be detected on a grid pattern, when the solid angle subtended by the surface of the earth at the detector is large. More simply put, given an ISGRS measurement with a field of view (FOV) with a radius of $2 \mathrm{~m}$, how would one establish the center-to-center spacing between adjacent measurements to ensure that no elevated areas of radioactivity remained undetected? An illustration of the geometric measurement question is provided below in Figure 1. Consider 
a detector FOV with radius, r. How does one determine d, the lattice spacing between adjacent measurement points? In the left hand diagram, $d$ results in undersampling. In the right hand diagram, $d^{\prime}\left(d^{\prime}<\mathrm{d}\right)$ results in oversampling.
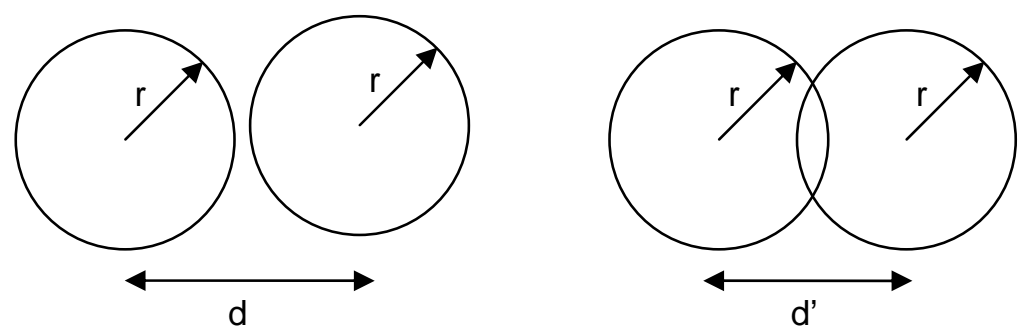

Figure 1. Illustration of selecting a detector field of view (FOV) and lattice spacing, d, to achieve a necessary "spatial" detection limit. When $d$ is greater than $r$, the area of interest is undersampled, as in the left-hand illustration. When $d$ is less than $r$, the area of interest is oversampled, as in the right-hand illustration.

In the mid to late 1990s, Reginatto et al. developed software at the U.S. Environmental Measurements Laboratory (EML) to "analyze data from a series of in situ measurements on a grid and identify potential localized areas of elevated activity." (Reginatto, 1997). The early version of this code was called ISD97, and later, In Situ Deconvolution and Mapping Program (ISDMAP). (Reginatto, 2000). The method of maximum entropy, from which ISDMAP was developed, is a method for unfolding (or deconvolving) either spatially or time-correlated data into constituent components. The method effectively reconstructs a projection of a source term that would yield the measured spatial response. While the method is very much of interest to ORISE, ISDMAP unfortunately does not appear to be widely applied since its development over six years ago. It is this methodology that may begin to provide insight toward the ultimate questions posed by the NRC:

- Are far-field measurements capable of detecting areas of elevated activity, where the surface area of the elevated activity is smaller than the FOV?

- Under some mathematical test, what is an optimal d for a given $r$, so that an elevated area of radius $\mathrm{r} / 10$ can be detected at 2 times the average radioactivity concentration of the measurement area described by radius, $r$ ?

\subsubsection{Application of ISGRS}

Beck et al. published one of the first papers on the use of gamma-ray spectrometers (high and low resolution) for in situ environmental measurements. (Beck, 1972) At that time of course, the Nuclear Instrumentation Methods (NIM) modules and data acquisition electronics were very large and essentially relegated to laboratory conditions. Nonetheless, the ideas and concepts were laid out in the 1970s. In 2003, Bailey published an intercomparison study of $\mathrm{NaI}$ and HPGe performance in an ideal laboratory setting. A number of application-based papers have been published in the last fifteen years demonstrating the performance of this method for the detection and characterization of radioactive material. 


\subsubsection{Depth of Source in Soil}

Most RESRAD model assumptions use a surficial source term for the top $15 \mathrm{~cm}$ of soil. Oertel evaluated ISGRS measurement methodologies for various soil depth profiles. (Oertel, 2004) If the source is distributed down into the soil, there are three factors that influence the observed count rate. For a given specific activity of the source, as the depth increases; (1) the distance to the detector increases, so the count rate decreases; (2) the detector views a larger source area, so the count rate increases; and (3) the photon attenuation in the soil increases, so the count rate decreases.

\subsubsection{Commercial Systems}

Within the United States, there are three methods/systems commercially available:

- Canberra In-Situ Object Counting System (ISOCS)

- Ortec ISOCART ${ }^{\mathrm{TM}}$ and Isotopic-32 software

- Eberline SNAPTM (Spectral Nondestructive Assay Platform)

There are a number of "third-party," do-it-yourself methods also used in practice. Some physics groups use MCNP to generate detector response functions; others may use a combination of SYNTH and ISOSHIELD or MICROSHIELD ${ }^{\text {TM }}$ to generate estimates of the detector efficiency, as used in that specific measurement application. In 2002, Reiman described software named EGAS (Environmental Gamma Ray Analysis), which was later applied at the Fernald site. (ref: US DOE, 20701-RP-0006, December 2004; ITRC 2006; and Roybal, 2003) Internationally, Zombori et al. from the Central Research Institute of Physics (CRIP) in Budapest, Hungary are credited with making advancements in these methods in large part because of their work on monitoring fallout after the Chernobyl accident. The authors have used a number of these methods previously, and worked with the IAEA and CRIP in 1991. All of these methods are directed toward achieving one result: calculating or inferring the source term that would generate the measured, high-resolution spectrum. This technique, in radiation transport, is often termed the adjoint problem.

Table 1 in Shebell's paper cites several additional participants engaged in an intercomparison study that took place in Grand Junction, CO, Duke Engineering and Services, U.S. Army Corp of Engineers, US Environmental Protection Agency Office of Radiation and Indoor Air (ORIA), and the EML. (Shebell, 2003) The intercomparison measurements were performed in 1999 and it is not quite clear whether any of these methods have been widely used since. This work was very interesting in that it tested seven systems against reference standards of uranium, thorium, potassium on an aircraft landing pad. The intercomparison results were favorable: " $84 \%$ of all measurements were within $20 \%$ of the reference values. Excluding ${ }^{226}$ Ra results, $90 \%$ of the measurements were within $20 \%$ of the reference values." These results describe method-to-method variation and differentiation rather than spatial effects.

The authors of this report have used all three of the commercial products listed above, though the measurements in this report were performed with the most recent version of the Canberra ISOCS system. Specification sheets, technical reports, and measurement tests are 
provided on each of the manufacturers three websites. ${ }^{2}$ The Canberra and Ortec systems are complete, including the HPGe detector, the data acquisition electronics, and analysis software. The Eberline system is the analysis software alone, written in LABVIEW.

\subsection{Theoretical Considerations}

\subsection{Detectors and Electronics}

High purity germanium detector performance is well described in the literature (Beck 1972; Shebell 2003). The theoretical considerations applicable to this work are to ensure that the gain is stabilized, the detector is well calibrated for energy, including shape factor parameters, and the digital electronics of the MCA are properly set.

\subsection{Mathematical Modeling}

In mathematical modeling, the detector response function is analyzed in such a way that each isotope detected is quantified. There are actually two ways to quantify the radioactive material: 1) prepare a calibration standard that is identical to the measurement unknown; 2) use radiation transport theory to predict the detector response function per unit radioactivity of each constituent radionuclide. Option 1 is impossible to do for every single case of measurement unknowns. Option 1 is normally performed under a set of controlled laboratory-like conditions. The results are published as benchmarks, from which the mathematical model performance is normalized.

As one example, a high-resolution spectrum collected after the Chernobyl accident (Figure 2) shows the following characteristics.

${ }^{2}$ Search under Canberra ISOCS, Ortec ISOCART, Ortec Isotopic-32, and Eberline SNAP. 


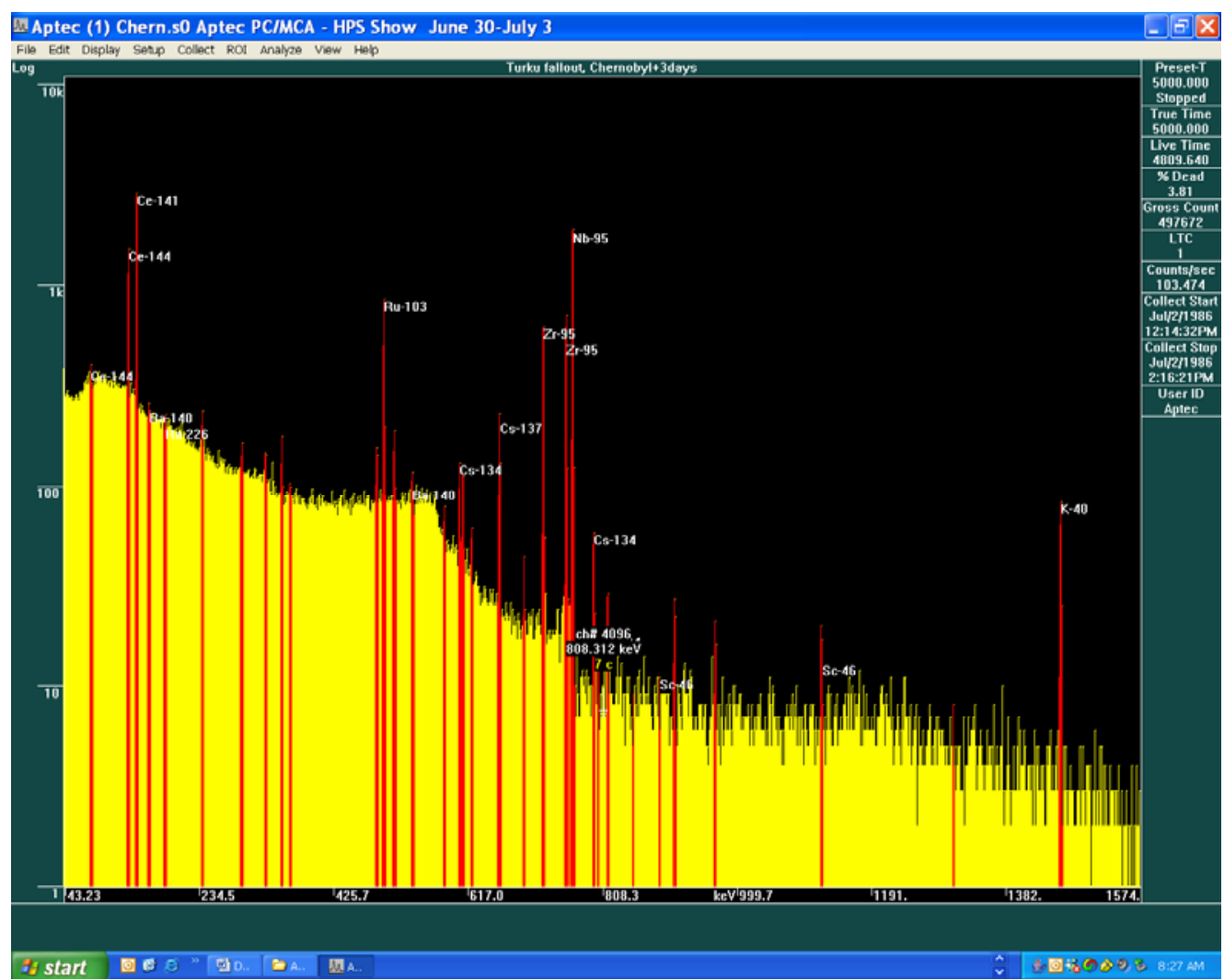

Figure 2. Characteristic High Resolution Gamma Ray Spectrum 
The spectrum is analyzed to produce a table of photopeak areas for each photopeak detected. The area of the photopeak is proportional to the quantity of a specific radionuclide. Each photopeak is associated with a specific isotope. A table is generated by radionuclide, gamma-ray energy detected, and associated photopeak area. The mathematical modeling step comes next.

All details of the measurement configuration must be known: the detector, collimator, gain, resolution, height, positioning, background, source geometry (disc, radius, thickness, distribution, lumps, soil properties, moisture content). Much of the source geometry and characteristics of the radioactive material itself are estimates and assumed by the analyst/engineer.

Mathematical modeling has significantly improved in the last 20 years, largely because of the computer revolution. A personal laptop computer can perform as many calculations as the large mainframes of the 1970s. This having been said, a mathematical representation of the measurement is established. Beck, DeCampo, and Gogolak in as early as 1972, established the formalism for making these types of calculations. (Beck et al., 1972)

Looking at a specific, basic example, consider a single radionuclide that emits only one gamma-ray during decay. It is considered monoenergetic. Beck et al. suggested the following mathematical model to describe the flux $\Phi(r, \theta)$, of gamma rays at distance $r$ from the source in the angular direction of $\theta$, of energy $E$ and height $h$ from the ground emitted from soil with a depth concentration profile that is exponential as a function of $z$ (depth):

$$
\phi(r, \theta)=2 \pi \int_{0}^{2 \pi \omega} \int_{h} \frac{S_{o}}{4 \pi r^{2}} e^{\left(\frac{-\alpha}{\rho} \rho z\right)} r^{2} \sin \theta e^{\left(\frac{-\mu_{s}(r-h)}{\omega}\right)} e^{\left(\frac{-\mu_{a} h}{\omega}\right)} d r d \theta
$$

where

$$
\begin{aligned}
& \mathrm{r}=\quad \text { the distance from each element of differential volume to the detector } \\
& \begin{array}{l}
\text { position } \\
\mathrm{z}=
\end{array} \\
& \mathrm{S}_{\mathrm{o}}=\text { depth (thickness) of the source term from the surface }(\mathrm{cm}) \\
& \alpha=\text { the reciprocal of the relaxation length of the exponentially-distributed activity } \\
& \\
& \varrho=\text { as a function of } \mathrm{z} \text {, depth }\left(\mathrm{cm}^{-1}\right) \\
& \mu_{\mathrm{a}}, \mu_{\mathrm{s}}=\text { the gamma-ray attenuation coefficients for air and soil, respectively }\left(\mathrm{cm}^{-1}\right)
\end{aligned}
$$

This model illustrates exactly what type of calculation must be performed to estimate the number of photons striking the detector with energy E. The detector registers each of these events explicitly in ISGRS (unlike any other technology). The intrinsic efficiency of the detector is known through calibration (or detector characterization). The result is that the source term of each radionuclide ( $\mathrm{pCi} / \mathrm{g}$ ) is directly measured and calculated precisely to the degree that the model parameters reflect the actual measurement conditions. Furthermore, uncertainty analyses are conducted to bound the model equations, similar to the mathematical models used for the transport of radionuclides in the environment (e.g. RESRAD). 
Commercial systems available for 15 years now have extended the geometry templates for describing the measurement conditions; have extensive libraries for the scattering and absorption coefficients; and have resulted in the publication of many papers on the validation, verification, and benchmarking of the methods, while preserving the proprietary nature of the formalism.

\subsubsection{Detector Efficiency Model Assumptions for Uniform Distribution}

In situ gamma ray spectrometers perform two functions: identify gamma-ray radionuclides present in the material of interest and quantify each detected radionuclide. This section discusses how radionuclide concentrations in assumed uniform distributions are determined using the modeling capabilities of the ISGRS. For low-level counting at background radiation levels, the photopeak identification algorithm is very important to ensure that the radionuclide false positive or false negative rates are acceptable. Parameters should be set to "detect only when sufficient statistical evidence exists." This is accomplished in a number of approved ways. For "difficult to detect" gamma-ray emitters, the spectrometer may be required to count longer or possibly, to scale from an easier to detect radionuclide of concern. Suffice it to say that the photopeak identification and radionuclide detection methods are extremely accurate. The quantification of each detected radionuclide, on the other hand, is subject to efficiency model assumptions used by the analyst.

A collimated ISGRS measures a disc source, with radius, $r$, and thickness $z$. The thickness (z) that can be detected is limited by the energy dependent attenuation coefficient that describes the scattering and absorption properties of the medium as a function of gammaray energy. The deeper the source is located in soil the less likely it will be detected. Under normal measurement circumstances with ISGRS a single small source (of $1 \mu \mathrm{Ci}$ ) buried any deeper than $50 \mathrm{~cm}$ will remain undetected. ${ }^{3}$ There are many cases, however, where ISGRS can be set up on contact with uncontaminated soil and used to measure for long periods of time to detect deeply buried sources (of significant activity) at depths of up to 5 meters. This application is a separate effort from the final status survey application, however.

When a 90-degree collimator is selected for use, the radius of the disc source is equivalent to the height of the detector. For example, with a detector height, h, equal to $100 \mathrm{~cm}$ (1 meter), the radius for the field of view is also $100 \mathrm{~cm}$. The field of view described by the radius $\mathrm{r}$, is not perfect: there are minor edge effects in establishing the detector response function at this boundary. These radial edge effects are relatively small however, when compared to the vertical profile of the source term. As alluded to earlier, the most important parameters to describe in the model are based on the depth of the source term, and any stratification or heterogeneities in the depth or areal distribution.

For final status surveys, the source term is normally defined (and modeled by ISGRS) by a disc source of thickness $z$, equal to $15 \mathrm{~cm}$. In keeping with the example above, the "disc source" with radius of $100 \mathrm{~cm}$ represented by:

\footnotetext{
${ }^{3}$ Detection limits for buried point sources must be modeled and calculated on a case by case basis. Excellent results can be achieved when "surveying" for a lost source. The $50-\mathrm{cm}$ value cited here is a general observation for a 15-min measurement conducted at 1 or 2 meters from the ground. 


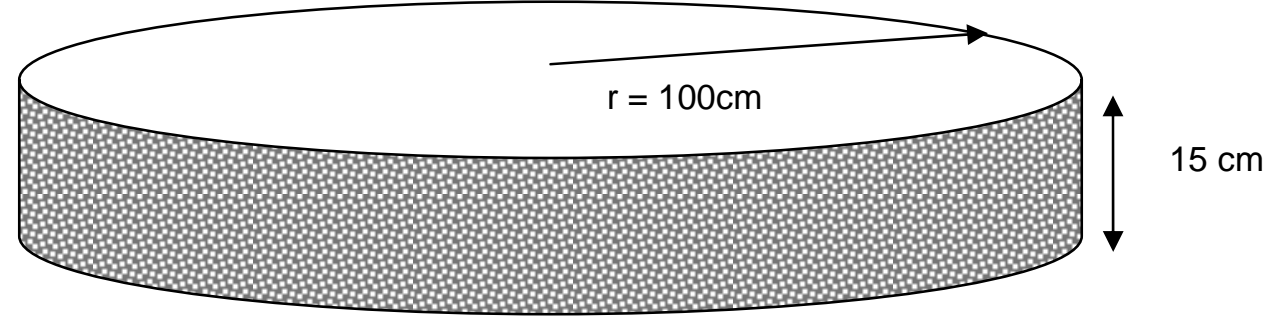

The sample volume of the disc source is:

$$
\pi(100 \mathrm{~cm})^{2} 15 \mathrm{~cm}=4.7 E+05 \mathrm{~cm}^{3}
$$

With a nominal density of soil equal to $1.7 \mathrm{~g} \mathrm{~cm}^{-3}$ the mass of the disc source is:

\section{$\pi(100 \mathrm{~cm})^{2} 15 \mathrm{~cm} 1.7 \mathrm{~g} \mathrm{~cm}^{-3}=8.01 E+05 \mathrm{~g}$}

Furthermore, if a uniform distribution of contamination is spread throughout this volume at $3.8 \mathrm{pCi} \mathrm{g}^{-1}$ (an arbitrary value as an example here), the total activity in the entire volume is:

$$
A=(8.01 E+05 g)\left(3.8 p C i g^{-1}\right)=3 \mu C i
$$

The mathematical efficiency function that is calculated by the system is based on a simple model such as this. As a result, the interpretation of the measurement results is as follows: the detector response (i.e. the integral number of photons detected under the photopeak of interest) corresponds to a uniform activity concentration of contaminant at ' $\mathrm{x}$ ' $\mathrm{pCi} / \mathrm{g}$. If there is reason to believe, either by direct measurement or otherwise, that the depth profile of the contaminant is not uniform at $15 \mathrm{~cm}$, then the mathematical efficiency function can be adjusted and the output modified accordingly. For the measurements reported here and for all final status survey measurements observed by the authors, the sample volume is normally calculated as presented. It is important to note (and not be fooled) that in using this efficiency calibration, if a buried source is detected and the surface contamination is zero, the measurement result will be biased low. Similarly, if a discrete particle does exist at the periphery of a detector FOV, in an otherwise clean surface soil, the measurement result will be biased low.

In summary, ISGRS measurement results must be clearly interpreted. Given a mathematical efficiency function to describe the source term of interest, the response of the detector is calibrated to provide a "volume weighted average" over the assumed measurement conditions (source uniformly mixed in $15 \mathrm{~cm}$ of surface soil and a measurement radius of 1 meter). It is possible to detect point sources deeper than $15 \mathrm{~cm}$ and/or discrete sources within the field of view, but the projected efficiency function under the experimental tests does not know how to model these conditions before the fact. The spectrometer only knows that it detected the contaminant within the FOV; it is up to the analyst to ensure that the proper model conditions are applied from which the efficiency function was calculated. 


\subsubsection{Detector Efficiency for Discrete Particles}

The previous section discussed the common ISGRS application of quantifying the radionuclide concentration within a particular soil volume - for example, over a radius of $1 \mathrm{~m}$ and depth of $15 \mathrm{~cm}$. This section presents an approach to determining the detector efficiency for detecting hot spots when the ISGRS is used to scan land areas. It is in this context that the detector efficiency was determined for discrete particles.

First, it is important to understand that scanning is performed to identify or detect the presence of areas of elevated contamination, which may be discrete particles. The purpose of scanning is not to quantify the activity in the elevated area. The difference is one of detectability versus measurability. According to MARSSIM, "Scanning surveys are performed to locate radiation anomalies indicating residual gross activity that may require further investigation or action" (MARSSIM 2000). Therefore, it is necessary to define ISGRS investigation levels during scanning, and to specify the nature of the further investigation once the investigation level is triggered.

Regarding the detection of discrete particles in this section of the report, the end-goal is detection of discrete particles, not evaluation of a volumetrically contaminated area against MARSSIM DCGL values. Therefore, the investigation level in this context is considered to be equal to the detection limit (i.e. MD A) for the particular photopeak being considered (e.g., Co-60 (1173 $\mathrm{keV}$ ), Cs-137 (661 keV) or Th-232 (911 keV from Ac-228)). That is, for a specified count time, if the net counts in the photopeak region exceeded the photopeak minimum detectable counts, then an investigation would be triggered. As noted earlier, this corresponds to the ISGRS parameter setting to "detect only when sufficient statistical evidence exists." Therefore, if the investigation level is exceeded, indicating that a particular radionuclide of concern may be present within or near the detector's FOV at a level distinguishable from background, then a conventional $\mathrm{NaI}$ scan might be conducted to confirm and/or identify the location of the discrete particle. Thus, a primary aspect of this study was to calculate the discrete particle activity, when located at various radial and depth locations that would result in further investigation. This discrete particle activity is also called the "hot spot MDA."

Two pieces of information are required to calculate the hot spot MDA as defined in this study: 1) the minimum detectable counts (abbreviated as "MD Counts," with the subscript "b" for "background") in the photopeak region from background spectra, and 2) the hot

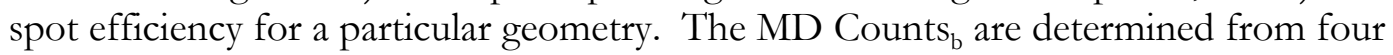
background spectra: natural background at 1- and 2- meter detector heights, and ISFSIsimulated background at 1- and 2- meter detector heights. Furthermore, the MD Counts ${ }_{\mathrm{b}}$ are generated from the ISGRS software and represent the minimum detectable counts for a fifteen minute count time for each of the three photopeak regions of interest in this study: $1173 \mathrm{keV}, 661 \mathrm{keV}$, and $911 \mathrm{keV}$. Thus a total of $12 \mathrm{MD}$ Counts in the photopeak region were generated in this study-one set of three for each of four background runs.

The MD Counts $\mathrm{s}_{\mathrm{b}}$ were determined somewhat differently for Co-60 and Cs-137 versus Th232 due to the fact that Th-232 is present in natural background. For the former two radionuclides, the ISGRS software was used to calculate the minimum detectable activity from the background spectra based on a 95\% detection level. The MDA from the system software was directly converted to MD Counts based on the detector efficiency for the 
particular photopeak energy (1173 keV and $661 \mathrm{keV})$. For Th-232, the MD Counts were $_{\mathrm{b}}$ calculated from the net peak area counts present in the $911 \mathrm{keV}$ peak in each background spectra. Specifically, the MD Counts were based on a $95 \%$ detection level using the detection sensitivity equation of 3.29*SQRT(BKG COUNTS).

This equation and the experiment results are based on an assumption of a well quantified background. If this research were extrapolated to an instance where the background is not consistent or well quantified, the coefficient of 3.29 should be replaced by a coefficient of 4.65 (a factor of $\sqrt{2}$ higher).

The detector efficiency for discrete particles is empirically determined for many study permutations (three radionuclide sources, two detector heights, two or three radial locations - 0,1 , and $2 \mathrm{~m}$, and three depths). For each of these study permutations, the net counts in the photopeak area were divided by the experimentally-known discrete particle activity. Again, the Th-232 determination required additional consideration due to its presence in natural background. Therefore, the background net peak area counts were subtracted from the total net peak area counts due to the source, and then this difference was divided by the known source activity. The detector efficiency has units of net counts per $\mu \mathrm{Ci}$.

Finally, the hot spot MDA for a particular geometry is calculated by dividing the MD Counts $_{\mathrm{b}}$ (for the particular background spectrum and radionuclide being considered) by the detector efficiency. After several unit conversions, this yields the hot spot MDA in units of $\mu \mathrm{Ci}$. In this report for this method, the hot spot MDA represents the amount of activity at a particular radial and depth location relative to the ISGRS that could trigger an investigation if the investigation level is set to the MDA. It is precisely the information that is needed to assess the capability of the ISGRS when used in scanning mode. (The authors recognize that many licensees do not set the "investigation level" at the MDA, but rather to correspond to a specified volume when that volume is "filled" with an activity concentration at the DCGL $\mathrm{emc}_{\text {. }}$ Therefore, it is recognized that while a hot particle may be detectable, it may not trigger an "investigation".)

\subsection{Test Method}

The experimental test plan was submitted in draft form to the USNRC on June 13, 2006, and subsequently approved in final form on August 8, 2006 (Chapman and Boerner 2006). Selected material from the complete test plan is summarized here.

A series of controlled measurements was performed to evaluate a HPGe detector response when the source term of radioactive material is positioned at various points in the measurement space, that is, the analysis of "Spatially-Dependent Measurements of Surface and Near-Surface Radioactive Material Using In Situ Gamma Ray Spectrometry." The goal of the measurements is to supplement existing understanding of this method, performance capability, and limitations for use. This was not an exhaustive study of every set of measurement conditions and intercomparisons.

\subsection{Instrumentation}

Several radiation detection devices were used. The primary system was the HPGe system. Secondary measurements were collected with the conventional NaI scan instruments $(1.5$ in 
x 2.0 in, and 2.0 in x 2.0 in), and handheld microrem ( $\mu$ rem) meters. Radiation flux measurements of the three test sources were made not for direct analysis at this time, but with the thought that in the future some type of relative comparison could be assembled to evaluate detector response (HPGe vs. NaI scan). Some of this necessary raw data is now available for use in supplementing measurement parameters.

\subsubsection{HPGe System}

The ORISE laboratory maintains an n-type, reverse electrode, high-purity germanium detector from Canberra Industries, Inc. Canberra refers to its reverse electrode germanium detectors as ReGe. The detector is packaged as a complete ISOCS system.

The detector model is GR3819. Decoding the model number, the nominal relative efficiency is $\underline{38} \%$ and the FWHM (keV) at $1332 \mathrm{keV}$ is $\underline{1.9}$; hence, GR3819. The detector serial number is S/N 4976104. The detector has a beryllium window. The preamplifier is mounted directly to the detector, near the "Big MAC" (multi-attitude cryostat).

The system is equipped with a complete tapered collimator set. Measurements were acquired using the 90 -degree collimator. 50 millimeter $(\mathrm{mm})$ background shields were used.

The detector was positioned at 1-meter heights using the ISOCS cart, and at 2-meters using an ORISE-designed counting jig suspended from an engine lift. Counterweights were used to keep the detector orthogonal to the face of the earth.

A fully-integrated portable MCA including digital signal processor, high voltage power supply, digital stabilizer, and 16K memory/conversion gain was used for data acquisition. This product is called the Inspector-2000, or I2K.

A Dell laptop computer acquired the pulse height spectrum from the $\mathrm{I} 2 \mathrm{~K}$ using the GENIE-2000 acquisition and analysis software (S501C). Modeling analysis and interpretation of the measurement results made use of the ISOCS calibration software (S573C). The quality assurance update was enabled (S505U). A Canberra "Procount" software (S503C), while available for repeated measurement quality assurance, source checks, background checks, etc., was not used.

\subsubsection{Nal Detectors}

$\mathrm{NaI}$ detectors and associated electronics within the ORISE inventory were used to acquire background rates and source rates, for future intercomparison sensitivity measurements.

Two NaI detector sizes were used: 1.25 in x 1.5 in (Victoreen Model 489-55) and 2.0 in x 2.0 in (SPA-3 or PG-2, Eberline). Portable ratemeters included the PRM-6 (Eberline Instrument Corporation) and the Model 12 or 2221 (Ludlum Instrument Corporation).

\subsection{Test Sources}

Sources of ${ }^{137} \mathrm{Cs},{ }^{60} \mathrm{Co}$, and $\mathrm{Th}_{\text {nat }}$ were fabricated and placed in secondary containers to ensure that each source remained intact during use, particularly when placed in excavated, subsurface measurement locations. 
The amount of activity selected for each source was calculated from equivalent volumetric average concentrations affiliated with nominal DCGLs published in the literature. It is very important to understand how the source activity concentrations were derived. Each of the three source activities in microcuries $(\mu \mathrm{Ci})$ was derived to produce a DCGL-effective concentration for the entire measurement volume, described as a $1 \mathrm{~m}$ radius and $15 \mathrm{~cm}$ depth. The source activities are presented in Table 1 below.

Table 1. Test Sources Used for Experimental Measurements

\begin{tabular}{||c|c|c|c|}
\hline Radionuclide & $\begin{array}{c}\text { Mass of Source } \\
\text { Standard Matrix }\end{array}$ & Total Activity & $\begin{array}{c}\text { Photon Energy of } \\
\text { Interest } \\
\text { (keV) }\end{array}$ \\
\hline \hline Mixed-Gamma & $0.2941 \mathrm{~g}$ & $<1 \mu \mathrm{Ci}$ & $60 \mathrm{keV}-1.33 \mathrm{MeV}$ \\
\hline $\begin{array}{c}\text { Thorium Decay } \\
\text { Chain (in } \\
\text { equilibrium) }\end{array}$ & $1.022 \mathrm{E}+03 \mathrm{~g}$ & $\begin{array}{c}3.27 \mu \mathrm{Ci} \text { (total } \\
\text { activity) }\end{array}$ & $911.13(\mathrm{keV})$ \\
\hline Co-60 & $42.7 \mathrm{~g}$ & $1.2 \mu \mathrm{Ci}$ & 1332.49 (keV) \\
\hline Cs-137 & $525.2 \mathrm{~g}$ & $4.2 \mu \mathrm{Ci}$ & 661.08 (keV) \\
\hline Cs-137 & $\mathrm{N} / \mathrm{A}$ & $14 \mathrm{mCi}(\mathrm{in} 1985)$ & $\begin{array}{c}\text { Design a "flat" } \\
\text { spectrum }\end{array}$ \\
\hline
\end{tabular}

Note that the total thorium decay chain activity of $3.27 \mu \mathrm{Ci}$ is the sum of all 10 decay products of ${ }^{232} \mathrm{Th}$ in equilibrium, each with an activity of $0.327 \mu \mathrm{Ci}$. In this work, the ${ }^{228} \mathrm{Ac}$ photopeak at $911 \mathrm{keV}$ is detected and reported relative to the $0.327 \mu \mathrm{Ci}$ calibration value.

\subsection{Background Source}

Another objective of these tests was to evaluate the detector performance when ambient background radiation is increased by a factor of two. For reactor applications, in particular, it is often the case where final status surveys or "low level" surveys are conducted in areas where other sources of radiation are present in the vicinity of the measurement area, near an ISFSI for example. Background radiation levels can vary significantly by location (proximity of each measurement area to the external source) or in time.

Nominal background radiation rates at the ORISE test site are $10 \mu \mathrm{R}$ per hour. To increase the background, a $10 \mathrm{mCi}{ }^{137} \mathrm{Cs}$ source was placed inside a spectrum flattening pig. The spectrum flattening pig consisted of a 5-gal bucket filled with various materials to remove as much of the $662-\mathrm{keV}$ photopeak as possible in order to emulate what is believed to be a down-scattered spectrum observed from an ISFSI approximately 100 meters away. ${ }^{4}$

\footnotetext{
${ }^{4}$ Private Communication, Bruce Watson, USNRC (May 2006). Additional (but unsuccessful) efforts were made to contact Eric L. Darois, Radiation Safety \& Control Services, Inc. (603) 778-2871 Ext. 29 to corroborate on gamma-ray spectra emissions from ISFSIs.
} 


\subsection{Measurement Site}

The ORISE field laboratory for environmental studies was prepared accordingly. A site survey was completed to evaluate background of "uncontaminated" east Tennessee soil. The area was controlled under a radiation work permit (RWP). From the centerline of the detector, radii were marked with flags. Azimuthal rotations were made for progressive radii at zero depth, $7.5 \mathrm{~cm}$ depth, and 15 depth.

Figure 3 below shows the measurement site as engineers prepare to place the test sources at 7.5- and 15-cm depths.

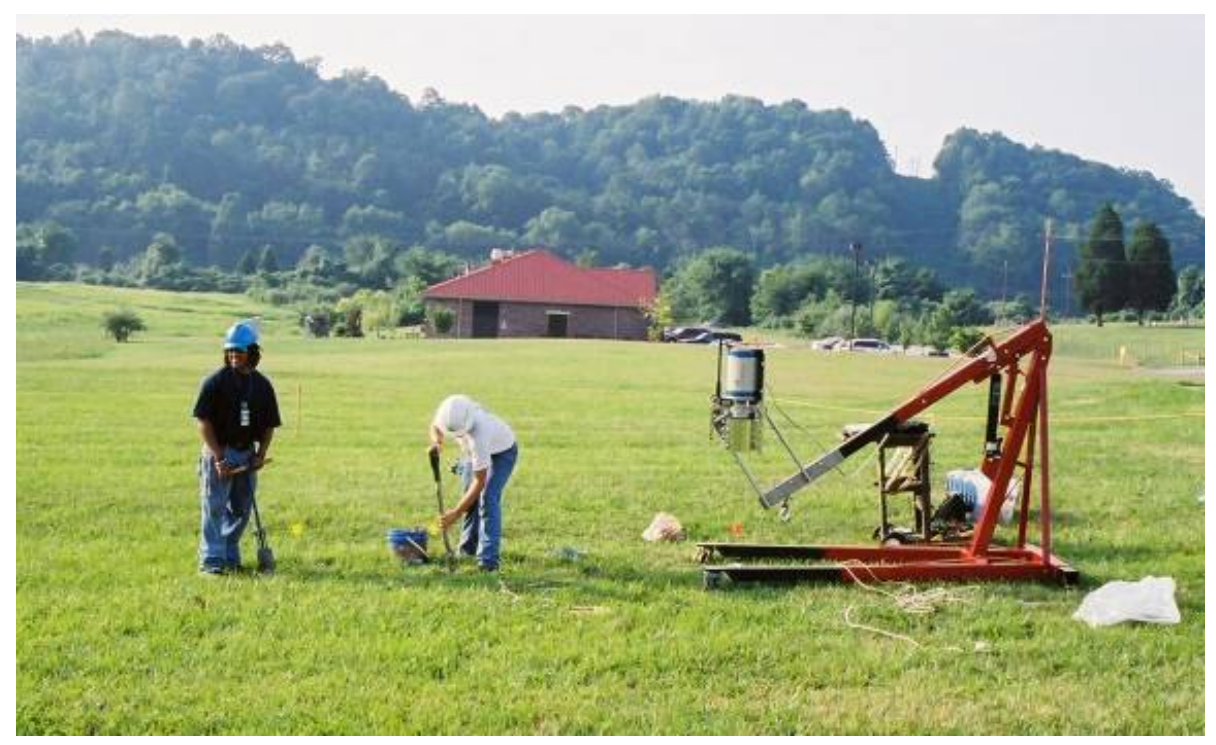

Figure 3. Engineers prepare the site for measurement. The ISOCS detector is mounted at 1 meter from the surface of the ground. Soil is exhumed for the placement of test sources. 
A separate view of the test area shows the proximity of the $10 \mathrm{mCi}{ }^{137} \mathrm{Cs}$ source to the measurement system in order to elevate the background by a factor of two.

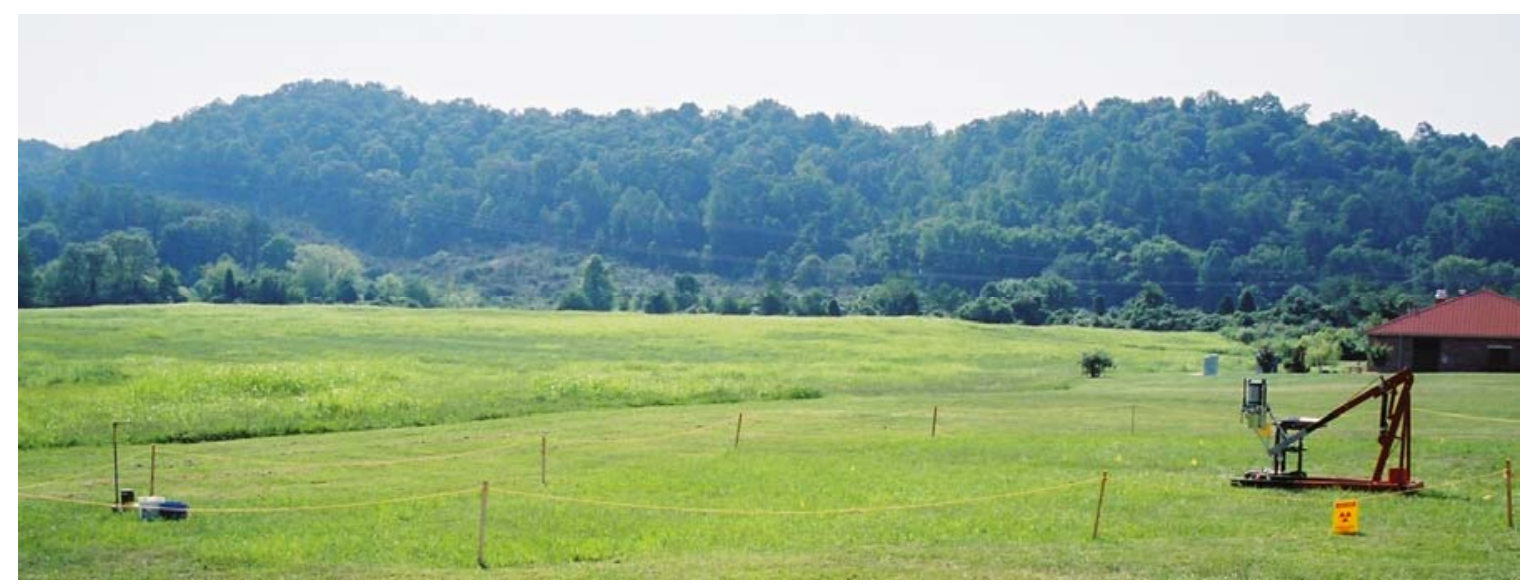

Figure 4 . An ISFSI Background Radiation Emulator is placed 40 feet from ISOCS detector to increase the local background by a factor of two.

\subsection{Data Acquisition and Analysis}

For the uniform distribution case, data were acquired within the GENIE 2K software. Photopeak areas and uncertainties were read into a Microsoft (MS) EXCEL spreadsheet for off-line analysis as needed. Most importantly, the raw data were analyzed by the ISOCS calibration software to generate the efficiency functions used to report measured activity concentration. From this same set of results, the MDC is calculated.

Alternatively, for the discrete particle case, raw count data from each of the study permutations were saved to an Excel spreadsheet for data analysis. Specifically, the net counts in the peak area generated by the GENIE $2 \mathrm{~K}$ software were divided by the experimental discrete particle activity to determine the efficiency in units of net counts per $\mu \mathrm{Ci}$. Hot spot MDAs were then calculated by dividing the MD Counts obtained from the background spectra by the particular detector efficiency. Two examples are provided.

Example 1: The MD Counts ${ }_{\mathrm{b}}$ for the ISFSI-simulated background at the 1-m detector height for the Co-60 $1173 \mathrm{keV}$ gamma line was 32.2 counts. [This value is determined from the ISGRS Nuclide MDA Report, which provides $0.1467 \mu \mathrm{Ci} /$ unit, multiplied by the efficiency (6.5958E-6), 2.22E6 dpm per $\mu \mathrm{Ci}$, and 15-min live time].

For the 1 meter detector height in the presence of ISFSI-simulated background, 1 meter radial location, and surface position (zero depth), the Co-60 source $(1.2 \mu \mathrm{Ci})$ produced a net count in the photopeak region $(1173 \mathrm{keV})$ of 117 counts. The detector efficiency for this particular discrete particle geometry is given by:

$$
\text { detector efficiency }=117 \text { counts } / 1.2 \mu \mathrm{Ci}=97.5 \text { counts } / \mu \mathrm{Ci}
$$


The hot spot MDA is calculated directly from MD Counts and detector efficiency:

$$
\begin{aligned}
\text { hot spot MDA } & =\text { MD Counts } / \text { detector efficiency } \\
& =32.2 \text { counts } /(97.5 \text { counts } / \mu \mathrm{Ci})=\mathbf{0 . 3 3 0} \boldsymbol{\mu} \mathbf{C i} \mathbf{C o -} \mathbf{6 0}
\end{aligned}
$$

Example 2: The MD Counts $\mathrm{b}_{\mathrm{b}}$ for the natural background (no ISFSI-simulated background) at the 1-m detector height for the Th-232 (Ac-228) $911 \mathrm{keV}$ gamma line was determined to be 28.8 counts above the background count. [This value is determined from the background net peak area of 76.5 counts for a 15-minute count time. The MD Counts $\mathrm{b}_{\mathrm{b}}$ is calculated by $3.29 * \operatorname{SQRT}(76.5)=28.8$ counts

For the 1 meter detector height with the Th-232 source directly below the detector ( 0 radial location), and surface position (zero depth), the source $(0.32 \mu \mathrm{Ci})$ produced a total net count in the photopeak region of 141 counts. The detector efficiency for this particular discrete particle geometry is given by:

$$
\text { detector efficiency }=(141-76.5) \text { counts } / 0.32 \mu \mathrm{Ci}=201.56 \text { counts } / \mu \mathrm{Ci}
$$

The hot spot MDA for Th-232 in this source configuration is calculated:

$$
\begin{aligned}
\text { hot spot MDA } & =\text { MD Counts } / \text { detector efficiency } \\
& =28.8 \text { counts } /(201.56 \text { counts } / \mu \mathrm{Ci})=\mathbf{0 . 1 4 3} \boldsymbol{\mu} \mathbf{C i} \mathbf{T h} \mathbf{- 2 3 2}
\end{aligned}
$$

These two examples, along with the results of many other discrete source experimental configurations, are shown in Tables 3 through 6.

\subsection{Results}

This section provides a number of answers to the important questions that were asked within the framework of US NRC RFTA 06-010. The most important section of these results follows immediately, answering the question: for purposes of conducting an in situ soil measurement, what are the important parameters that should be reviewed, evaluated, and understood in the measurement process? These results are not consolidated anywhere in the literature or even draft national standards. They are a product of this work, touching on most of the issues of interest for in situ measurements of soil for final status surveys under MARSSIM. The second section presents the direct measurement results --instrument sensitivity as a function of the studied variables: three sources $\left({ }^{137} \mathrm{Cs},{ }^{60} \mathrm{Co}\right.$, and $\left.\mathrm{Th}_{\mathrm{nat}}\right)$; two detector heights $(1 \mathrm{~m}, 2 \mathrm{~m})$; four source radii $(\mathrm{r}=0,1,2,3 \mathrm{~m})$; three source depths $\left((\mathrm{z}=0,7.5,15 \mathrm{~cm})\right.$; and two background distributions $\left(\mathrm{B}_{\mathrm{nat}}, 2 \mathrm{~B}_{\mathrm{nat}}\right)$.

\subsection{ISGRS Measurement Parameters}

Prior to initiating an ISGRS measurement of soil, the DQO process must be followed to ensure that, ultimately, the measurements provide results of desired quality. (EPA 2006) The primary questions that need to be answered in the DQO process are:

- What is the spatial resolution of the "sampling plan"?

0 What is the smallest area/volume of residual radioactivity that must be detected? This could be defined by the $\mathrm{DCGL}_{\mathrm{emc}}$, the area of which is 
bounded by three neighboring sampling points on a triangular grid or four sampling points on a square grid.

o What is the depth of the radioactive material? Is this a "fallout" measurement with deposition of radioactivity on surfaces? Is this a MARSSIM surface soil measurement (e.g. $15 \mathrm{~cm}$ ) ? ${ }^{5} \mathrm{Or}$, is the radioactivity deposited at depths greater than $15 \mathrm{~cm}$ ? By the time the final status survey is conducted, a $15 \mathrm{~cm}$ thick surface soil investigation should be the focus. This was the measurement assumption evaluated by this ORISE effort.

- What minimum detectable concentration is required?

o For the general, large area, far-field measurement, the site specific $\mathrm{DCGL}_{\mathrm{emc}}$ and DCGL $\mathrm{w}_{\mathrm{w}}$ are both of interest.

o For small areas of localized activity (e.g. discrete particles), MARSSIM does not explicitly address this question and for good reason: the dose assessment model is interested in the "average" concentration over relatively large areas.

When deploying the ISGRS system for the purpose of making an in situ soil measurement, Table 2 provides the most important parameters to evaluate and implement before the first measurement is conducted. This table also shows the system settings deployed for the ORISE feasibility tests. The DQO assessment for whether the proposed measurements will meet specified requirements cannot be performed without understanding each of these decision points and corresponding measurement settings. This table could be viewed as an initial strawman for a licensee checklist for conducting these types of ISGRS measurements against a requirements document, as part of the DQO process for a final status survey.

Table 2. Important Parameters for ISGRS Measurements

\begin{tabular}{|c|c|c|c|}
\hline Subsystem & Parameter & Discussion/Options & $\begin{array}{c}\text { ORISE } \\
\text { Experimental } \\
\text { Settings (or } \\
\text { Apparatus) } \\
\end{array}$ \\
\hline $\begin{array}{l}\text { Solid-state, } \\
\text { High- } \\
\text { resolution } \\
\text { Gamma-ray } \\
\text { Detector }\end{array}$ & $\begin{array}{l}\text { Type of high- } \\
\text { purity } \\
\text { germanium } \\
\text { (HPGe) } \\
\text { detector }\end{array}$ & $\begin{array}{l}\text { Planar (LeGe); coaxial-> n-type (or } \\
\text { reverse electrode germanium, ReGe), } \\
\text { p-type (HPGe), or broad-energy } \\
\text { germanium (BeGe) } \\
\text { Unless the radionuclide is very low } \\
\text { energy ( }<50 \mathrm{keV} \text { ) and "surface only," } \\
\text { planar detectors are not applicable. } \\
\text { Most ISGRS measurements are } \\
\text { performed with coaxial detectors } \\
\text { (ReGe, HPGe, BeGe) }\end{array}$ & $\begin{array}{l}\text { n-type, reverse } \\
\text { electrode detector. } \\
\text { Canberra model } \\
\text { GR3819. (38\% } \\
\text { relative efficiency, } 1.9 \\
\text { FWHM(keV)@1332 } \\
\text { keV } \\
\text { S/N } 4976104\end{array}$ \\
\hline
\end{tabular}

${ }^{5}$ Section 3.6.3.1 of MARSSIM states that "surface soil is the top layer of soil on a site that is available for direct exposure, growing plants, resuspension of particles for inhalation, and mixing from human disturbances. Surface soil may also be defined as the thickness of soil that can be measured using direct measurement or scanning techniques. Typically, this layer is represented as the top $15 \mathrm{~cm}$ (6 in) of soil (40CFR192)." 


\begin{tabular}{|c|c|c|c|}
\hline Subsystem & Parameter & Discussion/Options & $\begin{array}{c}\text { ORISE } \\
\text { Experimental } \\
\text { Settings (or } \\
\text { Apparatus) }\end{array}$ \\
\hline & Efficiency & $\begin{array}{l}\text { Most vendors provide this single } \\
\text { performance value under the } \\
\text { ANSI/IEEE Std } 325-1996 \text { definition. } \\
\text { For ISGRS, it is most important to } \\
\text { understand the complete efficiency } \\
\text { function over the energy range of } \\
\text { interest. For many applications, e.g. } \\
{ }^{137} \text { Cs, a } 60 \% \text { detector is not twice as } \\
\text { "good" as a } 30 \% \text { detector. Quality } \\
\text { ISGRS measurements have been } \\
\text { performed with detectors from } 20 \% \\
\text { to } 150 \% \text { efficient. }\end{array}$ & $\begin{array}{l}38 \% \text { (relative to 3" } \mathrm{x} \\
\text { 3" NaI at } 1.33 \mathrm{MeV} \text {, } \\
\text { as defined in } \\
\text { ANSI/IEEE Std } 325- \\
1996 \text { ) }\end{array}$ \\
\hline & $\begin{array}{c}\text { End- } \\
\text { Window/cap }\end{array}$ & $\begin{array}{l}\text { When the radionuclide of interest } \\
\text { emits low-energy photons, window } \\
\text { properties are important. If the } \\
\text { radionuclide is "at or near infinite } \\
\text { depth" then window material and } \\
\text { thickness is less important: the } \\
\text { photon does not survive the collisions } \\
\text { in the soil. For low-energy analysis, } \\
\text { use C or Be end-cap. }\end{array}$ & Beryllium window \\
\hline & $\begin{array}{c}\text { Detector } \\
\text { Characterization }\end{array}$ & $\begin{array}{l}\text { Manufacturer's engineering } \\
\text { evaluation/calibration of the detector. } \\
\text { This is a response function } \\
\text { normalization of mathematically } \\
\text { computed efficiency versus direct } \\
\text { measurement of point source, for } \\
\text { example, }{ }^{155} \mathrm{Eu} \text { and }{ }^{22} \mathrm{Na} \text {. The } \\
\text { normalized/calibrated efficiency } \\
\text { characteristics are then used in all } \\
\text { mathematical models developed for } \\
\text { the in situ analysis. This } \\
\text { characterization/calibration record is } \\
\text { not performed by all vendors. }\end{array}$ & Performed \\
\hline & Resolution & $\begin{array}{l}\text { For most deployed systems, expect a } \\
\text { nominal resolution of } 2 \mathrm{keV} \text { at } 1333 \\
\mathrm{keV} \text { and } 600 \mathrm{eV} \text { at } 122 \mathrm{keV} \text {. In most } \\
\text { cases, existing systems easily meet this } \\
\text { requirement; however, it is important } \\
\text { that the analyst calibrate the detector } \\
\text { for it. }\end{array}$ & $\begin{array}{l}\text { 1.9 FWHM (keV)@ } \\
1332 \mathrm{keV}\end{array}$ \\
\hline
\end{tabular}




\begin{tabular}{|c|c|c|c|}
\hline Subsystem & Parameter & Discussion/Options & $\begin{array}{l}\text { ORISE } \\
\text { Experimental } \\
\text { Settings (or } \\
\text { Apparatus) }\end{array}$ \\
\hline \multirow[t]{5}{*}{ Collimator } & Tapered & 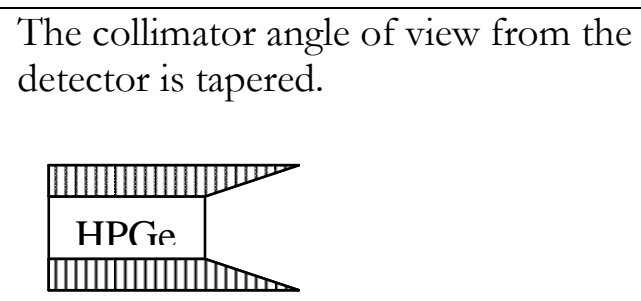 & Tapered \\
\hline & Non-tapered & 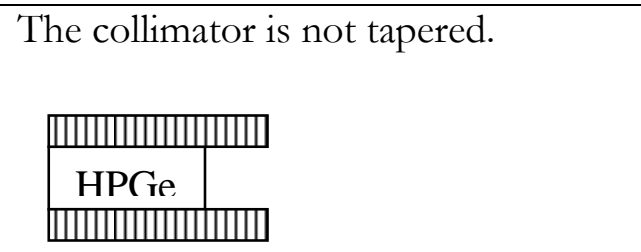 & $\mathrm{N} / \mathrm{A}$ \\
\hline & $\begin{array}{c}\text { Angular Field of } \\
\text { View (FOV) }\end{array}$ & $\begin{array}{l}\text { Various collimator sets are available } \\
\text { to measure small pipes (small solid } \\
\text { angle subtended by the source at the } \\
\text { detector). Most in situ soil } \\
\text { measurements use a 90-degree } \\
\text { collimator, though some have used } \\
\text { 180-degree collimators. This } \\
\text { parameter is very important when } \\
\text { defining the measurement capability } \\
\text { and whether the DQOs can be met. }\end{array}$ & 90-degree collimator \\
\hline & $\begin{array}{l}\text { Offset (or recess } \\
\text { of the detector) }\end{array}$ & $\begin{array}{l}\text { Refers to how far back into the } \\
\text { collimator the detector is located. } \\
\text { This is another technique to change } \\
\text { the field of view. }\end{array}$ & $\begin{array}{l}90 \text {-degree collimator } \\
\text { with corresponding } \\
\text { recess. }\end{array}$ \\
\hline & Back-shield & $\begin{array}{l}\text { Reduces background flux impinging } \\
\text { from the rear of the detector } \\
\text { (opposite the measurement sample). } \\
\text { A back-shield should be used to } \\
\text { reduce background. }\end{array}$ & Back-shield was used. \\
\hline
\end{tabular}




\begin{tabular}{|c|c|c|c|}
\hline Subsystem & Parameter & Discussion/Options & $\begin{array}{l}\text { ORISE } \\
\text { Experimental } \\
\text { Settings (or } \\
\text { Apparatus) }\end{array}$ \\
\hline $\begin{array}{l}\text { Counting } \\
\text { Geometry }\end{array}$ & $\begin{array}{l}\text { Standoff } \\
\text { (or detector } \\
\text { height) }\end{array}$ & $\begin{array}{l}\text { The further from the ground the } \\
\text { detector is placed, the larger the } \\
\text { "sampling area" and the smaller the } \\
\text { MDC (pCi/g) because more soil is } \\
\text { being measured (denominator) and } \\
\text { the angular sensitivity to incoming } \\
\text { photons is increased (numerator). } \\
\text { The further the standoff (or the } \\
\text { higher the detector is positioned), the } \\
\text { greater the "average } \\
\text { areal/volumetric" response. It is the } \\
\text { standoff, coupled with the FOV that } \\
\text { permits very low MDCs using ISGRS } \\
\text { to be achieved. }\end{array}$ & $\begin{array}{l}\text { The detector was } \\
\text { placed at } 1-\text { and } 2- \\
\text { meter heights. }\end{array}$ \\
\hline \multirow[t]{2}{*}{$\begin{array}{l}\text { Data } \\
\text { Acquisition } \\
\text { Settings }\end{array}$} & Gain & $\begin{array}{l}\text { The gain of the amplifier needs to be } \\
\text { adjusted to ensure that all photons of } \\
\text { interest are detected and registered by } \\
\text { the MCA. }\end{array}$ & $\begin{array}{l}4096 \text { channels, } \mathrm{E}_{\max }= \\
1.4 \mathrm{MeV} \text {. Linear. }\end{array}$ \\
\hline & $\begin{array}{l}\text { Count Time } \\
\text { (Live Time) }\end{array}$ & $\begin{array}{l}\text { The theoretical MDC decreases as } \\
1 / \sqrt{ } \text {. A factor of four increase in } \\
\text { count time decreases the MDC by a } \\
\text { factor of two. This is the only } \\
\text { measurement setting that can be } \\
\text { expressed as an absolute performance } \\
\text { measurement parameter. }\end{array}$ & 15 minutes, live time. \\
\hline \multirow[t]{2}{*}{$\begin{array}{l}\text { Analysis } \\
\text { Model } \\
\text { Parameters }\end{array}$} & $\begin{array}{c}\text { Depth of } \\
\text { Contaminant }\end{array}$ & $\begin{array}{l}\text { Most analyses for a final status survey } \\
\text { use a contaminant depth of } 15 \mathrm{~cm} \text {. } \\
\text { (Section 3.6.3.1 of MARSSIM) } \\
\text { Because photon scattering and } \\
\text { absorption in soil are exponential } \\
\text { functions (Beer's Law), contaminant } \\
\text { depth must be properly understood in } \\
\text { order to yield accurate analysis results. }\end{array}$ & $15 \mathrm{~cm}$ \\
\hline & $\begin{array}{l}\text { Contaminant } \\
\text { Distribution as } \\
\text { Function of } \\
\text { Depth } \\
\text { (e.g. uniform, } \\
\text { exponential) }\end{array}$ & $\begin{array}{l}\text { The distribution of the contaminant is } \\
\text { normally either uniform or } \\
\text { exponentially distributed. This } \\
\text { parameter is important if the } \\
\text { contaminant is believed to exist at } \\
\text { depth or the contaminant emits low } \\
\text { energy photons (less than } 150 \mathrm{keV} \text { ). }\end{array}$ & Uniform \\
\hline
\end{tabular}




\begin{tabular}{|c|c|c|c|}
\hline Subsystem & Parameter & Discussion/Options & $\begin{array}{l}\text { ORISE } \\
\text { Experimental } \\
\text { Settings (or } \\
\text { Apparatus) }\end{array}$ \\
\hline & $\begin{array}{l}\text { Contaminant } \\
\text { Profile } \\
\text { (stratification, } \\
\text { lumps) }\end{array}$ & $\begin{array}{l}\text { Efficiency models available } \\
\text { commercially can account for } \\
\text { stratification in the source term, } \\
\text { nonuniformities in the source, and to } \\
\text { some degree "lumps". This effort } \\
\text { lends itself to uncertainty bounding in } \\
\text { the model results. }\end{array}$ & $\begin{array}{l}\text { None - simple, } \\
\text { uniform, distribution } \\
\text { of surface } \\
\text { contamination at } 15 \\
\mathrm{~cm} .\end{array}$ \\
\hline & $\begin{array}{c}\text { Matrix } \\
\text { Properties }\end{array}$ & $\begin{array}{l}\text { Chemical properties of the local soil, } \\
\text { including moisture density and } \\
\text { igneous rock stratifications in the } \\
\text { measurement sample. }\end{array}$ & $\begin{array}{l}\text { East Tennessee soil } \\
\text { with } 28 \% \text { moisture } \\
\text { content (nominal). }\end{array}$ \\
\hline & $\begin{array}{l}\text { Application of } \\
\text { Most Accurate } \\
\text { Model }\end{array}$ & $\begin{array}{l}\text { All available process knowledge about } \\
\text { the actual site contaminant profile } \\
\text { should be accounted for in the model. } \\
\text { All parameters discussed above } \\
\text { should be represented properly, } \\
\text { including description of the detector, } \\
\text { collimator, field of view, contaminant } \\
\text { profile, geologic setting, etc. }\end{array}$ & $\begin{array}{l}\text { Surface contaminated } \\
\text { East Tennessee soil. } \\
\text { A simple model was } \\
\text { run for this set of } \\
\text { benchmark tests. }\end{array}$ \\
\hline & $\begin{array}{l}\text { Multi-Energy } \\
\text { Model } \\
\text { Correction }\end{array}$ & $\begin{array}{l}\text { Some information about the } \\
\text { contaminant profile can be accounted } \\
\text { for by direct measurement, when } \\
\text { multiple photon energies are emitted } \\
\text { from the same radionuclide. }\end{array}$ & $\begin{array}{l}\text { These methods were } \\
\text { not used for these } \\
\text { tests. }\end{array}$ \\
\hline & $\mathrm{MDC}$ & $\begin{array}{l}\text { The Minimum Detectable } \\
\text { Concentration (MDC) is one of the } \\
\text { most misunderstood terms in ISGRS. } \\
\text { It is important to review the } \\
\text { methodology and the assumptions } \\
\text { used to describe "the source term" } \\
\text { for which the MDC is calculated. }\end{array}$ & $\begin{array}{l}\text { MDC formulation } \\
\text { within the Genie } 2 \mathrm{~K} \\
\text { software. The } \\
\text { standard model was } \\
\text { used: measurement } \\
\text { volume is the product } \\
\text { of the FOV }\left(\mathrm{m}^{2}\right) \text { and } \\
0.015 \mathrm{~m} \text { depth. }\end{array}$ \\
\hline
\end{tabular}




\begin{tabular}{|c|c|c|c|}
\hline Subsystem & Parameter & Discussion/Options & $\begin{array}{c}\text { ORISE } \\
\text { Experimental } \\
\text { Settings (or } \\
\text { Apparatus) } \\
\end{array}$ \\
\hline \multirow[t]{2}{*}{$\begin{array}{l}\text { Analysis of } \\
\text { the High } \\
\text { Resolution } \\
\text { Spectrum }\end{array}$} & $\begin{array}{l}\text { Background } \\
\text { Subtraction }\end{array}$ & $\begin{array}{l}\text { When the radiocontaminant of } \\
\text { interest is naturally occurring, then } \\
\text { active background subtraction is } \\
\text { necessary (spectral stripping). When } \\
\text { the radiocontaminant does not exist } \\
\text { in the natural spectrum, then standard } \\
\text { photopeak area integration methods } \\
\text { are sufficient. }\end{array}$ & $\begin{array}{l}\text { For thorium, which is } \\
\text { naturally occurring, } \\
\text { background spectra } \\
\text { were used to strip } \\
\text { from the measurement } \\
\text { signal. For }{ }^{137} \mathrm{Cs} \text { and } \\
{ }^{60} \mathrm{Co} \text {, no spectrum } \\
\text { stripping was } \\
\text { necessary. "Naturally } \\
\text { occurring" }{ }^{137} \mathrm{Cs} \\
\text { fallout from weapons } \\
\text { tests was not detected } \\
\text { in } 15 \text { minutes. }\end{array}$ \\
\hline & $\begin{array}{c}\text { Multiplet } \\
\text { Deconvolution }\end{array}$ & $\begin{array}{l}\text { Multiplet deconvolution is normally } \\
\text { not required for fission products. For } \\
\text { source materials (uranium and } \\
\text { thorium) and special nuclear materials } \\
\text { (plutonium), multiplet deconvolution } \\
\text { is necessary and can significantly } \\
\text { impact the measurement results. }\end{array}$ & $\begin{array}{l}\text { No multiplet } \\
\text { deconvolution was } \\
\text { used for these } \\
\text { measurements. }\end{array}$ \\
\hline
\end{tabular}

\subsection{Measurement Results}

The raw data files are presented in Appendix B. Six summary graphs (Figure 5) are provided to show the measured activity concentration for each of the three test sources, with and without the Independent Spent Fuel Storage Installation Background Emulator (ISFSIBE) source. With the ISFSIBE source present background at the detector was $20 \mu \mathrm{R} / \mathrm{h}$, twice that of natural background in the Oak Ridge area.

ISFSIBE Disabled

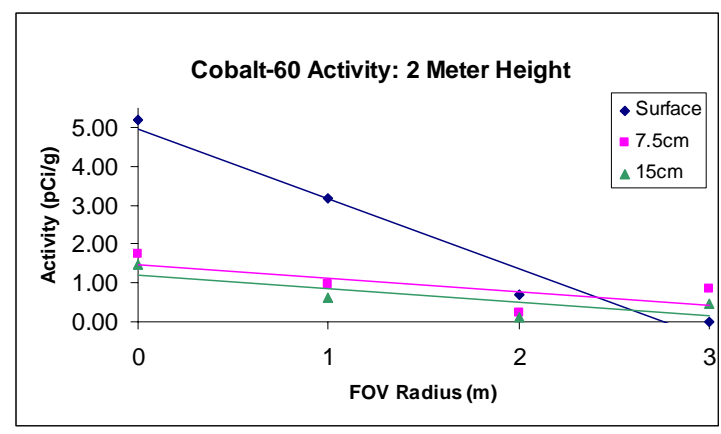

ISFSIBE Enabled

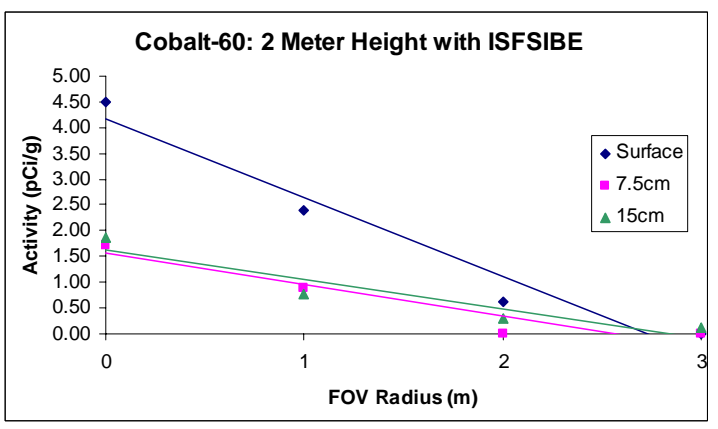



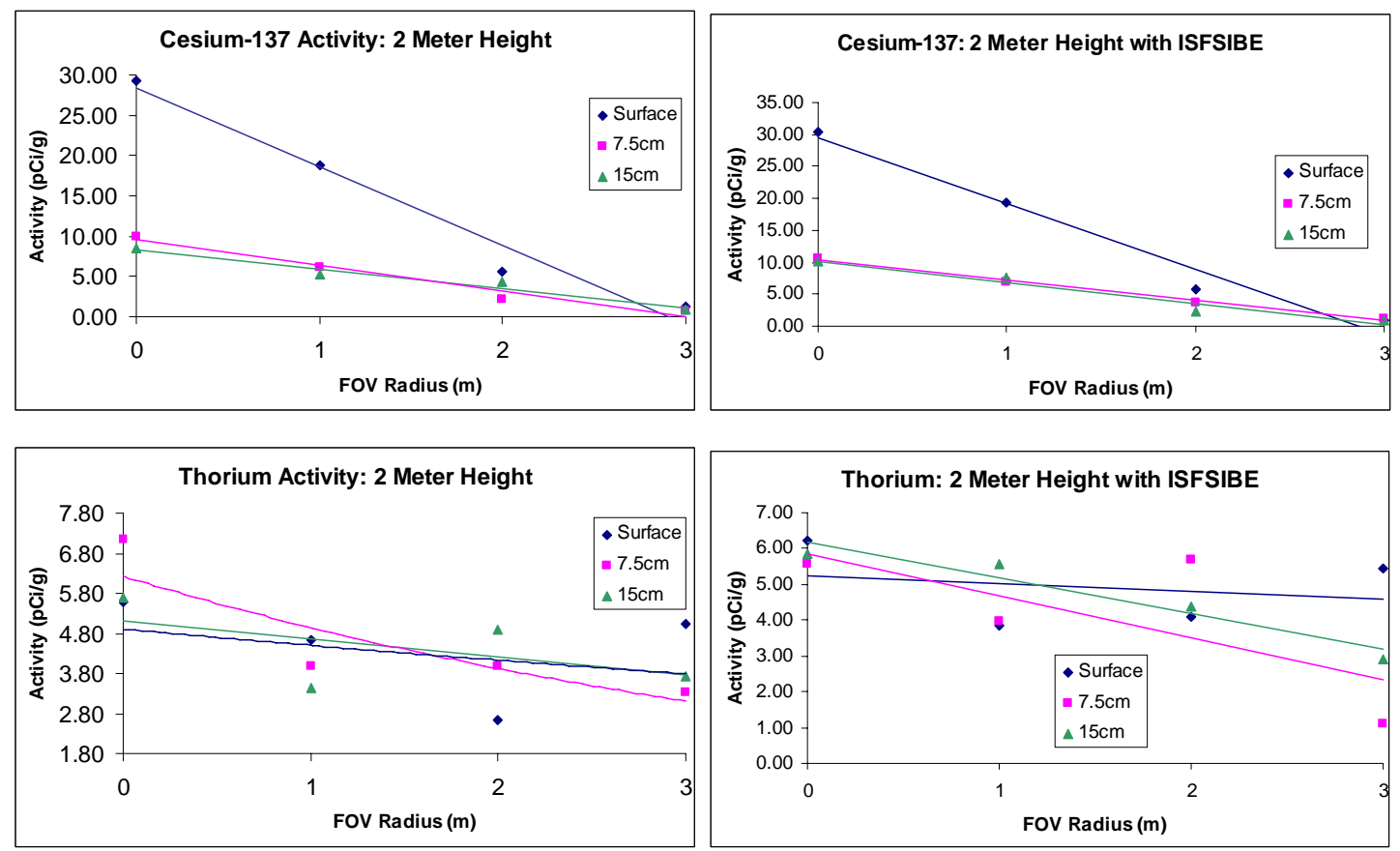

Figure 5. Plots of the Measurement Results for Each of the Three Sources in Each Source Location (at the 2-meter position)

As expected, all nuclides follow the same basic trend of decreasing measured activity as the source moves away from the detector's axis, and with increasing depth. The thorium data does not show this trend very clearly due to low source activity in comparison to the natural thorium in the ground. Some additional effort should be applied to the case when the radiocontaminant is present in natural background as well. Another inconsistency can be seen with Co-60 at $7.5 \mathrm{~cm}$ and $15 \mathrm{~cm}$, where the measured activity at $15 \mathrm{~cm}$ is greater than at $7.5 \mathrm{~cm}$. The reason for the Co-60 inconsistency at these depths is weak source activity combined with random experimental error. Reproducibility of the results is normally very good, though, measurement inconsistencies can occur. In a final status survey methodology, some measurement reproducibility measurements should be conducted, particularly when a measurement outlier is detected.

\subsection{Hot Spot MDAs}

Tables 3 through 6 in this section provide hot spot MDAs for the various experimental configurations of the discrete source activity. These tables provide the hot spot MDAs for 1- and 2- $\mathrm{m}$ detector heights for both natural background and ISFSI-enhanced background permutations. The results indicate that when the discrete source is directly beneath the detector at the $1-\mathrm{m}$ height it is possible to detect 0.02 to $0.04 \mu \mathrm{Ci}$ of $\mathrm{Co}-60$ or Cs- 137 . When the detector height is increased to 2-m, the hot spot MDA for each radionuclide increases as well to 0.08 to $0.16 \mu \mathrm{Ci}$. This is due to the detector's greater FOV at the 2 -m height and the corresponding $1 / \mathrm{r}^{2}$ decrease in geometric efficiency. Similarly for both detector heights studied, as the discrete source is moved from directly beneath the detector to $1 \mathrm{~m}$ radius, the hot spot MDAs increase by a factor of 5 to 8 for both Co-60 and Cs-137. Also it is 
interesting to note that increasing the depth of the discrete source burial from surface to 15 $\mathrm{cm}$ has less of an impact on the hot spot MDA than does moving it to the 1-m radial location.

The Th-232 discrete source was often times indistinguishable from background at the source activity studied. For many of the configurations tested, the hot spot MDA for Th-232 ranged from 0.14 to $0.36 \mu \mathrm{Ci}$.

Finally, Tables 5 and 6 illustrate the impact that the ISFSI-enhanced background had on the hot spot MDA. For the most part, the impact was not that significant. Comparing the Co60 MDAs in Tables 3 and 5 indicates that the enhanced background only marginally increased the MDA for the 1-m detector height.

An overall conclusion based on this study is that for Co-60, Cs-137, and Th-232, for a number of experimental conditions that include depths up to $15 \mathrm{~cm}$ and radial locations out to $2 \mathrm{~m}$, it is generally possible to detect $1 \mu \mathrm{Ci}$ (and many times less than $1 \mu \mathrm{Ci}$ ) of a discrete particle using ISGRS.

Put in context, determination of a discrete particle MDA is only one parameter in the process of developing an investigation level. A discrete particle with an activity greater than the MDA will produce a photopeak that is distinguishable from background, but not necessarily high enough to trigger an investigation. It is also important to remember that MARSSIM is based on concentration; an averaging volume is needed to correlate a discrete particle MDA to an elevated area MDC. 
Table 3. 1-meter Detector Height, Natural Background

\begin{tabular}{|c|c|c|c|}
\hline \multicolumn{4}{|c|}{ Cobalt-60 (1.2 $\mu \mathrm{Ci})(\mathrm{MD}$ Counts 33.4$)$} \\
\hline Radius (m) & Depth (cm) & Net Peak Area & Hot Spot MDA $(\mu \mathrm{Ci})$ \\
\hline 0 & 0 & 1070 & 0.037 \\
\hline 1 & 0 & 137 & 0.292 \\
\hline 0 & 7.5 & 467 & 0.086 \\
\hline 1 & 7.5 & 76.3 & 0.525 \\
\hline 0 & 15 & 253 & 0.158 \\
\hline 1 & 15 & 103 & 0.389 \\
\hline \multicolumn{4}{|c|}{ Cesium-137 (4.2 $\mu \mathrm{Ci})$ (MD Counts 28.5 ) } \\
\hline Radius (m) & Depth (cm) & Net Peak Area & "Hot Spot MDA $(\mu \mathrm{Ci})$ \\
\hline 0 & 0 & 6480 & 0.018 \\
\hline 1 & 0 & 905 & 0.132 \\
\hline 0 & 7.5 & 2280 & 0.053 \\
\hline 1 & 7.5 & 388 & 0.309 \\
\hline 0 & 15 & 1260 & 0.095 \\
\hline 1 & 15 & 415 & 0.289 \\
\hline \multicolumn{4}{|c|}{ Thorium-232 (0.32 $\mu \mathrm{Ci})(\mathrm{MD}$ Counts 28.8$)$} \\
\hline Radius (m) & Depth (cm) & Net Peak Area & Hot Spot MDA $(\mu \mathrm{Ci})$ \\
\hline 0 & 0 & 141 & 0.143 \\
\hline 1 & 0 & 86 & $\begin{array}{l}\text { Indistinguishable from } \\
\text { background }^{\mathrm{a}}\end{array}$ \\
\hline 0 & 7.5 & 107 & 0.302 \\
\hline 1 & 7.5 & 104 & 0.305 \\
\hline 0 & 15 & 69.5 & $\begin{array}{c}\text { Indistinguishable from } \\
\text { background }^{\mathrm{a}}\end{array}$ \\
\hline 1 & 15 & 72.6 & $\begin{array}{c}\text { Indistinguishable from } \\
\text { background }^{\mathrm{a}}\end{array}$ \\
\hline
\end{tabular}

a Th-232 (Ac-228 $911 \mathrm{keV}$ ) background net peak area is 76.5 counts. 
Table 4. 2-meter Detector Height, Natural Background

\begin{tabular}{|c|c|c|c|}
\hline \multicolumn{4}{|c|}{ Cobalt-60 (1.2 $\mu \mathrm{Ci})(\mathrm{MD}$ Counts 33.2) } \\
\hline Radius (m) & Depth (cm) & Net Peak Area & "Hot Spot MDA $(\mu \mathrm{Ci})$ \\
\hline 0 & 0 & 251 & 0.159 \\
\hline 1 & 0 & 34 & 1.173 \\
\hline 0 & 7.5 & 83.7 & 0.477 \\
\hline 1 & 7.5 & 60.4 & 0.660 \\
\hline 0 & 15 & 70.8 & 0.563 \\
\hline 1 & 15 & 30 & 1.329 \\
\hline \multicolumn{4}{|c|}{ Cesium-137 (4.2 $\mu \mathrm{Ci})$ (MD Counts 28.5) } \\
\hline Radius (m) & Depth (cm) & Net Peak Area & "Hot Spot MDA $(\mu \mathrm{Ci})$ \\
\hline 0 & 0 & 1460 & 0.082 \\
\hline 1 & 0 & 277 & 0.432 \\
\hline 2 & 0 & 64.5 & 1.855 \\
\hline 0 & 7.5 & 499 & 0.240 \\
\hline 1 & 7.5 & 315 & 0.380 \\
\hline 2 & 7.5 & 104 & 1.150 \\
\hline 0 & 15 & 423 & 0.283 \\
\hline 1 & 15 & 257 & 0.465 \\
\hline 2 & 15 & 82.8 & 1.455 \\
\hline \multicolumn{4}{|c|}{ Thorium-232 (0.32 $\mu \mathrm{Ci})$ (MD Counts 29.2) } \\
\hline Radius (m) & Depth (cm) & Net Peak Area & Hot Spot MDA $(\mu \mathrm{Ci})$ \\
\hline 0 & 0 & 81.7 & $\begin{array}{c}\text { Indistinguishable from } \\
\text { background }^{\mathrm{a}}\end{array}$ \\
\hline 1 & 0 & 39.6 & $\begin{array}{l}\text { Indistinguishable from } \\
\text { background }^{2}\end{array}$ \\
\hline 0 & 7.5 & 105 & 0.356 \\
\hline 1 & 7.5 & 58.9 & $\begin{array}{c}\text { Indistinguishable from } \\
\text { background }^{\mathrm{a}}\end{array}$ \\
\hline 0 & 15 & 84.3 & $\begin{array}{c}\text { Indistinguishable from } \\
\text { background }^{a}\end{array}$ \\
\hline 1 & 15 & 51 & $\begin{array}{c}\text { Indistinguishable from } \\
\text { background }^{a}\end{array}$ \\
\hline
\end{tabular}

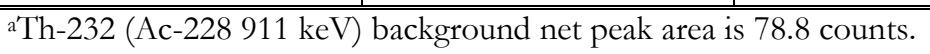


Table 5. 1-meter Detector Height, ISFSI-Enhanced Background

\begin{tabular}{|c|c|c|c|}
\hline \multicolumn{4}{|c|}{ Cobalt-60 (1.2 $\mu \mathrm{Ci})(\mathrm{MD}$ Counts 32.2) } \\
\hline Radius (m) & Depth (cm) & Net Peak Area & Hot Spot MDA $(\mu \mathrm{Ci})$ \\
\hline 0 & 0 & 942 & 0.041 \\
\hline 1 & 0 & 117 & 0.330 \\
\hline 0 & 7.5 & 242 & 0.160 \\
\hline 1 & 7.5 & 48.9 & 0.791 \\
\hline 0 & 15 & 263 & 0.147 \\
\hline 1 & 15 & 115 & 0.336 \\
\hline \multicolumn{4}{|c|}{ Cesium-137 (4.2 $\mu \mathrm{Ci})$ (MD Counts 26.2) } \\
\hline Radius (m) & Depth (cm) & Net Peak Area & Hot Spot MDA $(\mu \mathrm{Ci})$ \\
\hline 0 & 0 & 5910 & 0.019 \\
\hline 1 & 0 & 991 & 0.111 \\
\hline 2 & 0 & 74.7 & 1.475 \\
\hline 0 & 7.5 & 1920 & 0.057 \\
\hline 1 & 7.5 & 583 & 0.189 \\
\hline 2 & 7.5 & 54.4 & 2.025 \\
\hline 0 & 15 & 1620 & 0.068 \\
\hline 1 & 15 & 545 & 0.202 \\
\hline 2 & 15 & 82.2 & 1.340 \\
\hline \multicolumn{4}{|c|}{ Thorium-232 (0.32 $\mu \mathrm{Ci})(\mathrm{MD}$ Counts 25.9) } \\
\hline Radius (m) & Depth (cm) & Net Peak Area & Hot Spot MDA $(\mu \mathrm{Ci})$ \\
\hline 0 & 0 & 115 & 0.157 \\
\hline 1 & 0 & 89.6 & 0.302 \\
\hline 2 & 0 & 67.3 & $\begin{array}{l}\text { Indistinguishable from } \\
\text { background }^{\mathrm{a}}\end{array}$ \\
\hline 0 & 7.5 & 107 & 0.185 \\
\hline 1 & 7.5 & 71 & $\begin{array}{c}\text { Indistinguishable from } \\
\text { background }^{\mathrm{a}}\end{array}$ \\
\hline 2 & 7.5 & 71.9 & $\begin{array}{c}\text { Indistinguishable from } \\
\text { background }^{\mathrm{a}}\end{array}$ \\
\hline 0 & 15 & 110 & 0.173 \\
\hline 1 & 15 & 88.9 & 0.310 \\
\hline 2 & 15 & 54 & $\begin{array}{c}\text { Indistinguishable from } \\
\text { background }^{\mathrm{a}}\end{array}$ \\
\hline
\end{tabular}

aTh-232 (Ac-228 $911 \mathrm{keV}$ ) background net peak area is 62.1 counts. 
Table 6. 2-meter Detector Height, ISFSI-Enhanced Background

\begin{tabular}{|c|c|c|c|}
\hline \multicolumn{4}{|c|}{ Cobalt-60 (1.2 $\mu \mathrm{Ci})(\mathrm{MD}$ Counts 27.9) } \\
\hline Radius (m) & Depth (cm) & Net Peak Area & "Hot Spot MDA $(\mu \mathrm{Ci})$ \\
\hline 0 & 0 & 219 & 0.153 \\
\hline 1 & 0 & 119 & 0.281 \\
\hline 2 & 0 & 40 & 0.837 \\
\hline 0 & 7.5 & 81.7 & 0.410 \\
\hline 1 & 7.5 & 44.1 & 0.759 \\
\hline 0 & 15 & 88.5 & 0.378 \\
\hline 1 & 15 & 38 & 0.881 \\
\hline \multicolumn{4}{|c|}{ Cesium-137 (4.2 $\mu \mathrm{Ci})$ (MD Counts 25.5) } \\
\hline Radius (m) & Depth (cm) & Net Peak Area & "Hot Spot MDA $(\mu \mathrm{Ci})$ \\
\hline 0 & 0 & 1560 & 0.069 \\
\hline 1 & 0 & 961 & 0.112 \\
\hline 2 & 0 & 283 & 0.379 \\
\hline 0 & 7.5 & 520 & 0.206 \\
\hline 1 & 7.5 & 342 & 0.314 \\
\hline 2 & 7.5 & 184 & 0.583 \\
\hline 0 & 15 & 510 & 0.210 \\
\hline 1 & 15 & 382 & 0.281 \\
\hline 2 & 15 & 112 & 0.957 \\
\hline \multicolumn{4}{|c|}{ Thorium-232 $(0.32 \mu \mathrm{Ci})(\mathrm{MD}$ Counts 24.8$)$} \\
\hline Radius (m) & Depth (cm) & Net Peak Area & Hot Spot MDA $(\mu \mathrm{Ci})$ \\
\hline 0 & 0 & 91.3 & 0.232 \\
\hline 1 & 0 & 56 & $\begin{array}{l}\text { Indistinguishable from } \\
\text { background }^{\text {a }}\end{array}$ \\
\hline 2 & 0 & 61.2 & $\begin{array}{c}\text { Indistinguishable from } \\
\text { background }^{\mathrm{a}}\end{array}$ \\
\hline 0 & 7.5 & 81.3 & 0.327 \\
\hline 1 & 7.5 & 58.6 & $\begin{array}{c}\text { Indistinguishable from } \\
\text { background }^{\mathrm{a}}\end{array}$ \\
\hline 2 & 7.5 & 84.2 & 0.292 \\
\hline 0 & 15 & 84.8 & 0.286 \\
\hline 1 & 15 & 82 & 0.318 \\
\hline 2 & 15 & 63.5 & $\begin{array}{c}\text { Indistinguishable from } \\
\text { background }^{\text {a }}\end{array}$ \\
\hline
\end{tabular}

aTh-232 (Ac-228 $911 \mathrm{keV}$ ) background net peak area is 57 counts. 


\subsection{Minimum Detectable Concentration Using ISOCS Modeling of Hot Spots}

For each photopeak region of interest, the background event rate is determined, the efficiency of the far-field model is applied and the MDC is calculated using the Currie method. As built into the Genie 2000's Gamma Analysis software, ORISE reports this value at the $95 \%$ confidence level. An experimental MDC was calculated by analyzing spectra taken with no test sources within $6 \mathrm{~m}$ of the field of view. This was the lowest possible MDC achievable by the ISOCS detector in the area where the measurements were performed.

All tested source-detector geometries $(\mathrm{r}, \theta, \mathrm{z}, \mathrm{h})$ can be modeled in predictable ways to yield accurate results. The accuracy of the measurement result is dependent on how well the mathematical model represents the physical properties of the environment. The primary objective achieved by these tests is to answer what the "figure of merit" is for detecting activity concentrations at the DCGL. The figures in appendix B show the predicted trends in reported activity as a function of the tested variables. Model equations can describe, in every detail, the more complicated form of Beer's law $\left(e^{-\mu x}\right)$ to provide estimates of the source term. What is important to note is that the sources prepared for this test were between factors of 5 and 10 below DCGL ${ }_{\text {emc }}$ values reported in the literature. For example, consider Table 7 below. A "nominal" DCGL $\mathrm{emc}_{\mathrm{e}}$ of $15 \mathrm{pCi} / \mathrm{g}$ yields a total activity of 11.3 $\mu \mathrm{Ci}$ in a 1 square meter area of density $1.7 \mathrm{~g} \mathrm{~cm}^{-3}$ and thickness $15 \mathrm{~cm}$. Hence, the source activity tested was one-tenth this effective $\mathrm{DCGL}_{\mathrm{emc}}$ concentration over that measurement volume.

Table 7. Radionuclides and Nominal DCGL Values and Corresponding Source Activity

\begin{tabular}{|c|c|c|c|}
\hline Radionuclide & $\begin{array}{l}\text { Nominal DCGL } \mathrm{emc} \text { and } \\
\text { Total Activity }(\mathrm{r}=1 \mathrm{~m} ; \\
\left.\mathrm{z}=15 \mathrm{~cm} ; \varrho=1.7 \mathrm{~g} \mathrm{~cm}^{-3}\right)\end{array}$ & $\begin{array}{l}\text { Test Source Activity } \\
\qquad(\mathrm{r}=1 \mathrm{~m} ; \mathrm{z}=15 \mathrm{~cm} ; \\
\left.\varrho=1.7 \mathrm{~g} \mathrm{~cm}^{-3}\right)\end{array}$ & $\begin{array}{c}\text { Ratio of } \\
\text { DCGL }_{\text {emc }} \text { to } \\
\text { Test Source } \\
\text { Activity }\end{array}$ \\
\hline${ }^{60}$ Cobalt & $11.3 \mu \mathrm{Ci} @ 15 \mathrm{pCi} / \mathrm{g}$ & $1.2 \mu \mathrm{Ci} @ 1.6 \mathrm{pCi} / \mathrm{g}$ & 9.4 \\
\hline${ }^{137}$ Cesium & $49.8 \mu \mathrm{Ci} @ 66 \mathrm{pCi} / \mathrm{g}$ & $4.2 \mu \mathrm{Ci} @ 5.6 \mathrm{pCi} / \mathrm{g}$ & 11.8 \\
\hline Thorium (nat) & $2.3 \mu \mathrm{Ci} @ 3 \mathrm{pCi} / \mathrm{g}$ & $0.5 \mu \mathrm{Ci} @ 0.66 \mathrm{pCi} / \mathrm{g}$ & 4.6 \\
\hline
\end{tabular}

For these test cases, this level of activity was detected and qualified (but incorrectly quantified because of "standard model" assumptions, which were understood as baseline assumptions, given the measurement objectives). The data plots of the measured activities for each of the measured conditions are presented in Appendix B. The worst-case measurement conditions are tabularized here. Specifically, when each of the sources whose activity concentration for the measured volume is one-tenth a nominal DCGL, the measured activity concentration (assuming the standard model) divided by the measured MDC is presented. This is a figure of merit for how well the system detected the tested amount of radioactivity above the MDC. In most measurement situations, the sources were detected 
well above the MDC when placed on the fringe of the FOV. The ratio is less than one for ${ }^{60} \mathrm{Co}$ because the source activity was four times that of ${ }^{137} \mathrm{Cs}$. One may ask a question: how can the computed activity be less than the MDC? The MDC background parameter is a random variable. Hence, it is possible to compute an MDC that is greater than the measured value on the basis of the background estimate. Table 8 is a complete listing of the measurement results, expressed as the figure of merit ratio: detected activity concentration divided by the calculated MDC for that measurement arrangement.

Table 8. Ratios of the Measured Activity Concentration Divided by the Calculated MDC for a Source Positioned on the Fringe of the FOV for Detector Heights of 1 and 2 meters, with and without the ISFSIBE, and at all 3 Source Depths

\begin{tabular}{|l|c|c|c|c||}
\hline & $\begin{array}{c}\mathbf{1} \\
\text { meter }\end{array}$ & $\begin{array}{c}\mathbf{2} \\
\text { meter }\end{array}$ & $\begin{array}{c}\text { 1 meter } \\
\text { ISFSIBE }\end{array}$ & $\begin{array}{c}\text { 2 meter } \\
\text { ISFSIBE }\end{array}$ \\
\hline Co-60 & & & & \\
\hline Surface & 3.85 & 1.39 & 5.11 & 0.68 \\
\hline $7.5 \mathrm{~cm}$ & 2.50 & 0.34 & 1.19 & 0.00 \\
\hline $15 \mathrm{~cm}$ & 4.55 & 0.19 & 3.21 & 0.32 \\
\hline Cs-137 & & & & \\
\hline Surface & 11.33 & 5.32 & 15.83 & 5.51 \\
\hline $7.5 \mathrm{~cm}$ & 6.25 & 2.76 & 8.80 & 3.73 \\
\hline $15 \mathrm{~cm}$ & 9.41 & 2.11 & 8.75 & 2.30 \\
\hline Thorium & & & & \\
\hline Surface & 2.59 & 0.91 & 2.35 & 2.21 \\
\hline $7.5 \mathrm{~cm}$ & 3.42 & 1.76 & 1.70 & 2.87 \\
\hline $15 \mathrm{~cm}$ & 1.92 & 3.30 & 2.26 & 1.83 \\
\hline
\end{tabular}

In all situations the MDC is less than a nominal DCGL (at least by a factor of 15 to 20). The discrete particles fabricated were detected in nearly all cases, and at the most extreme source positions: $\mathrm{h}=2 \mathrm{~m}, \mathrm{z}=15 \mathrm{~cm}, \mathrm{r}=2 \mathrm{~m}$.

\subsection{Conclusions}

During June and July, 2006, a series of ISGRS measurements were made at the ORISE field test laboratory for environmental studies. High-resolution gamma-ray spectrometry measurements were made of radionuclide standards placed within the field of view of an HPGe detector at surface and near-surface positions. A set of numerical results were presented that show detection capability. The conclusions from this work are many-fold:

1. Detection capability is far below nominal $\mathrm{DCGL}_{\mathrm{w}}$ and $\mathrm{DCGL}_{\mathrm{emc}}$ values for the three sources tested $\left({ }^{137} \mathrm{Cs},{ }^{60} \mathrm{Co}\right.$, and $\left.\mathrm{Th}_{\text {nat }}\right)$. It is important, however, to understand the most important parameters affiliated with these measurements to understand performance and limitations of the analytical results. Table 2 is an excellent summary of these parameters, serving as a assay checklist for whether measurement parameters were set properly. 
2. Spatial dependencies described by various source-to-detector configurations as a function of detector height, and source radial, azimuthal, or depth position, are easily predicted and accounted for by the modeling software currently available. When the modeling software is used to describe the detector efficiency for the entire sample volume (for example a cylinder of soil, with radius $1 \mathrm{~m}$ and depth $15 \mathrm{~cm}$ ), small volumetric samples of radioactivity are detectable out to the periphery of the FOV. Because the model estimates the detector response function for the entire "average volumetric response", the concentration reported is biased low mostly by the sheer volume of soil that makes up the denominator of activity concentration (pCi/g). An ISGRS far field measurement, by design, cannot isolate relative discrete particles within the FOV. For imaging small localized areas, other technologies may need to be considered: walk-over $\mathrm{NaI}$ scans, pixelated array of detectors (with spatially recorded event rates), a position-sensitive diode such as "Cartogam" that registers the angle of incidence of the incoming photon and reconstructs from the $(r, \theta)$ event registration, a map of the contamination area. Remember that collecting spatially sensitive data versus average spatial data requires much more time to achieve "good statistics," particularly as the radionuclide concentration becomes extremely small. Other methods for analyzing fixed-grid data are available and should be evaluated e.g., ISDMAP (Reginatto et al., 1997).

3. ISGRS measurement results and the uncertainty that can be estimated directly from the measurement are significantly more accurate than the calculations used to set the DCGL. Quite simply, an analyst who sets the model parameters for ISGRS can remove a significant fraction of parameter guess work from the measurement. Conversely, based on ORISE experience, an analyst estimating dose equivalent per unit residual activity concentration accepts much greater uncertainty and guess work in describing the physical transport mechanisms of the site and hence accepts much greater uncertainties in the prediction.

4. In addition to the measurement-based evaluations conducted in this report, the ability to simply detect discrete particles (hot spots) was investigated to a more limited extent with corresponding MDA calculations for the three test radionuclides. As anticipated, hot spot MDAs were primarily a function of source placement (including depth) relative to the detector and detector height. An overall conclusion was reached that it is generally possible to detect activities as low as $1 \mu \mathrm{Ci}$ (and often many times lower than this activity) of a discrete particle using ISGRS. It was noted that determination of a discrete particle MDA is one parameter in the process of developing an investigation level.

Due to the fact that the ISGRS effort in support of RFTA 06-010 was an initial investigation at ORISE facilities, follow-on field research is recommended to examine the discrete particle issue in greater detail and to improve this research effort. If repeated at ORISE, all test conditions would be re-evaluated, including the use of higher activity test sources and longer counting times.

5. There are dozens of reports available on ISGRS performance, benchmarking of results, and verification/validation of software. If these type of measurements are to 
be put into widespread (production) use for final status surveys, a number of tasks need to be investigated:

a. The USNRC should decide and assess whether the "discrete particle" problem is one that should be reconciled in the dose model or the measurement protocol, or both. At the moment, the dose model and the MARSSIM approach rely on average concentrations over relatively large areas and volumes. The measurement protocols in turn are set up primarily to ensure that the concentration of residual radioactivity is below the corresponding $\mathrm{DCGL}_{\mathrm{emc}}$ and DCGL $\mathrm{w}_{\mathrm{w}}$. Discrete particles are not explicitly addressed.

b. Somewhat related to $4 \mathrm{a}$, what specifically are the spatial measurement requirements? If better spatial resolution is required for ISGRS, then ORISE should provide additional information on the performance criteria. What other measurements can and should augment ISGRS? How can various collimators and detector heights be used to achieve better spatial selectivity? Should better methods be deployed for identifying discrete particles (e.g. NaI arrays on a golf cart, pixelated arrays)? Better methods in this regard are defined as methods that remove the person-to-person uncertainty and variation in the ability to detect a spot of radioactivity during a final survey (refer to NUREG-1507).

c. ISGRS measurements for final status surveys of soil should be conducted according to an adopted, consensus standard method. A number of issues to consider: 1) training and qualification of the technician, of the analyst, and of the quality assurance organization; 2) calibration and operation; 3) mathematical model preparation and verification (draft ASTM standard committee C26.12); 4) performance metrics for spatial response; 5) a checklist of parameters to check and review once a measurement and analysis has been conducted (see Table 2 in the Results section). All five of these issues have been discussed nationally and internationally in other programs: material protection and control, safeguards and security, and waste management. Many of the needs can be addressed by consolidating many of the ideas that exist in other applications of the same technology. Several answers and solutions to these issues are provided in this report.

6. Until a set of measurement specifications are written and approved, ISGRS should not replace $\mathrm{NaI}$ scanning or soil sample collection and analysis. ISGRS can be used successfully to augment the D\&D process, provide real-time feedback on radionuclide concentrations, and to confirm radionuclide distribution. ISGRS provides the most accurate means available to measure the "average" radionuclide concentration in a large volume, on the order of a 1 - to $2-\mathrm{m}$ radius and $15 \mathrm{~cm}$ depth. This is much more cost effective than sampling (composite or otherwise) the equivalent volume and submitting the samples to the laboratory.

7. ISGRS use in reactor operations is extremely insensitive to external background, in magnitude or variation, when shielded properly. Its use is not limited by what power 
it has, but rather the application in which it is used and then implemented by the technical staff. It is recognized that ISGRS is much more expensive to purchase and to use, but a cost benefit analysis was not prepared here. A cost analysis is cited in the US DOE document, DOE/EM-0618, December 2001.

\subsection{Recommendations for Further Work}

The measurements and analysis conducted for this project provide a solid framework for additional effort:

1. A NUREG should be drafted to address how ISGRS technology may be implemented to augment the MARSSIM data collection effort.

2. There are no current specifications for how well any measurement methodology must perform for hot particle detection. These specifications should be drafted and include appropriate concepts for benchmarking computer models, validating computational results (with direct measurement tests), verifying that the software is performing as described, and providing recommendations for Quality Assurance (QA) requirements on how the data is reduced, analyzed, and presented.

3. Compare measurement capability between ISGRS and NaI scanning; and ISGRS and sampling and analysis.

4. Evaluate more completely the suite of detector response functions for describing a measurement on the fringe and at depths greater than $15 \mathrm{~cm}$. These measurements were performed at $1 \mathrm{~m}, 2 \mathrm{~m}$, and $3 \mathrm{~m}$. ORISE recommends that follow-on measurements employ testing at smaller spacing intervals such as 0.8, 0.9, 1.0, 1.1, 1.2 meters, etc. Additional measurements should also be collected using sources buried below $15 \mathrm{~cm}$.

5. Construct and calibrate source standards that are low activity, but uniformly distributed as the ISGRS disc source explained in this document.

6. Prepare a methodology for establishing baseline MDAs for various measurement conditions: background spectrum, detector efficiency, collimator type, radionuclide, detector height above ground, and count time. A lookup table of "achievable MDAs" would provide the USNRC with useful information in assessing whether a licensee will be able to meet the DCGL measurement requirements.

7. Initiate Table 2 as a strawman for a checklist for checking licensee measurement parameters and procedures in the field.

8. Use real measurement data and setup field experiments to test ISDMAP. 


\section{References}

ANSI/IEEE Std 325-1996, IEEE Standard Test Procedures for Germanium Gamma-Ray Detectors.

Bailey P., "Comparison of NaI and HPGe Minimum Detectable Activities," USDOE Environmental measurements Laboratory, EML-619, (November 2003).

Beck, H. L. DeCampo J.A., Gogolak C.V., "In Situ Ge(Li) and NaI(Tl) Gamma-Ray Spectroscopy," HASL-258, (September 1972).

Chapman J., Boerner A., "Experimental Test Plan for In Situ Gamma Ray Spectroscopy (ISGRS) Use in Final Status Surveys," ORISE report to the USNRC under RFTA-06010, (August 8, 2006).

“Data Quality Assessment: Statistical Methods for Practitioners,” U.S. Environmental Protection Agency, EPA QA/G-92, (February 2006).

Dehmel J. , Schneider S. "Technical Considerations for Using in situ Gamma Spectroscopy in Conducting Final Status Surveys," HPJ vol.84 (6 Suppl) : S136-40, (June 2003).

Fong S.H, Alverez J.L. "Data Quality Objectives for Surface-Soil Cleanup Operation Using in Situ Gamma Spectrometry for Concentration Measurements," HPJ vol72(2):286-295, (February 1997).

HASL-300, “The Procedures Manual of The Environmental Measurements Laboratory," Volume I, 28th Edition, available online http://www.eml.st.dhs.gov/publications/procman/, (February 1997).

Helfer I.K, Miller, K.M. “Calibration Factors for Ge Detectors Used for Field Spectrometry,” HPJ vol55(1):15-29, (July 1988).

“ISOCS for Free Release," USDOE, Deactivation and Decommissioning Focus Area, DOE/EM-0618, (December 2001).

ITRC (Interstate Technology \& Regulatory Council). "Real-Time Measurement of Radionuclides in Soil: Technology and Case Studies," RAD-4. (from: www.itrcweb.org) (2006).

Kalb, P. "Comparability of ISOCS Instrument in Radionuclide Characterization at Brookhaven National Laboratory,” BNL-52607-01/04-Rev, (March 2001).

Nir-El Y., "In Situ Hot Spot Measurements With HPGe Detector 0.1 M Above Ground," HPJ vol79(4):396-401, (October 2000).

NUREG-1506, "Measurement Methods for Radiological Surveys in Support of New Decommissioning Criteria," Draft Report for Comment, USNRC, (August 1995). 
NUREG-1507, "Minimum Detectable Concentrations With Typical Radiation Survey Instruments for Various Contaminants in Field Conditions," USNRC, (June 1998).

NUREG-1575, "Multi-Agency Radiation Survey and Site Investigation Manual (MARSSIM)," revision 1, (August 2000).

Oertel, C.P., et al., "In Situ Depth Profiling of ${ }^{137} \mathrm{Cs}$ Contamination In Soils At The Idaho National Engineering And Environmental Laboratory," HPJ vol87(6):664-669, (December 2004).

Reginatto M., Bailey P., Shebell P. "A User's Guide for the Computer Program ISDMAP: Analysis and Mapping of In-Situ Gamma-Ray Spectrometry and Soil Sample Data," Environmental Measurements Laboratory, USDOE, EML-610, (November 2000).

Reginatto M., Shebell P., Miller K. "ISD97, a Computer Program to Analyze Data From a Series of In Situ Measurements on a Grid and Identify Potential Localized Areas of Elevated Activity," Environmental Measurements Laboratory, USDOE, EML-590, (October 1997).

Roybal L.G. et al., "Real-Time Soil Characterization and Analysis Systems Used at US Department of Energy Closure Sites in Ohio," Proceedings of Waste Management 2003, (February 23-27, 2003).

Shebell P., et al, “An In Situ Gamma-Ray Spectrometry Intercomparison,” HPJ vol85(6):662-677, (December 2003).

SW-846, "Test Methods for Evaluating Solid Waste, Physical/Chemical Methods, Chapter 9 - Sampling” USEPA (1986).

US DOE "User Guidelines, Measurement Strategies, and Operational Factors for Deployment of In Situ Gamma Spectrometry at the Fernald Site," US DOE, 20701-RP0006, (December 2004).

US NRC RFTA-06-010, "In Situ Gamma Ray Spectroscopy (ISGRS) Use in Final Status Surveys," Office of Nuclear Material Safety and Safeguards, Division of Waste Management and Environmental Protection, (June 19, 2006).

Venkarataman, R., Bronson, F., Atrashkevich, V., Young, B., and Field, M., "Validation of In-Situ Object Counting System (ISOCS) Mathematical Efficiency Software," Nuclear Instruments and Methods in Physics Research, A422 (1999) pp. 450-454.

Zombori P., Andrasi A, Nemeth I. "A New Method for the Determination of Radionuclide Distribution in the Soil by in situ Gamma-ray Spectrometry," Budapest, Hungary: Central Research Institute for Physics, Hungarian Academy of Sciences, KFKI-199220/K. (1992). 


\section{Appendix A. Primary Steps in the Field Measurements and Analysis Procedure}

This appendix provides a step-by-step process that describes how the ORISE ISGRS measurements were performed and analyzed.

1. The ISOCS detector was mounted on an engine lift using an adaptor designed by ORISE. This allowed the detector to be raised to 1,2, and $3 \mathrm{~m}$ heights.

2. AC power was supplied to the laptop and Inspector 2000 MCA.

3. At the start of each day, an energy calibration was performed by counting a mixed gamma source for 15 minutes. The detector was then calibrated by running a Certificate File Energy Calibration using the appropriate source certificate. The energy "shape" calibration was addressed by deleting peaks that had an extremely low FWHM or if the peak had a FWHM value that did not meet the required statistics. The shape factor calibration is as important as the energy calibration.

4. High-resolution spectra were acquired from each source at different radii and depths, starting on the axis of the detector and then moving outward in $1 \mathrm{~m}$ increments to $3 \mathrm{~m}$. This was done for surface, $7.5 \mathrm{~cm}$, and $15 \mathrm{~cm}$ depths in the soil. Each spectrum was saved, backed up, and analyzed. Each spectrum retains the energy calibration done at the beginning of the day (in the CAM file).

5. Analysis of the detector response function was performed by creating efficiency files for detectors positioned at 1 and $2 \mathrm{~m}$ heights. Canberra's ISOCS Geometry Composer was used for this task, generating efficency functions for the FOV and 15 cm depth.

6. Within the Analysis Sequence File, the default "Currie MDA" analysis script was used and modified to report the analysis results for Co-60, Cs-137, and only the 911 $\mathrm{keV}$ peak for Ac-228 ( $\left.\mathrm{Th}_{\text {nat }}\right)$.

7. The Currie MDA analysis script was then run on all spectra. Each time, the activity and MDA was recorded by hand into a spreadsheet, where further calculations were performed. The spreadsheet is located in Appendix B. Actinium-228 was used to quantify thorium in equilibrium.

A note about the Currie MDA formulation: this analysis is one of several specifications that can be used. ORISE believes that it is the most widely used method. However, it may be prudent to test other formulations for appropriateness to this measurement situation. The MDA designation implies that Minimum Detectable Activity is calculated; however, the software is capable of dividing this value (in $\mu \mathrm{Ci}$ ) by the mass of the sample, to arrive at an MDC (Minimum Detectable Concentration). 


\section{Appendix B. Data Summary}

Each of the data tables shows the Spectrum ID (formatted to describe the sequence of the measurement, detector height, the source radial position (axis, $1 \mathrm{~m}, 2 \mathrm{~m}, 3 \mathrm{~m}$ ), source depth (surface, $7.5 \mathrm{~cm}, 15 \mathrm{~cm}$ ), and with or without BE (background enhancement at 2x). The Geometry Filename is the name of the efficiency function file used by the analysis sequence/data reduction step: $2 \mathrm{~m}-15 \mathrm{~cm}$.ecc is the efficiency file for the detector at $2 \mathrm{~m}$ and the FOV a radius of $2 \mathrm{~m}$ and depth of $15 \mathrm{~cm}$, uniformly contaminated. Similarly, the $1 \mathrm{~m}$ $15 \mathrm{~cm}$.ecc file describes the detector at a height of $1 \mathrm{~m}$. The source radius and depth is provided. The results for each case are: Total Activity ( $\mu \mathrm{Ci})$ for the distributed source case along with the measured MDA ( $\mu \mathrm{Ci})$. The Activity concentration and MDA concentration are the prior two values $(\mu \mathrm{Ci})$ divided by the mass of soil $(800 \mathrm{~kg}$ at $1 \mathrm{~m}$ height; and $3200 \mathrm{~kg}$ at $2 \mathrm{~m}$ height). The last number reported, Activity per MDA, is simply the ratio of the detected quantity divided by the measured MDA. When the sources were within the FOV, this ratio is almost always greater than at the periphery. On average, the source activities used were significantly greater than the detection capabilities of the system.

\section{B.1 Background Measurements}

Background measurement results with the ISOCS detector. MDA calculated for ${ }^{137} \mathrm{Cs}$, distributed source. Height of the detector, $h=1$ meter.

$\begin{array}{lcccccc} & \begin{array}{c}\text { Geometry } \\ \text { Filename }\end{array} & \begin{array}{c}\text { Radius } \\ (\mathrm{m})\end{array} & \begin{array}{c}\text { Depth } \\ (\mathrm{cm})\end{array} & \begin{array}{c}\text { Total Activity } \\ (\mu \mathrm{Ci})\end{array} & \begin{array}{c}\text { Total Activity } \\ \text { Uncertainty } \\ (\mu \mathrm{Ci})\end{array} & \begin{array}{c}\text { MDA } \\ (\mu \mathrm{Ci})\end{array} \\ \text { Spectrum ID } & & 1 & 15 & 0.77 & 0.14 & 0.34 \\ \text { 8-background-1 } & \text { 1-meter-15cm.ecc } & 1 & 15 & 0.81 & 0.12 & 0.26 \\ \text { 9-background-2 } & & 1 & 15 & 0.55 & 0.13 & 0.36 \\ \text { 10-background-3 } & & 1 & 15 & 1.2 & 0.16 & 0.35 \\ \text { 11-background-4 } & 1 & 15 & 0.76 & 0.16 & 0.43 \\ \text { 13-background } & & & & 0.818 & & \end{array}$

\section{B.2 2-Meter Measurement Results, with ISFSIBE}

\section{Cobalt-60}

$\begin{array}{lcccccccc}\text { Spectrum ID } & \begin{array}{c}\text { Geometry } \\ \text { Filename }\end{array} & \begin{array}{c}\text { Radius } \\ (\mathrm{m})\end{array} & \begin{array}{c}\text { Depth } \\ (\mathrm{cm})\end{array} & \begin{array}{c}\text { Total Activity } \\ (\mu \mathrm{Ci})\end{array} & \begin{array}{c}\text { MDA } \\ (\mu \mathrm{Ci})\end{array} & \begin{array}{c}\text { Activity } \\ (\mathrm{pCi} / \mathrm{g})\end{array} & \begin{array}{c}\text { MDA } \\ (\mathrm{pCi} / \mathrm{g})\end{array} & \begin{array}{c}\text { Activity } \\ \text { per MDA }\end{array} \\ \text { 63-2m-axis-surf-BE } & \text { 2-meter-15cm.ecc } & 0 & 0 & 3.4 & 0.53 & 4.51 & 0.70 & 6.42 \\ \text { 64-2m-1m-surf-BE } & \text { 2-meter-15cm.ecc } & 1 & 0 & 1.8 & 0.55 & 2.39 & 0.73 & 3.27 \\ \text { 65-2m-2m-surf-BE } & \text { 2-meter-15cm.ecc } & 2 & 0 & 0.46 & 0.68 & 0.61 & 0.90 & 0.68 \\ \text { 66-2m-3m-surf-BE } & \text { 2-meter-15cm.ecc } & 3 & 0 & 0 & 0.44 & 0.00 & 0.58 & 0.00 \\ \text { 67-2m-axis-7.5-BE } & \text { 2-meter-15cm.ecc } & 0 & 7.5 & 1.3 & 0.4 & 1.72 & 0.53 & 3.25 \\ \text { 68-2m-1m-7.5-BE } & \text { 2-meter-15cm.ecc } & 1 & 7.5 & 0.68 & 0.5 & 0.90 & 0.66 & 1.36 \\ 69-2 \mathrm{~m}-2 \mathrm{~m}-7.5-B E & \text { 2-meter-15cm.ecc } & 2 & 7.5 & 0 & 0.53 & 0.00 & 0.70 & 0.00 \\ \text { 70-2m-3m-7.5-BE } & \text { 2-meter-15cm.ecc } & 3 & 7.5 & 0 & 0.53 & 0.00 & 0.70 & 0.00 \\ 71-2 \mathrm{~m}-\text {-axis-15-BE } & \text { 2-meter-15cm.ecc } & 0 & 15 & 1.4 & 0.49 & 1.86 & 0.65 & 2.86 \\ 72-2 \mathrm{~m}-1 \mathrm{~m}-15-\mathrm{BE} & \text { 2-meter-15cm.ecc } & 1 & 15 & 0.59 & 0.42 & 0.78 & 0.56 & 1.40 \\ 73-2 \mathrm{~m}-2 \mathrm{~m}-15-\mathrm{BE} & \text { 2-meter-15cm.ecc } & 2 & 15 & 0.22 & 0.69 & 0.29 & 0.92 & 0.32 \\ 74-2 \mathrm{~m}-3 \mathrm{~m}-15-\mathrm{BE} & \text { 2-meter-15cm.ecc } & 3 & 15 & 0.08 & 0.44 & 0.11 & 0.58 & 0.18\end{array}$




\section{Cesium-137}

Spectrum ID
$63-2 \mathrm{~m}$-axis-surf-BE
$64-2 \mathrm{~m}-1 \mathrm{~m}$-surf-BE
$65-2 \mathrm{~m}-2 \mathrm{~m}$-surf-BE
$66-2 \mathrm{~m}-3 \mathrm{~m}-\mathrm{surf}-\mathrm{BE}$
$67-2 \mathrm{~m}-\mathrm{axis}-7.5-\mathrm{BE}$
$68-2 \mathrm{~m}-1 \mathrm{~m}-7.5-\mathrm{BE}$
$69-2 \mathrm{~m}-2 \mathrm{~m}-7.5-\mathrm{BE}$
$70-2 \mathrm{~m}-3 \mathrm{~m}-7.5-\mathrm{BE}$
$71-2 \mathrm{~m}-\mathrm{axis}-15-\mathrm{BE}$
$72-2 \mathrm{~m}-1 \mathrm{~m}-15-\mathrm{BE}$
$73-2 \mathrm{~m}-2 \mathrm{~m}-15-\mathrm{BE}$
$74-2 \mathrm{~m}-3 \mathrm{~m}-15-\mathrm{BE}$

Geometry
Filename
2-meter-15cm.ecc
2-meter-15cm.ecc
2-meter-15cm.ecc
2-meter-15cm.ecc
2-meter-15cm.ecc
2-meter-15cm.ecc
2-meter-15cm.ecc
2-meter-15cm.ecc
2-meter-15cm.ecc
2-meter-15cm.ecc
2-meter-15cm.ecc
2-meter-15cm.ecc

\section{Thorium}

$\begin{array}{ll}\text { Spectrum ID } & \text { Geometry } \\ \text { 63-2m-axis-surf-BE } & \text { Filename } \\ \text { 64-2m-1m-surf-BE } & \text { 2-meter-15cm.ecc } \\ 65-2 \mathrm{~m}-2 \mathrm{~m} \text {-surf-BE } & \text { 2-meter-15cm.ecc } \\ 66-2 \mathrm{~m}-3 \mathrm{~m} \text {-surf-BE } & \text { 2-meter-15cm.ecc } \\ 67-2 \mathrm{~m}-\mathrm{axis}-7.5-\mathrm{BE} & \text { 2-meter-15cm.ecc } \\ 68-2 \mathrm{~m}-1 \mathrm{~m}-7.5-\mathrm{BE} & \text { 2-meter-15cm.ecc } \\ 69-2 \mathrm{~m}-2 \mathrm{~m}-7.5-\mathrm{BE} & \text { 2-meter-15cm.ecc } \\ 70-2 \mathrm{~m}-3 \mathrm{~m}-7.5-\mathrm{BE} & \text { 2-meter-15cm.ecc } \\ 71-2 \mathrm{~m}-\mathrm{axis}-15-\mathrm{BE} & \text { 2-meter-15cm.ecc } \\ 72-2 \mathrm{~m}-1 \mathrm{~m}-15-\mathrm{BE} & \text { 2-meter-15cm.ecc } \\ 73-2 \mathrm{~m}-2 \mathrm{~m}-15-\mathrm{BE} & \text { 2-meter-15cm.ecc } \\ 74-2 \mathrm{~m}-3 \mathrm{~m}-15-\mathrm{BE} & \text { 2-meter-15cm.ecc }\end{array}$

$\begin{array}{cc}\begin{array}{c}\text { Radius } \\ (\mathrm{m})\end{array} & \begin{array}{c}\text { Depth } \\ (\mathrm{cm})\end{array} \\ 0 & 0 \\ 1 & 0 \\ 2 & 0 \\ 3 & 0 \\ 0 & 7.5 \\ 1 & 7.5 \\ 2 & 7.5 \\ 3 & 7.5 \\ 0 & 15 \\ 1 & 15 \\ 2 & 15 \\ 3 & 15\end{array}$

Total Activity
$(\mu \mathrm{Ci})$
23
14.5
4.3
0.64
7.9
5.2
2.8
0.82
7.7
5.7
1.7
0.68

$\begin{array}{rr}\begin{array}{l}\text { Radius } \\ (\mathrm{m})\end{array} & \begin{array}{l}\text { Depth } \\ (\mathrm{cm})\end{array} \\ 0 & 0 \\ 1 & 0 \\ 2 & 0 \\ 3 & 0 \\ 0 & 7.5 \\ 1 & 7.5 \\ 2 & 7.5 \\ 3 & 7.5 \\ 0 & 15 \\ 1 & 15 \\ 2 & 15 \\ 3 & 15\end{array}$

\begin{tabular}{|c|c|c|c|}
\hline $\begin{array}{l}\text { MDA } \\
(\mu \mathrm{Ci})\end{array}$ & $\begin{array}{l}\text { Activity } \\
\text { (pCi/g) }\end{array}$ & $\begin{array}{l}\mathrm{MDA} \\
(\mathrm{pCi} / \mathrm{g})\end{array}$ & $\begin{array}{c}\text { Activity } \\
\text { per MDA }\end{array}$ \\
\hline 1 & 30.50 & 1.33 & 23.00 \\
\hline 0.95 & 19.23 & 1.26 & 15.26 \\
\hline 0.78 & 5.70 & 1.03 & 5.51 \\
\hline 0.58 & 0.85 & 0.77 & 1.10 \\
\hline 0.95 & 10.48 & 1.26 & 8.32 \\
\hline 0.67 & 6.90 & 0.89 & 7.76 \\
\hline 0.75 & 3.71 & 0.99 & 3.73 \\
\hline 0.44 & 1.09 & 0.58 & 1.86 \\
\hline 0.69 & 10.21 & 0.92 & 11.16 \\
\hline 0.65 & 7.56 & 0.86 & 8.77 \\
\hline 0.74 & 2.25 & 0.98 & 2.30 \\
\hline 0.9 & 0.90 & 1.19 & 0.76 \\
\hline
\end{tabular}

Total Activity $\mathrm{MDA}$

$(\mu \mathrm{C}$

\begin{tabular}{rrr}
$\begin{array}{r}\text { Activity } \\
(\mathrm{pCi} / \mathrm{g})\end{array}$ & $\begin{array}{l}\text { MDA } \\
(\mathrm{pCi} / \mathrm{g})\end{array}$ & $\begin{array}{r}\text { Activity } \\
\text { per MDA }\end{array}$ \\
6.23 & 2.25 & 2.76 \\
3.85 & 2.25 & 1.71 \\
4.11 & 1.86 & 2.21 \\
5.44 & 1.86 & 2.93 \\
5.57 & 2.25 & 2.47 \\
3.98 & 1.99 & 2.00 \\
\hline 5.70 & 1.99 & 2.87 \\
1.09 & 1.99 & 0.55 \\
5.84 & 2.25 & 2.59 \\
5.57 & 2.39 & 2.33 \\
4.38 & 2.39 & 1.83 \\
2.92 & 3.85 & 0.76 \\
\hline
\end{tabular}



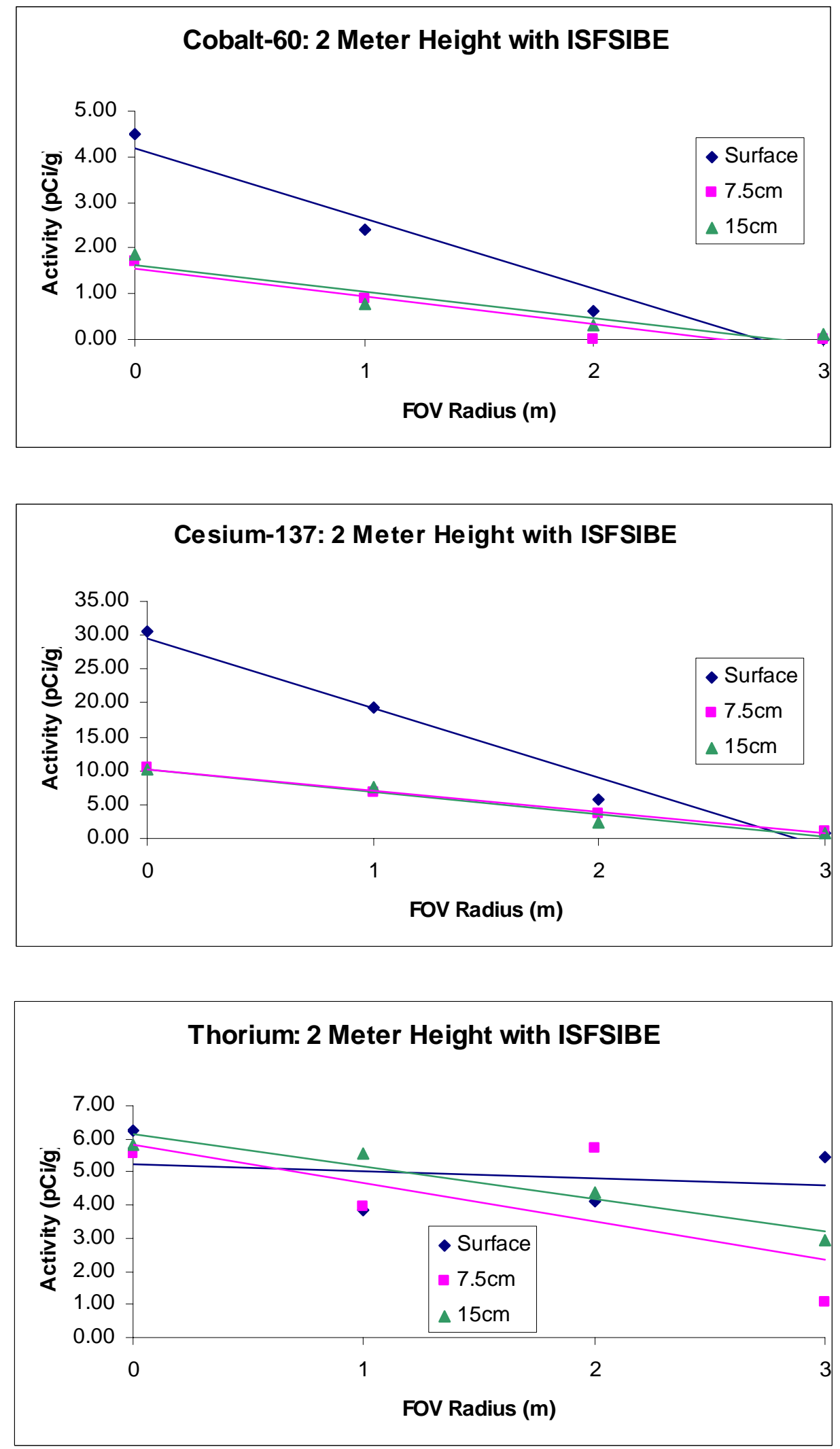


\section{B.3 1-Meter Measurement Results, with ISFSIBE}

\section{Cobalt-60}

Spectrum ID

48-1m-axis-surface-BE

50-1m-1m-surface-BE

51-1m-2m-surf-BE

52-1m-3m-surf-BE

53-1m-axis-7.5-BE

54-1m-1m-7.5-BE

55-1m-2m-7.5-BE

56-1m-3m-7.5-BE

77-1m-axis-15-BE

58-1m-1m-15-BE

59-1m-2m-15-BE

60-1m-3m-15-BE
Geometry Filename

1 -meter-15cm.ecc

1 -meter-15cm.ecc

1 -meter-15cm.ecc

1 -meter-15cm.ecc

1 -meter-15cm.ecc

1 -meter-15cm.ecc

1 -meter- $15 \mathrm{~cm}$.ecc

1 -meter- $15 \mathrm{~cm} . \mathrm{ecc}$

1 -meter- $15 \mathrm{~cm}$. ecc

1 -meter-15cm.ecc

1 -meter- $15 \mathrm{~cm} . \mathrm{ecc}$

1 -meter- $15 \mathrm{~cm}$.ecc

$\begin{array}{cc}\begin{array}{c}\text { Radius } \\ (\mathrm{m})\end{array} & \begin{array}{c}\text { Depth } \\ (\mathrm{cm})\end{array} \\ 0 & 0 \\ 1 & 0 \\ 2 & 0 \\ 3 & 0 \\ 0 & 7.5 \\ 1 & 7.5 \\ 2 & 7.5 \\ 3 & 7.5 \\ 0 & 15 \\ 1 & 15 \\ 2 & 15 \\ 3 & 15\end{array}$

Total
Activity
$(\mu \mathrm{Ci})$
3.7
0.46
0.038
0
0.86
0.25
0
0.12
1
0.45
0
0

\section{Cesium-137}

Spectrum ID

48-1m-axis-surface-BE

Geometry Filename

1 -meter-15cm.ecc

1 -meter- $15 \mathrm{~cm}$.ecc

1 -meter- $15 \mathrm{~cm} . \mathrm{ecc}$

1 -meter- $15 \mathrm{~cm} . \mathrm{ecc}$

1 -meter-15cm.ecc

1 -meter- $15 \mathrm{~cm}$.ecc

1 -meter- $15 \mathrm{~cm}$.ecc

1-meter-15cm.ecc

1 -meter- $15 \mathrm{~cm}$. ecc

1 -meter-15cm.ecc

1 -meter-15cm.ecc

1 -meter- $15 \mathrm{~cm}$.ecc
Radius Depth

(m) (cm)

Total

Activity

$(\mu \mathrm{Ci})$

22.4

3.8

0.28

0.11

7.3

2.2

0.21

0.25

6.14

2.1

0.31

0.18
59-1m-2m-15-BE

60-1m-3m-15-BE

$\begin{array}{cc}\text { MDA } & \text { Activity } \\ (\mu \mathrm{Ci}) & (\mathrm{pCi} / \mathrm{g}) \\ 0.21 & 4.91 \\ 0.09 & 0.61 \\ 0.14 & 0.05 \\ 0.14 & 0.00 \\ 0.32 & 1.14 \\ 0.21 & 0.33 \\ 0.14 & 0.00 \\ 0.13 & 0.16 \\ 0.14 & 1.33 \\ 0.14 & 0.60 \\ 0.13 & 0.00 \\ 0.13 & 0.00\end{array}$

MDA

(pCi/g)

0.28

0.12

0.19

0.19

0.42

0.28

0.19

0.17

0.19

0.19

0.17

0.17

Activity

per

MDA

17.62

5.11

0.27

0.00

2.69

1.19

0.00

0.92

7.14

3.21

0.00

0.00

\section{Thorium}

Spectrum ID

48-1m-axis-surface-BE

50-1m-1m-surface-BE

51-1m-2m-surf-BE

52-1m-3m-surf-BE

53-1m-axis-7.5-BE

54-1m-1m-7.5-BE

55-1m-2m-7.5-BE

56-1m-3m-7.5-BE

77-1m-axis-15-BE

58-1m-1m-15-BE

59-1m-2m-15-BE

60-1m-3m-15-BE
Geometry Filename

1 -meter-15cm.ecc

1 -meter- $15 \mathrm{~cm}$.ecc

1 -meter- $15 \mathrm{~cm}$.ecc

1 -meter-15cm.ecc

1 -meter- $15 \mathrm{~cm}$.ecc

1 -meter-15cm.ecc

1 -meter-15cm.ecc

1 -meter-15cm.ecc

1 -meter-15cm.ecc

1 -meter-15cm.ecc

1-meter-15cm.ecc

1 -meter-15cm.ecc

$\begin{array}{cc}\begin{array}{c}\text { Radius } \\ (\mathrm{m})\end{array} & \begin{array}{c}\text { Depth } \\ (\mathrm{cm})\end{array} \\ 0 & 0 \\ 1 & 0 \\ 2 & 0 \\ 3 & 0 \\ 0 & 7.5 \\ 1 & 7.5 \\ 2 & 7.5 \\ 3 & 7.5 \\ 0 & 15 \\ 1 & 15 \\ 2 & 15 \\ 3 & 15\end{array}$

\begin{tabular}{|c|c|c|c|}
\hline $\begin{array}{l}\text { MDA } \\
(\mu \mathrm{Ci})\end{array}$ & $\begin{array}{l}\text { Activity } \\
\text { (pCi/g) }\end{array}$ & $\begin{array}{l}\mathrm{MDA} \\
(\mathrm{pCi} / \mathrm{g})\end{array}$ & $\begin{array}{l}\text { Activity } \\
\text { per } \\
\text { MDA }\end{array}$ \\
\hline 0.37 & 29.71 & 0.49 & 60.54 \\
\hline 0.24 & 5.04 & 0.32 & 15.83 \\
\hline 0.11 & 0.37 & 0.15 & 2.55 \\
\hline 0.16 & 0.15 & 0.21 & 0.69 \\
\hline 0.32 & 9.68 & 0.42 & 22.81 \\
\hline 0.25 & 2.92 & 0.33 & 8.80 \\
\hline 0.13 & 0.28 & 0.17 & 1.62 \\
\hline 0.14 & 0.33 & 0.19 & 1.79 \\
\hline 0.25 & 8.14 & 0.33 & 24.56 \\
\hline 0.24 & 2.79 & 0.32 & 8.75 \\
\hline 0.12 & 0.41 & 0.16 & 2.58 \\
\hline 0.12 & 0.24 & 0.16 & 1.50 \\
\hline
\end{tabular}

$\begin{array}{ccccc}\begin{array}{c}\text { Total } \\ \text { Activity } \\ (\mu \mathrm{Ci})\end{array} & \begin{array}{c}\text { MDA } \\ (\mu \mathrm{Ci})\end{array} & \begin{array}{c}\text { Activity } \\ (\mathrm{pCi} / \mathrm{g})\end{array} & \begin{array}{c}\text { MDA } \\ (\mathrm{pCi} / \mathrm{g})\end{array} & \begin{array}{c}\text { Activity } \\ \text { per } \\ \text { MDA }\end{array} \\ 1.5 & 0.94 & 1.99 & 1.25 & 1.60 \\ 1.2 & 0.51 & 1.59 & 0.68 & 2.35 \\ 0.87 & 0.46 & 1.15 & 0.61 & 1.89 \\ 0.66 & 0.46 & 0.88 & 0.61 & 1.43 \\ 1.4 & 0.6 & 1.86 & 0.80 & 2.33 \\ 0.92 & 0.54 & 1.22 & 0.72 & 1.70 \\ 0.93 & 0.43 & 1.23 & 0.57 & 2.16 \\ 0.92 & 0.39 & 1.22 & 0.52 & 2.36 \\ 1.43 & 0.54 & 1.90 & 0.72 & 2.65 \\ 1.2 & 0.53 & 1.59 & 0.70 & 2.26 \\ 0.7 & 0.43 & 0.93 & 0.57 & 1.63 \\ 0.93 & 0.51 & 1.23 & 0.68 & 1.82\end{array}$



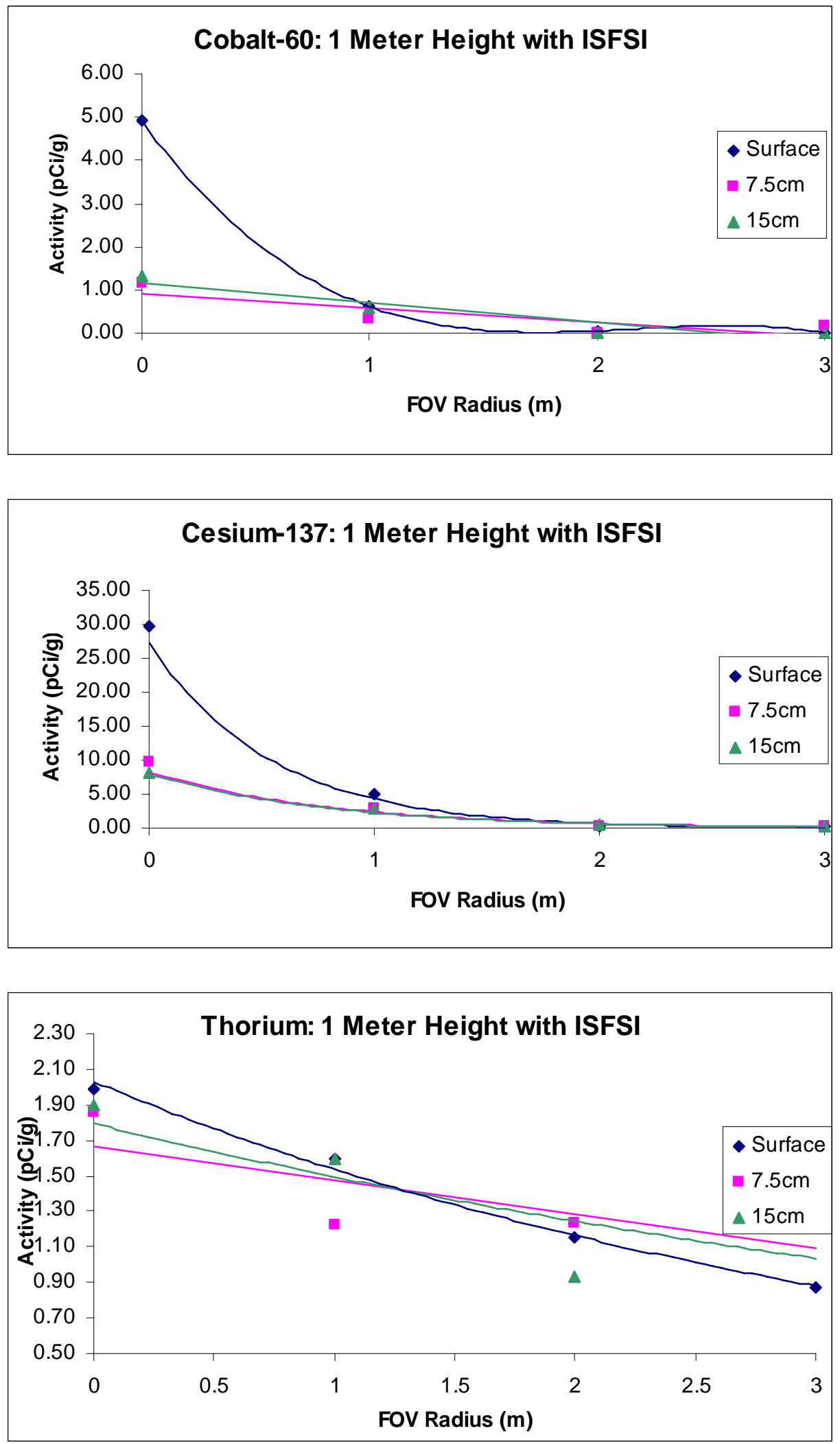


\section{B.4 2-Meter Measurement Results, without ISFSIBE}

Cobalt-60

$\begin{array}{lcccccccc} & \begin{array}{c}\text { Geometry } \\ \text { Filename }\end{array} & \begin{array}{c}\text { Radius } \\ (\mathrm{m})\end{array} & \begin{array}{c}\text { Depth } \\ (\mathrm{cm})\end{array} & \begin{array}{c}\text { Total } \\ \text { Activity } \\ (\mu \mathrm{Ci})\end{array} & \begin{array}{c}\text { MDA } \\ (\mu \mathrm{Ci})\end{array} & \begin{array}{c}\text { Activity } \\ (\mathrm{pCi} / \mathrm{g})\end{array} & \begin{array}{c}\text { MDA } \\ (\mathrm{pCi} / \mathrm{g})\end{array} & \begin{array}{c}\text { Activity } \\ \text { per } \\ \text { MDA }\end{array} \\ \text { 32-2m-axis-surf } & \text { 2-meter-15cm.ecc } & 0 & 0 & 3.9 & 0.54 & 5.17 & 0.72 & 7.22 \\ \text { 33-2m-1m-surf } & \text { 2-meter-15cm.ecc } & 1 & 0 & 2.4 & 0.46 & 3.18 & 0.61 & 5.22 \\ \text { 34-2m-2m-surf } & \text { 2-meter-15cm.ecc } & 2 & 0 & 0.53 & 0.38 & 0.70 & 0.50 & 1.39 \\ \text { 35-2m-3m-surf } & \text { 2-meter-15cm.ecc } & 3 & 0 & 0 & 0.5 & 0.00 & 0.66 & 0.00 \\ \text { 37-2m-axis-7.5 } & \text { 2-meter-15cm.ecc } & 0 & 7.5 & 1.3 & 0.43 & 1.72 & 0.57 & 3.02 \\ \text { 38-2m-1m-7.5 } & \text { 2-meter-15cm.ecc } & 1 & 7.5 & 0.74 & 0.7 & 0.98 & 0.93 & 1.06 \\ 39-2 \mathrm{~m}-2 \mathrm{~m}-7.5 & \text { 2-meter-15cm.ecc } & 2 & 7.5 & 0.18 & 0.53 & 0.24 & 0.70 & 0.34 \\ 40-2 \mathrm{~m}-3 \mathrm{~m}-7.5 & \text { 2-meter-15cm.ecc } & 3 & 7.5 & 0.64 & 0.51 & 0.85 & 0.68 & 1.25 \\ 41-2 \mathrm{~m}-\mathrm{axis}-15 & \text { 2-meter-15cm.ecc } & 0 & 15 & 1.1 & 0.39 & 1.46 & 0.52 & 2.82 \\ 42-2 \mathrm{~m}-1 \mathrm{~m}-15 & \text { 2-meter-15cm.ecc } & 1 & 15 & 0.46 & 0.43 & 0.61 & 0.57 & 1.07 \\ 43-2 \mathrm{~m}-2 \mathrm{~m}-15 & \text { 2-meter-15cm.ecc } & 2 & 15 & 0.1 & 0.53 & 0.13 & 0.70 & 0.19 \\ 44-2 \mathrm{~m}-3 \mathrm{~m}-15 & \text { 2-meter-15cm.ecc } & 3 & 15 & 0.34 & 0.51 & 0.45 & 0.68 & 0.67\end{array}$

\section{Cesium-137}

\begin{tabular}{lc} 
& \multicolumn{1}{c}{$\begin{array}{c}\text { Geometry } \\
\text { Spectrum ID }\end{array}$} \\
32-2m-axis-surf & 2-meter-15cm.ecc \\
33-2m-1m-surf & 2-meter-15cm.ecc \\
34-2m-2m-surf & 2-meter-15cm.ecc \\
$35-2 \mathrm{~m}-3 \mathrm{~m}$-surf & 2-meter-15cm.ecc \\
$37-2 \mathrm{~m}-\mathrm{axis}-7.5$ & 2-meter-15cm.ecc \\
$38-2 \mathrm{~m}-1 \mathrm{~m}-7.5$ & 2-meter-15cm.ecc \\
$39-2 \mathrm{~m}-2 \mathrm{~m}-7.5$ & 2-meter-15cm.ecc \\
$40-2 \mathrm{~m}-3 \mathrm{~m}-7.5$ & 2-meter-15cm.ecc \\
$41-2 \mathrm{~m}-\mathrm{axis}-15$ & 2-meter-15cm.ecc \\
$42-2 \mathrm{~m}-1 \mathrm{~m}-15$ & 2-meter-15cm.ecc \\
$79-2 \mathrm{~m}-2 \mathrm{~m}-15$ & 2-meter-15cm.ecc \\
$44-2 \mathrm{~m}-3 \mathrm{~m}-15$ & 2-meter-15cm.ecc
\end{tabular}

$\begin{array}{ccccccc}\begin{array}{c}\text { Radius } \\ (\mathrm{m})\end{array} & \begin{array}{c}\text { Depth } \\ (\mathrm{cm})\end{array} & \begin{array}{c}\text { Total } \\ \text { Activity } \\ (\mu \mathrm{Ci})\end{array} & \begin{array}{c}\text { MDA } \\ (\mu \mathrm{Ci})\end{array} & \begin{array}{c}\text { Activity } \\ (\mathrm{pCi} / \mathrm{g})\end{array} & \begin{array}{c}\text { MDA } \\ (\mathrm{pCi} / \mathrm{g})\end{array} & \begin{array}{c}\text { Activity } \\ \text { per } \\ \text { MDA }\end{array} \\ 0 & 0 & 22.1 & 0.98 & 29.31 & 1.30 & 22.55 \\ 1 & 0 & 14.2 & 0.87 & 18.83 & 1.15 & 16.32 \\ 2 & 0 & 4.2 & 0.79 & 5.57 & 1.05 & 5.32 \\ 3 & 0 & 0.97 & 0.48 & 1.29 & 0.64 & 2.02 \\ 0 & 7.5 & 7.5 & 0.79 & 9.95 & 1.05 & 9.49 \\ 1 & 7.5 & 4.7 & 0.62 & 6.23 & 0.82 & 7.58 \\ 2 & 7.5 & 1.6 & 0.58 & 2.12 & 0.77 & 2.76 \\ 3 & 7.5 & 0.49 & 0.47 & 0.65 & 0.62 & 1.04 \\ 0 & 15 & 6.4 & 0.7 & 8.49 & 0.93 & 9.14 \\ 1 & 15 & 3.9 & 0.79 & 5.17 & 1.05 & 4.94 \\ 2 & 15 & 3.3 & 0.76 & 4.38 & 1.01 & 4.34 \\ 3 & 15 & 0.64 & 0.75 & 0.85 & 0.99 & 0.85\end{array}$

\section{Thorium}

\begin{tabular}{|c|c|c|c|c|c|c|c|c|}
\hline Spectrum ID & $\begin{array}{l}\text { Geometry } \\
\text { Filename }\end{array}$ & $\begin{array}{l}\text { Radius } \\
\text { (m) }\end{array}$ & $\begin{array}{l}\text { Depth } \\
\text { (cm) }\end{array}$ & $\begin{array}{c}\text { Total } \\
\text { Activity } \\
(\mu \mathrm{Ci})\end{array}$ & $\begin{array}{l}\mathrm{MDA} \\
(\mu \mathrm{Ci})\end{array}$ & $\begin{array}{l}\text { Activity } \\
\text { (pCi/g) }\end{array}$ & $\begin{array}{l}\mathrm{MDA} \\
(\mathrm{pCi} / \mathrm{g})\end{array}$ & $\begin{array}{c}\text { Activity } \\
\text { per } \\
\text { MDA }\end{array}$ \\
\hline 32-2m-axis-surf & 2-meter-15cm.ecc & 0 & 0 & 4.2 & 1.74 & 5.57 & 2.31 & 2.41 \\
\hline $33-2 m-1 m-s u r f$ & 2 -meter- $15 \mathrm{~cm} . e c c$ & 1 & 0 & 3.5 & 1.64 & 4.64 & 2.18 & 2.13 \\
\hline $34-2 m-2 m-s u r f$ & 2 -meter- $15 \mathrm{~cm}$.ecc & 2 & 0 & 2 & 2.2 & 2.65 & 2.92 & 0.91 \\
\hline $78-2 m-3 m-s u r f$ & 2 -meter-15cm.ecc & 3 & 0 & 2.8 & 1.5 & 3.71 & 1.99 & 1.87 \\
\hline $37-2 \mathrm{~m}$-axis- 7.5 & 2 -meter- $15 \mathrm{~cm} . e c c$ & 0 & 7.5 & 5.4 & 1.2 & 7.16 & 1.59 & 4.50 \\
\hline $38-2 m-1 m-7.5$ & 2 -meter-15cm.ecc & 1 & 7.5 & 3 & 1.7 & 3.98 & 2.25 & 1.76 \\
\hline $39-2 m-2 m-7.5$ & 2 -meter- $15 \mathrm{~cm} . \mathrm{ecc}$ & 2 & 7.5 & 3 & 1.7 & 3.98 & 2.25 & 1.76 \\
\hline $40-2 m-3 m-7.5$ & 2 -meter- $15 \mathrm{~cm} . \mathrm{ecc}$ & 3 & 7.5 & 2.5 & 1.5 & 3.32 & 1.99 & 1.67 \\
\hline 41-2m-axis-15 & 2 -meter- $15 \mathrm{~cm} . \mathrm{ecc}$ & 0 & 15 & 4.3 & 1.6 & 5.70 & 2.12 & 2.69 \\
\hline $42-2 m-1 m-15$ & 2 -meter- $15 \mathrm{~cm} . \mathrm{ecc}$ & 1 & 15 & 2.6 & 2 & 3.45 & 2.65 & 1.30 \\
\hline $43-2 m-2 m-15$ & 2 -meter- $15 \mathrm{~cm} . \mathrm{ecc}$ & 2 & 15 & 3.2 & 1.8 & 4.24 & 2.39 & 1.78 \\
\hline $44-2 m-3 m-15$ & 2 -meter- $15 \mathrm{~cm} . e c c$ & 3 & 15 & 2.8 & 1.6 & 3.71 & 2.12 & 1.75 \\
\hline
\end{tabular}



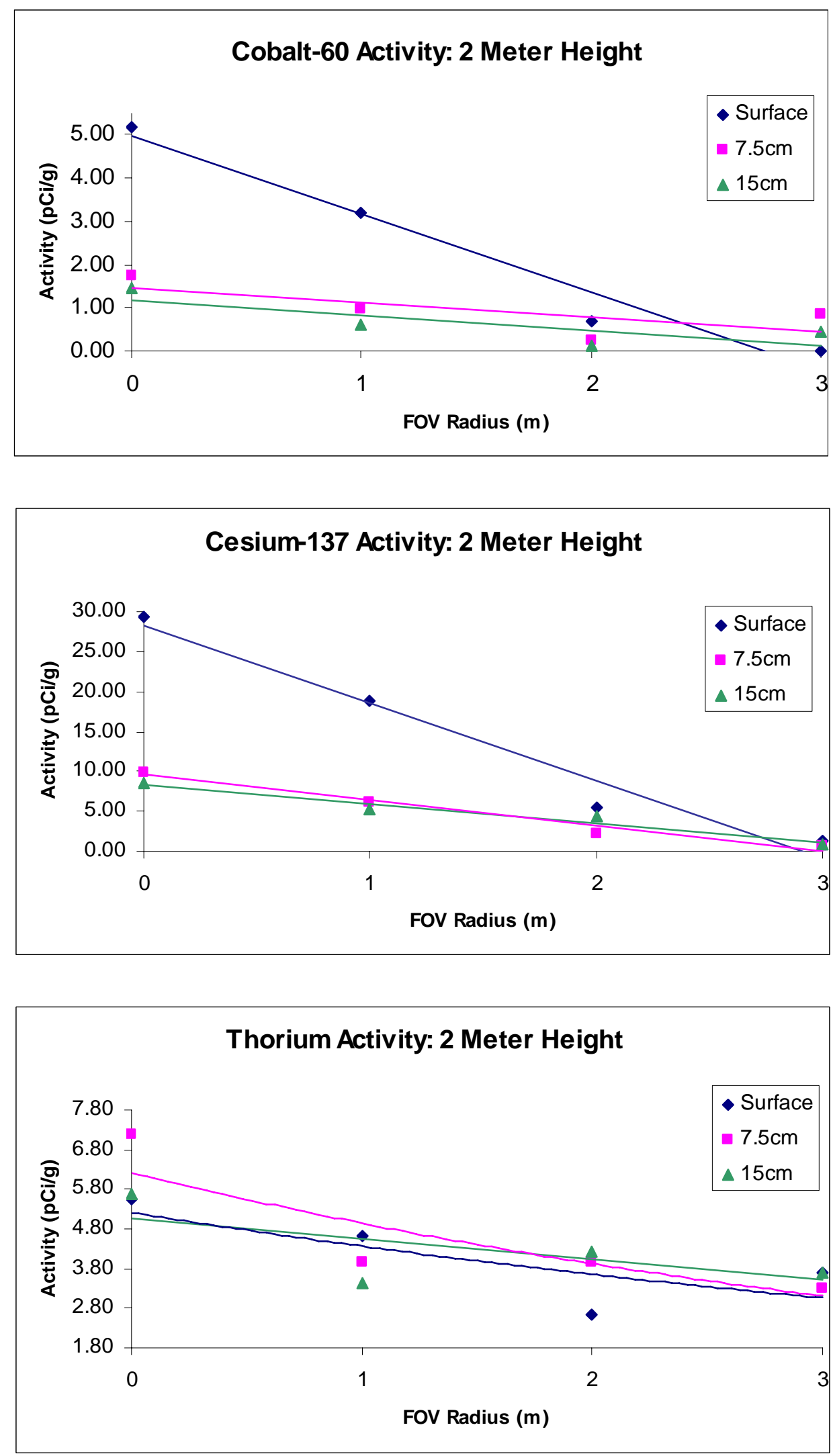


\section{B.5 1-Meter Measurement Results, without ISFSIBE}

Cobalt-60

Spectrum ID

14-1m-axis

$15-1 \mathrm{~m}-1 \mathrm{~m}$

$16-1 \mathrm{~m}-2 \mathrm{~m}$

$17-1 \mathrm{~m}-3 \mathrm{~m}$

18-1m-axis-7.5

$19-1 \mathrm{~m}-1 \mathrm{~m}-7.5$

$20-1 \mathrm{~m}-2 \mathrm{~m}-7.5$

$21-1 \mathrm{~m}-3 \mathrm{~m}-7.5$

76-1m-axis-15

$26-1 \mathrm{~m}-1 \mathrm{~m}-15$

$27-1 \mathrm{~m}-2 \mathrm{~m}-15$

$30-1 \mathrm{~m}-3 \mathrm{~m}-15$

\section{Cesium-137}

Spectrum ID

14-1m-axis

$15-1 \mathrm{~m}-1 \mathrm{~m}$

$16-1 \mathrm{~m}-2 \mathrm{~m}$

$17-1 \mathrm{~m}-3 \mathrm{~m}$

$18-1 \mathrm{~m}$-axis- 7.5

$19-1 \mathrm{~m}-1 \mathrm{~m}-7.5$

20-1m-2m-7.5

21-1m-3m-7.5

76-1m-axis-15

26-1m-1m-15

27-1m-2m-15

$30-1 \mathrm{~m}-3 \mathrm{~m}-15$
1.59

$\begin{array}{cccccccc}\text { Geometry } & \begin{array}{c}\text { Radius } \\ \text { Filename }\end{array} & \begin{array}{c}\text { Depth } \\ (\mathrm{cm})\end{array} & \begin{array}{c}\text { Total } \\ \text { Activity } \\ (\mu \mathrm{Ci})\end{array} & \begin{array}{c}\text { MDA } \\ (\mu \mathrm{Ci})\end{array} & \begin{array}{c}\text { Activity } \\ \mathrm{pCi} / \mathrm{g}\end{array} & \begin{array}{c}\text { MDA } \\ \mathrm{pCi} / \mathrm{g}\end{array} & \begin{array}{c}\text { Activity } \\ \text { per } \\ \text { MDA }\end{array} \\ \text { 1-meter-15cm.ecc } & 0 & 0 & 4.2 & 0.18 & 5.57 & 0.24 & 23.33 \\ \text { 1-meter-15cm.ecc } & 1 & 0 & 0.5 & 0.13 & 0.66 & 0.17 & 3.85 \\ \text { 1-meter-15cm.ecc } & 2 & 0 & 0 & 0.13 & 0.00 & 0.17 & 0.00 \\ \text { 1-meter-15cm.ecc } & 3 & 0 & 0.16 & 0.15 & 0.21 & 0.20 & 1.07 \\ \text { 1-meter-15cm.ecc } & 0 & 7.5 & 1.8 & 0.19 & 2.39 & 0.25 & 9.47 \\ \text { 1-meter-15cm.ecc } & 1 & 7.5 & 0.3 & 0.12 & 0.40 & 0.16 & 2.50 \\ \text { 1-meter-15cm.ecc } & 2 & 7.5 & 0.015 & 0.12 & 0.02 & 0.16 & 0.13 \\ \text { 1-meter-15cm.ecc } & 3 & 7.5 & 0 & 0.12 & 0.00 & 0.16 & 0.00 \\ \text { 1-meter-15cm.ecc } & 0 & 15 & 1 & 0.19 & 1.33 & 0.25 & 5.26 \\ \text { 1-meter-15cm.ecc } & 1 & 15 & 0.5 & 0.11 & 0.66 & 0.15 & 4.55 \\ \text { 1-meter-15cm.ecc } & 2 & 15 & 0.2 & 0.13 & 0.27 & 0.17 & 1.54 \\ \text { 1-meter-15cm.ecc } & 3 & 15 & 0 & 0.12 & 0.00 & 0.16 & 0.00\end{array}$

Total

Activity

$(\mu \mathrm{Ci})$

24.6

3.4

0

0.02

8.6

1.5

0.041

0.028

4.7

1.6

0.18

0
MDA

$(\mu \mathrm{Ci})$

0.37

0.3

0.2

0.2

0.31

0.24

0.22

0.22

0.31

0.17

0.19

0.19
Activity

$\mathrm{pCi} / \mathrm{g}$

32.63

4.51

0.00

0.03

11.41

1.99

0.05

0.04

6.23

2.12

0.24

0.00
MDA

$\mathrm{pCi} / \mathrm{g}$

0.49

0.40

0.27

0.27

0.41

0.32

0.29

0.29

0.41

0.23

0.25

0.25
Activity

per

MDA

66.49

11.33

0.00

0.10

27.74

6.25

0.19

0.13

15.16

9.41

0.95

0.00

\section{Thorium}

\begin{tabular}{|c|c|}
\hline Spectrum ID & $\begin{array}{l}\text { Geometry } \\
\text { Filename }\end{array}$ \\
\hline 14-1m-axis & 1-meter- $15 \mathrm{~cm} . \mathrm{ecc}$ \\
\hline $15-1 \mathrm{~m}-1 \mathrm{~m}$ & 1-meter-15cm.ecc \\
\hline $16-1 m-2 m$ & 1-meter- $15 \mathrm{~cm} . \mathrm{ecc}$ \\
\hline $17-1 m-3 m$ & 1 -meter- $15 \mathrm{~cm} . \mathrm{ecc}$ \\
\hline $18-1 \mathrm{~m}$-axis- 7.5 & 1 -meter- $15 \mathrm{~cm} . e c c$ \\
\hline $19-1 \mathrm{~m}-1 \mathrm{~m}-7.5$ & 1 -meter- $15 \mathrm{~cm} . e c c$ \\
\hline $20-1 \mathrm{~m}-2 \mathrm{~m}-7.5$ & 1-meter- $15 \mathrm{~cm} . \mathrm{ecc}$ \\
\hline $21-1 \mathrm{~m}-3 \mathrm{~m}-7.5$ & 1-meter- $15 \mathrm{~cm} . \mathrm{ecc}$ \\
\hline 76-1m-axis-15 & 1-meter- $15 \mathrm{~cm} . \mathrm{ecc}$ \\
\hline $26-1 \mathrm{~m}-1 \mathrm{~m}-15$ & 1-meter- $15 \mathrm{~cm} . \mathrm{ecc}$ \\
\hline $27-1 m-2 m-15$ & 1-meter- $15 \mathrm{~cm} . \mathrm{ecc}$ \\
\hline $30-1 m-3 m-15$ & 1-meter- $15 \mathrm{~cm} . e c c$ \\
\hline
\end{tabular}

Ra

$\begin{array}{ccccc}\begin{array}{c}\text { Total } \\ \text { Activity } \\ (\mu \mathrm{Ci})\end{array} & \begin{array}{c}\text { MDA } \\ (\mu \mathrm{Ci})\end{array} & \begin{array}{c}\text { Activity } \\ \mathrm{pCi} / \mathrm{g}\end{array} & \begin{array}{c}\text { MDA } \\ \mathrm{pCi} / \mathrm{g}\end{array} & \begin{array}{c}\text { Activity } \\ \text { per } \\ \text { MDA }\end{array} \\ 1.8 & 0.62 & 2.39 & 0.82 & 2.90 \\ 1.01 & 0.39 & 1.34 & 0.52 & 2.59 \\ 0.82 & 0.31 & 1.09 & 0.41 & 2.65 \\ 0.73 & 0.39 & 0.97 & 0.52 & 1.87 \\ 1.38 & 0.71 & 1.83 & 0.94 & 1.94 \\ 1.3 & 0.38 & 1.72 & 0.50 & 3.42 \\ 0.82 & 0.42 & 1.09 & 0.56 & 1.95 \\ 0.74 & 0.31 & 0.98 & 0.41 & 2.39 \\ 0.9 & 0.6 & 1.19 & 0.80 & 1.50 \\ 0.94 & 0.49 & 1.25 & 0.65 & 1.92 \\ 0.85 & 0.36 & 1.13 & 0.48 & 2.36 \\ 0.79 & 0.47 & 1.05 & 0.62 & 1.68\end{array}$



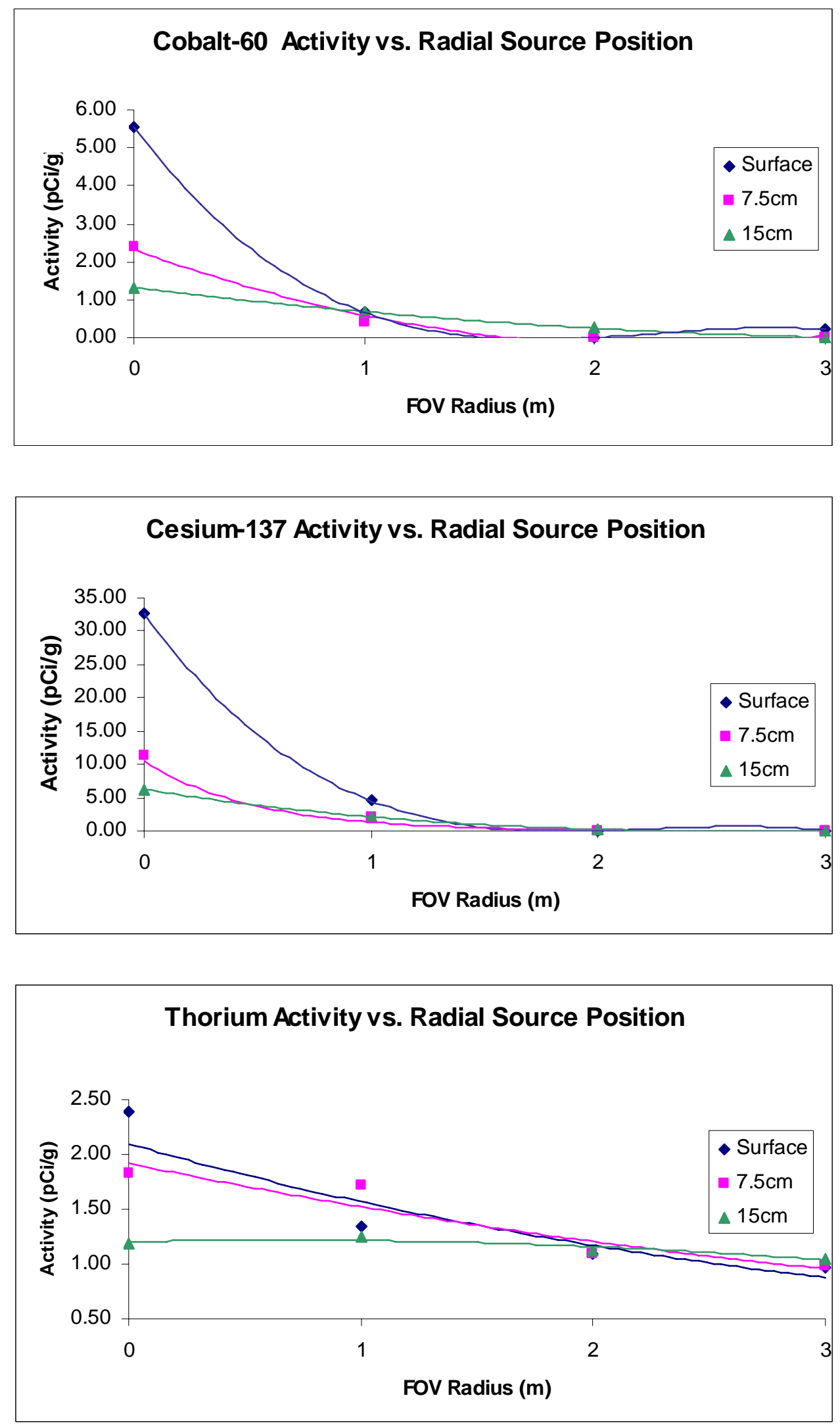


\section{Appendix C. Spectral Data from the Experiments}

This appendix shows the raw spectral files for the measurements conducted at a height of 1 meter, with three sources together on the ground surface placed sequentially at each of four radii: $\mathrm{r}=0,1,2,3 \mathrm{~m}$,

The three sources were Th(nat), Co-60, and Cs-137. The photopeaks of interest are labeled in the data images below: Cs-137 (662keV), Ac-228 (911 keV), and Co-60 (1117 keV and

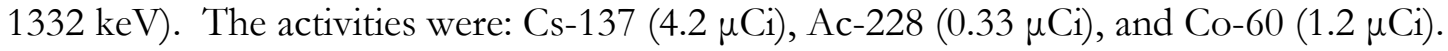

The photopeaks of interest decrease in size as the sources are moved from $r=0$, to $r=1$, to $\mathrm{r}=2$, to $\mathrm{r}=3 \mathrm{~m}$; that is, the detector is less and less efficient at detecting a source as it moves from the center line out to the radius of the FOV. The data plots of measured activity concentration versus source location are prepared by determining the photopeak area divided by the mathematical efficiency curve of the system.

\section{Spectrum $14(r=0)$}

This is the source location with the highest detection efficiency. All four photopeaks are easily observed. The Ac-228 photopeak at $911 \mathrm{keV}$ does include some contribution from natural background (terrestrial Th-232).

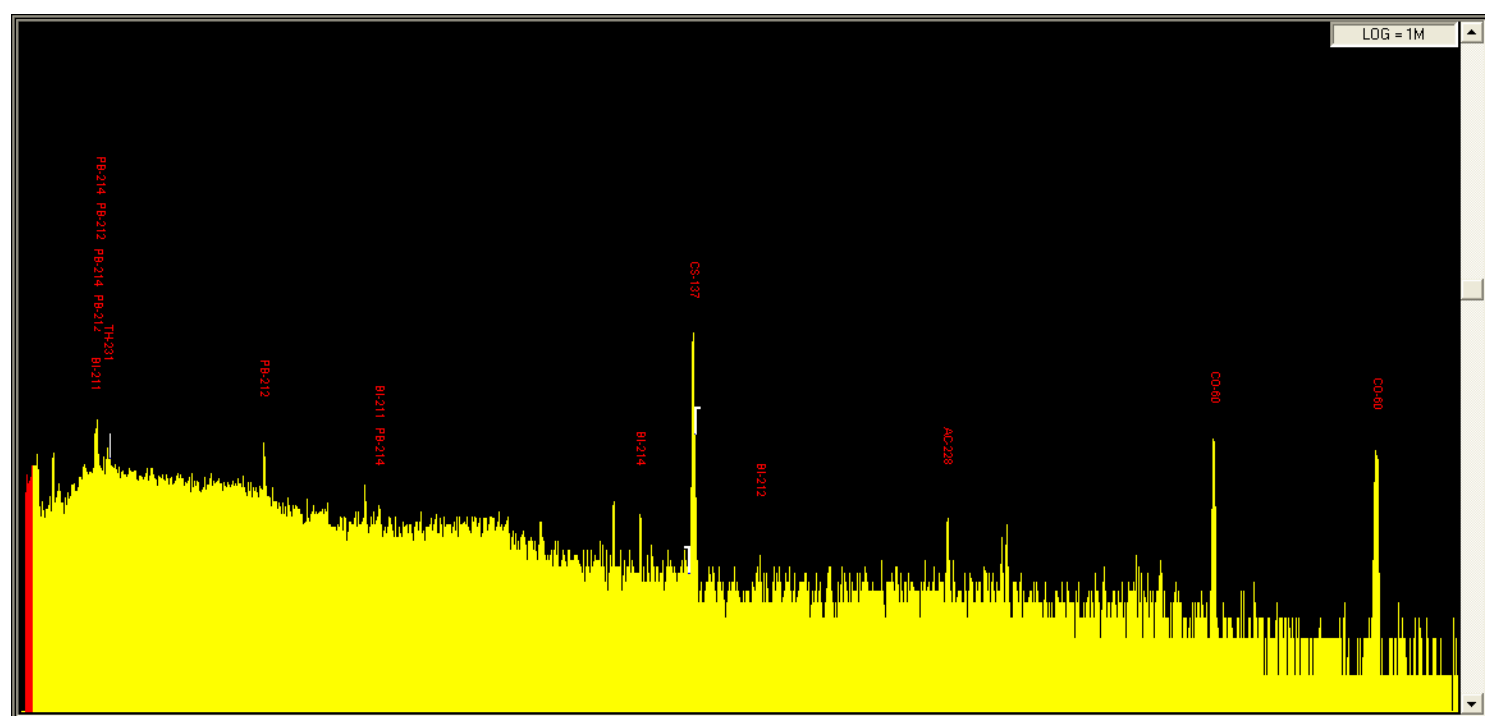




\section{Spectrum $15(\mathrm{r}=1)$}

With a detector height of 1 meter and a 90-degree collimator, the radius for the FOV is 1 meter. The sources are also at 1 meter on the fringe, or on the edge of the field of view. The photopeaks of interest are still detectable (clearly observable) for $\mu \mathrm{Ci}$ quantity sources.

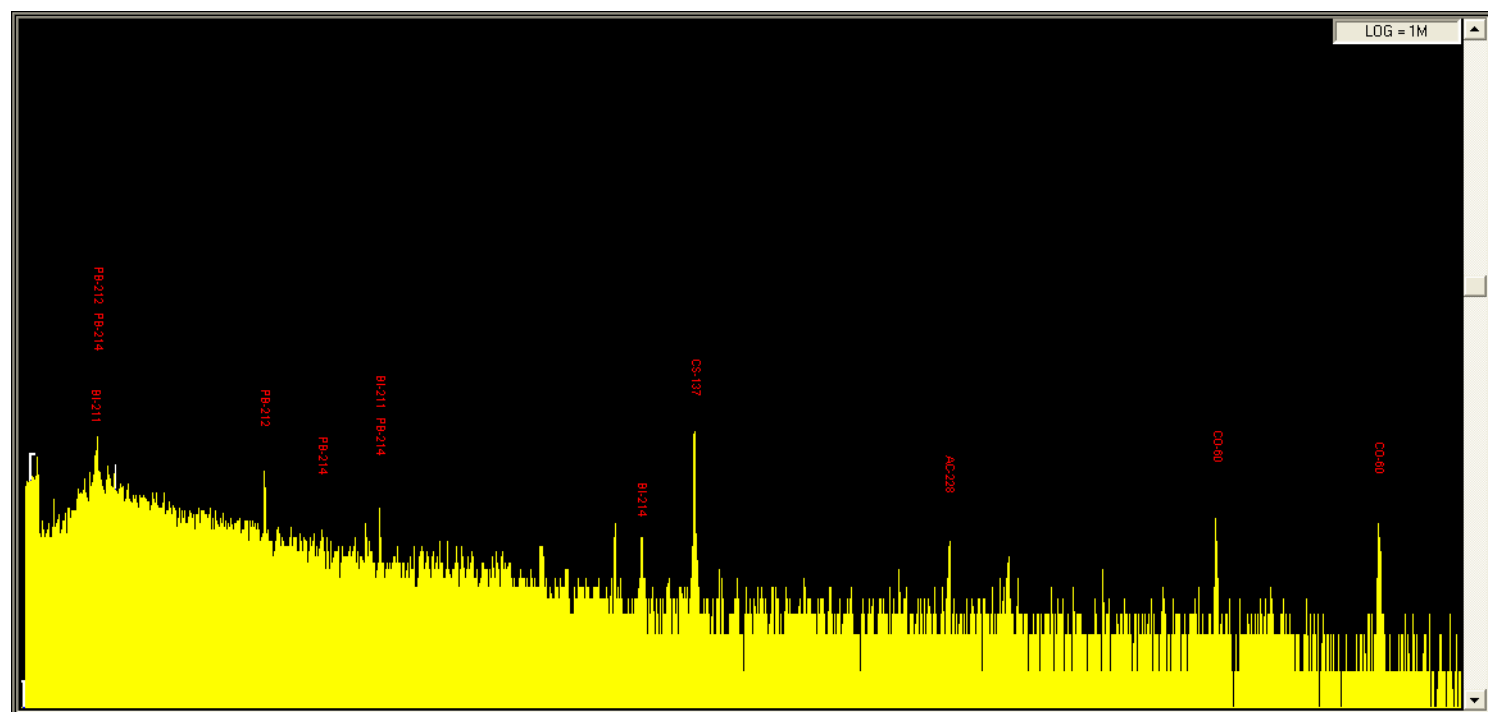

\section{Spectrum $16(r=2)$}

At 2 meters, the sources are not detectable. The Ac-228 photopeak is natural background.

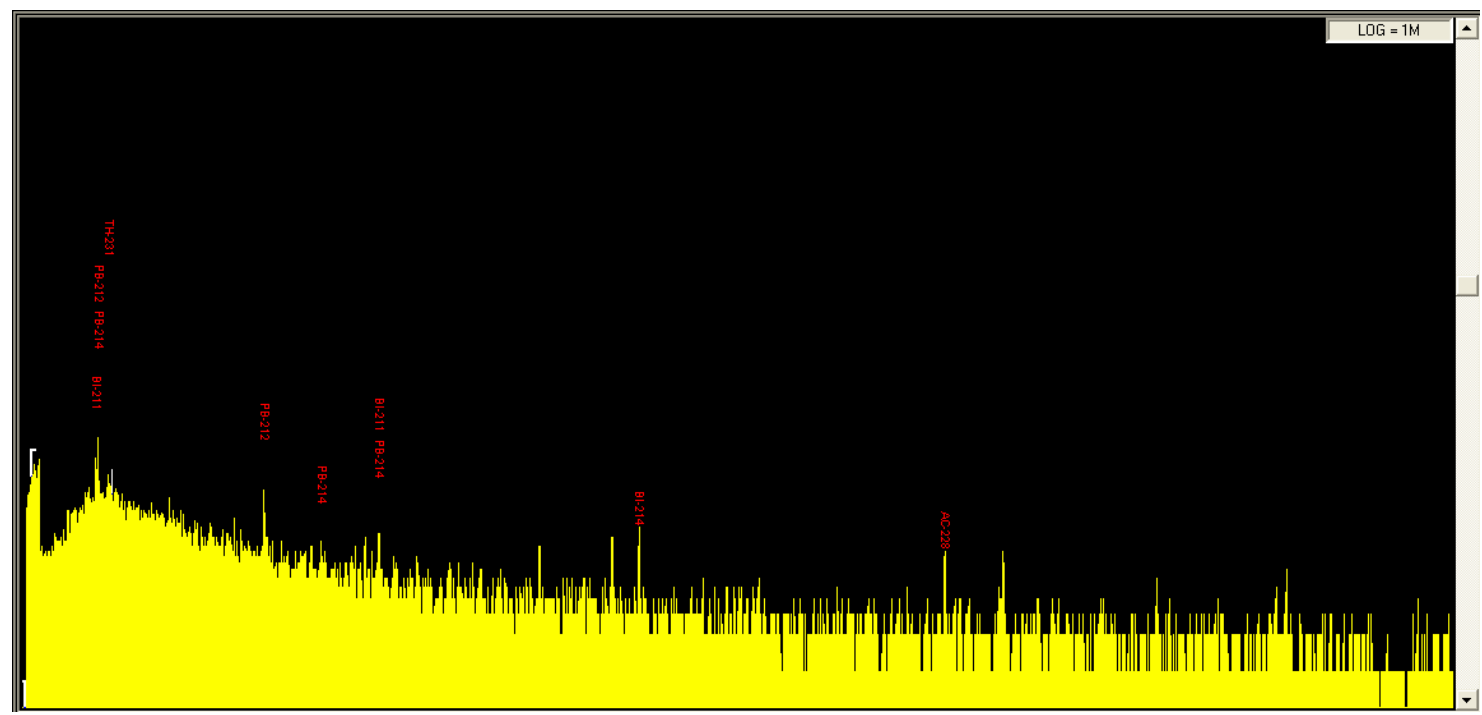




\section{Spectrum $17(\mathrm{r}=3)$}

At 3 meters, the sources are not detectable. The Ac-228 photopeak is natural background.

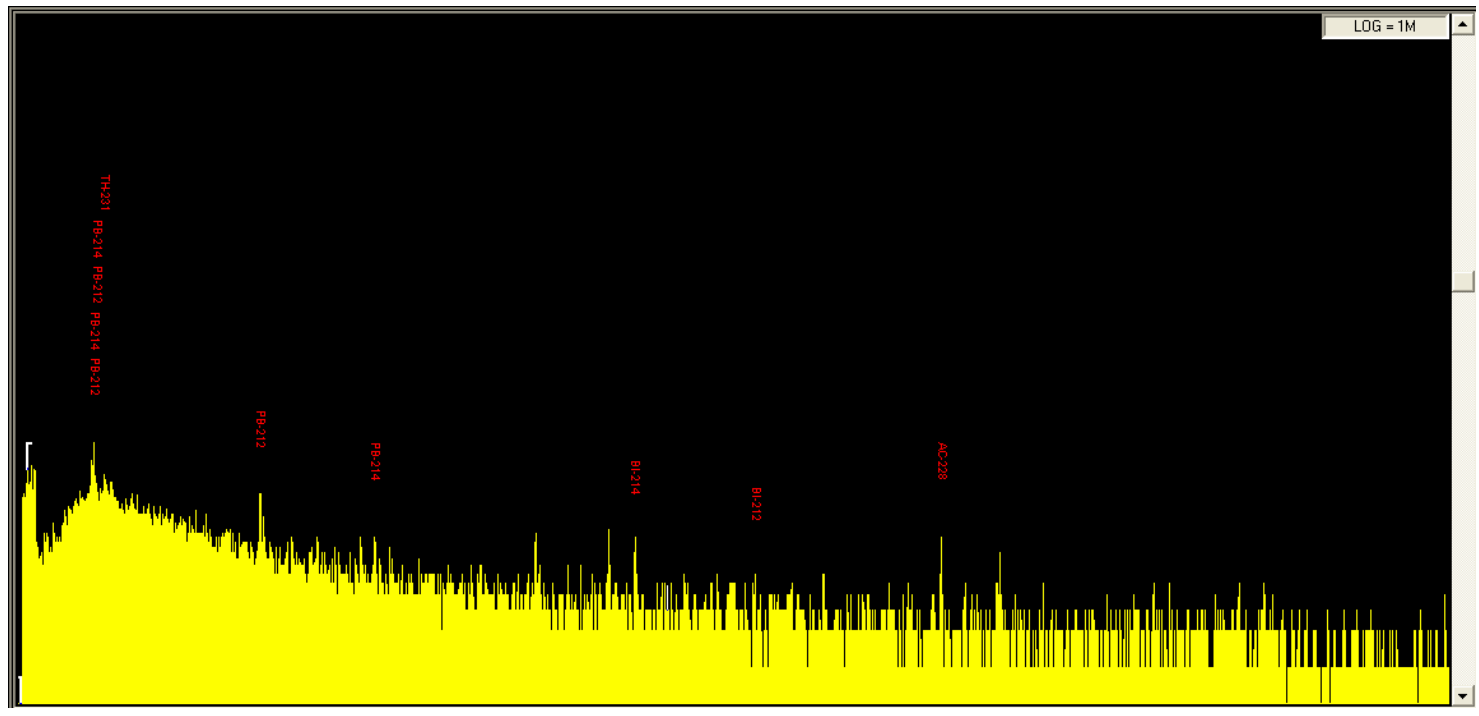




\section{Appendix D. Adjustments to the Efficiency Model}

In section 3, a description was provided for how the efficiency model was established for these measurements. The source term was defined (and modeled by ISGRS) by a disc source of thickness d, equal to $15 \mathrm{~cm}$. With a detector positioned at $100 \mathrm{~cm}$ and a 90 -degree collimator, a "disc source" with radius of $100 \mathrm{~cm}$ is:

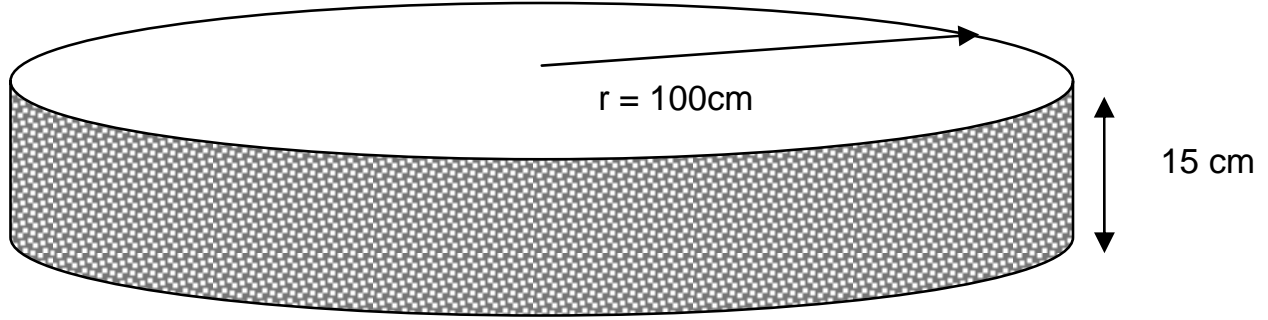

The sample volume of the disc source is:

$\pi(100 \mathrm{~cm})^{2} 15 \mathrm{~cm}=4.7 E+05 \mathrm{~cm}^{3}$

With a nominal density of soil equal to $1.7 \mathrm{~g} \mathrm{~cm}^{-3}$ the mass of the disc source is:

$\pi(100 \mathrm{~cm})^{2} 15 \mathrm{~cm} 1.7 \mathrm{~g} \mathrm{~cm}^{-3}=8.01 E+05 \mathrm{~g}$

Furthermore, if a uniform distribution of contamination is spread throughout this volume at $3.8 \mathrm{pCi}^{-1}$, the total activity in the entire volume is:

$A=(8.01 E+05 g)\left(3.8 p C i g^{-1}\right)=3 \mu C i$

The mathematical efficiency function that is calculated by the system is based on a simple model such as this. As a result, the interpretation of the measurement results is as follows: the detector response (i.e. the integral number of photons detected under the photopeak of interest) corresponds to a uniform activity concentration of contaminant at $\mathrm{x} \mathrm{pCi} / \mathrm{g}$. If there is reason to believe, either by direct measurement or otherwise, that the depth profile of the contaminant is not uniform at $15 \mathrm{~cm}$, then the mathematical efficiency function can be adjusted and the output modified accordingly. For the measurements reported here and for all final status survey measurements observed by the authors, the sample volume is normally calculated as presented. It is important to note that using this efficiency calibration if a buried source is detected and the surface contamination is zero, the measurement result will be biased low. Similarly, if a discrete particle does exist at the periphery of a detector FOV, in an otherwise clean surface soil, the measurement result will be biased low. 
Several questions have been asked about how the device accounts for source depth or whether it can be "calibrated" to discrete particles. The mathematical efficiency functions that can be described are limitless. If the analyst is aware of any specific features of the source term that needs to be accounted for, it can be modeled. This appendix was written to describe specifically the analysis sequence file that was used to reduce the measurement data, and to provide alternative efficiency functions for the actual measurements that were performed. From these efficiency functions, MDA estimates can be made (which include all the uncertainties in the model equations). This presentation of data is limited to the 1-meter measurement situation.

\section{Standard Analysis Sequence File for the ORISE Measurements at a Detector Height of 1 meter}

The activity concentration results presented for each measurement case (again, with the efficiency function as physically described above) was computed with the following set of analysis sequence steps.

\begin{tabular}{|c|c|c|}
\hline \multicolumn{3}{|l|}{ Acquisition } \\
\hline Channels & \multicolumn{2}{|l|}{8192} \\
\hline Acq Mode & \multicolumn{2}{|l|}{$\mathrm{PHA}+$} \\
\hline MCA Type & \multicolumn{2}{|l|}{$\mathrm{I} 2 \mathrm{~K}$} \\
\hline AMP Type & \multicolumn{2}{|l|}{ DSP } \\
\hline ADC Type & \multicolumn{2}{|l|}{ DSP } \\
\hline HVPS Type & \multicolumn{2}{|c|}{$\mathrm{I} 2 \mathrm{~K} \mathrm{HV}$} \\
\hline \multicolumn{3}{|l|}{ Analysis } \\
\hline Peak Locate & \multicolumn{2}{|c|}{ Standard Library } \\
\hline NID & \multicolumn{2}{|c|}{ Standard Library } \\
\hline \multicolumn{3}{|l|}{ Analysis Steps } \\
\hline Peak Locate & & Unidentified $2^{\text {nd }}$ Difference \\
\hline Peak Area & & Sum / Non-Linear LSQ Fit \\
\hline Efficiency Co & rection & Standard (ISOCS) \\
\hline Nuclide Iden & fication & NID w/ Interf. Corr. \\
\hline Detection Lir & & Currie MDA \\
\hline Reporting & & Standard \\
\hline \multicolumn{3}{|l|}{ Calibration } \\
\hline Energy & & $-4.783 \mathrm{E}-02 \mathrm{keV}+1.726 \mathrm{E}-01 \mathrm{C}$ \\
\hline FWHM & & $7.236 \mathrm{E}-01+3.648 \mathrm{E}-02(\mathrm{E})^{1 / 2}$ \\
\hline Low Tail & & $3.291 \mathrm{E}+00-1.33 \mathrm{E}-03(\mathrm{E})$ \\
\hline \multicolumn{3}{|c|}{$\begin{array}{l}\text { Efficiency (example for } 1 \text { meter, 90-deg collimator; FOV, radius }=1 \text { meter, depth }=15 \mathrm{~cm}) \\
\ln (\text { Eff })=-9.198 \mathrm{E}+01+53.42 \ln (\mathrm{E})-1.301 \mathrm{E}+01 \ln (\mathrm{E})^{2}+1.388 \ln (\mathrm{E})^{3}-5.522 \mathrm{E}-02 \ln (\mathrm{E})^{4}\end{array}$} \\
\hline
\end{tabular}


The end result is a logarithmic, 4th order fit of the efficiency against energy.

If the question is asked, what is the efficiency for a point source (in this case a Marinellisized beaker full of "contaminated" soil), positioned at the various test locations? This is a calculable quantity. For the test positions of the sources $(r=0,1,2,3 \mathrm{~m})$ and $(\mathrm{d}=0,7.5,15$ $\mathrm{cm}$ ) the efficiencies as a function of energy are provided in the table below. For comparison, the efficiency values for the Base Case are also provided---the efficiencies calculated from a disc source, radius $1 \mathrm{~m}$ and depth $15 \mathrm{~cm}$ (last column in the table).

Table 9. Efficiencies for Discrete Sources and the Volumetric Base Case

\begin{tabular}{|c|c|c|c|c|c|c|c|c|c|c|c|c|c|}
\hline Ener & $\begin{array}{l}r=0 \\
d=0\end{array}$ & $\begin{array}{l}\mathrm{r}=0 \\
\mathrm{~d}=7.5\end{array}$ & $\begin{array}{l}r=0 \\
d=15\end{array}$ & $\begin{array}{l}r=1 \\
d=0\end{array}$ & $\begin{array}{l}\mathrm{r}=1 \\
d=7.5\end{array}$ & $\begin{array}{l}r=1 \\
d=15\end{array}$ & $\begin{array}{l}r=2 \\
d=0\end{array}$ & $\begin{array}{l}r=2 \\
d=7.5\end{array}$ & $\begin{array}{l}r=2 \\
d=15\end{array}$ & $\begin{array}{l}r=3 \\
d=0\end{array}$ & $\begin{array}{l}r=3 \\
d=7.5\end{array}$ & $\begin{array}{l}r=3 \\
d=15\end{array}$ & $\begin{array}{l}\text { 1-meter } \\
\text { Baseline }\end{array}$ \\
\hline 50 & $1.46 \mathrm{E}-04$ & 2.07E-06 & $2.99 \mathrm{E}-08$ & 7.70E-05 & $1.18 \mathrm{E}-06$ & $1.78 \mathrm{E}-08$ & $0.00 \mathrm{E}+00$ & $0.00 \mathrm{E}+00$ & 3.34E-25 & $0.00 \mathrm{E}+00$ & $0.00 \mathrm{E}+00$ & $0.00 \mathrm{E}+00$ & $6.54 \mathrm{E}-06$ \\
\hline 80 & $1.54 \mathrm{E}-04$ & 1.27E-05 & $1.06 \mathrm{E}-06$ & 7.92E-05 & $7.01 \mathrm{E}-06$ & $6.13 \mathrm{E}-07$ & $5.60 \mathrm{E}-45$ & $3.77 \mathrm{E}-30$ & $1.00 \mathrm{E}-14$ & $0.00 \mathrm{E}+00$ & $0.00 \mathrm{E}+00$ & $0.00 \mathrm{E}+00$ & $.26 \mathrm{E}-05$ \\
\hline 100 & $1.49 \mathrm{E}-04$ & $1.70 \mathrm{E}-05$ & $1.96 \mathrm{E}-06$ & $7.54 \mathrm{E}-05$ & $9.24 \mathrm{E}-06$ & $1.11 \mathrm{E}-06$ & $0.00 \mathrm{E}+00$ & $0.00 \mathrm{E}+00$ & $9.00 \mathrm{E}-21$ & $0.00 \mathrm{E}+00$ & $0.00 \mathrm{E}+00$ & $0.00 \mathrm{E}+00$ & $1.42 \mathrm{E}-05$ \\
\hline 120 & $1.47 \mathrm{E}-04$ & $1.99 \mathrm{E}-05$ & $2.74 \mathrm{E}-06$ & $7.05 \mathrm{E}-05$ & 3E-05 & 48E-06 & +00 & $2.38 \mathrm{E}-43$ & $08 \mathrm{E}-17$ & $0.00 \mathrm{E}+00$ & $0.00 \mathrm{E}+00$ & $0.00 \mathrm{E}+00$ & 1.47E-05 \\
\hline 150 & 12E-04 & $2.26 \mathrm{E}-05$ & -06 & -05 & -05 & -06 & $5.36 \mathrm{E}-43$ & $.40 \mathrm{E}-29$ & -14 & $0.00 \mathrm{E}+00$ & $E+00$ & $0.00 \mathrm{E}+00$ & 1.45E-05 \\
\hline 238.6 & $1.18 \mathrm{E}-04$ & 2.45E-05 & $.14 \mathrm{E}-06$ & $=-05$ & $80 \mathrm{E}-06$ & BE-06 & $.09 \mathrm{E}-19$ & $.33 \mathrm{E}-15$ & $29 \mathrm{E}-11$ & IE-21 & $2.55 \mathrm{E}-22$ & $.72 \mathrm{E}-23$ & $1.22 \mathrm{E}-05$ \\
\hline 300 & 1.04E-04 & 2.43E-05 & $.72 \mathrm{E}$ & 05 & 6 E-06 & -06 & E-15 & $.54 \mathrm{E}-13$ & $.85 \mathrm{E}-10$ & $54 \mathrm{E}-15$ & E-15 & E-16 & $1.09 \mathrm{E}-05$ \\
\hline 338.3 & 9.50E-05 & 2.36E-05 & $.90 \mathrm{E}-06$ & 3.16E-05 & 3E-06 & E-06 & 4.13E-13 & $.54 \mathrm{E}-12$ & 4.32E-10 & $.36 \mathrm{E}-13$ & $.95 \mathrm{E}-13$ & $.05 E-14$ & 1.03E-05 \\
\hline 400 & 8.40E-05 & 2.26E-05 & $.13 \mathrm{E}-06$ & $2.72 \mathrm{E}-05$ & $11 \mathrm{E}-06$ & $.35 \mathrm{E}-06$ & $4.52 \mathrm{E}-11$ & $.97 \mathrm{E}-11$ & L.15E-09 & $1.13 \mathrm{E}-10$ & $2.67 \mathrm{E}-11$ & $6.28 \mathrm{E}-12$ & $9.42 \mathrm{E}-06$ \\
\hline 583.2 & $.31 \mathrm{E}-05$ & 2.01E-05 & $.49 \mathrm{E}-06$ & 1.93E-05 & 91E-06 & $.41 \mathrm{E}-06$ & 1.67E-08 & $.47 \mathrm{E}-09$ & $.91 \mathrm{E}-09$ & $3.23 \mathrm{E}-08$ & $9.48 \mathrm{E}-09$ & 2.79E-09 & 7.85E-06 \\
\hline 661.66 & $5.75 \mathrm{E}-05$ & 94E-05 & $.59 \mathrm{E}-06$ & 1.73E-05 & 56E-06 & $.43 \mathrm{E}-06$ & 4.96E-08 & $.80 \mathrm{E}-08$ & 1.25E-08 & 8.99E-08 & $2.81 \mathrm{E}-08$ & 8.81E-09 & 7.42E-06 \\
\hline 11.2 & 4.67E-05 & 5 & $92 \mathrm{E}-06$ & 1.3 & -06 & -06 & $2.89 \mathrm{E}-07$ & E-07 & 5.04E-08 & 4.72E-07 & -07 & E-08 & $6.47 \mathrm{E}-06$ \\
\hline 73.24 & -05 & -05 & $7.06 \mathrm{E}-06$ & 05 & $E-06$ & -06 & -07 & -07 & 07 & -07 & -07 & -07 & $5.79 \mathrm{E}-06$ \\
\hline 1332.5 & $3.54 \mathrm{E}-05$ & $1.56 \mathrm{E}-05$ & $6.95 \mathrm{E}-06$ & 1.05 & $E-06$ & -06 & $7.95 \mathrm{E}-07$ & $35 \mathrm{E}-07$ & -07 & -06 & -07 & -07 & $5.44 \mathrm{E}-06$ \\
\hline & & & & & & & & & & & & & \\
\hline 14.5 & $2.03 \mathrm{E}-05$ & $1.09 \mathrm{E}-05$ & $5.95 \mathrm{E}-06$ & $6.25 \mathrm{E}-06$ & $3.84 \mathrm{E}-06$ & $2.32 \mathrm{E}-06$ & $1.08 \mathrm{E}-06$ & $5.59 \mathrm{E}-07$ & $3.05 \mathrm{E}-07$ & $1.43 \mathrm{E}-06$ & $7.38 \mathrm{E}-07$ & 3.86E-07 & $3.29 \mathrm{E}-06$ \\
\hline
\end{tabular}

When plotted appropriately, expected characteristics arise: the deeper the source is buried, the smaller the efficiency; the further the source is moved from the centerline $(r=0)$, the smaller the efficiency. Each of these plots are actual data that have been fitted, by method of least squares, accordingly. 
The four efficiency curves as the source is moved from $r=0$ to $r=3 \mathrm{~m}$, in $1 \mathrm{~m}$ increments, are shown below. The Base Case is also shown for comparison.
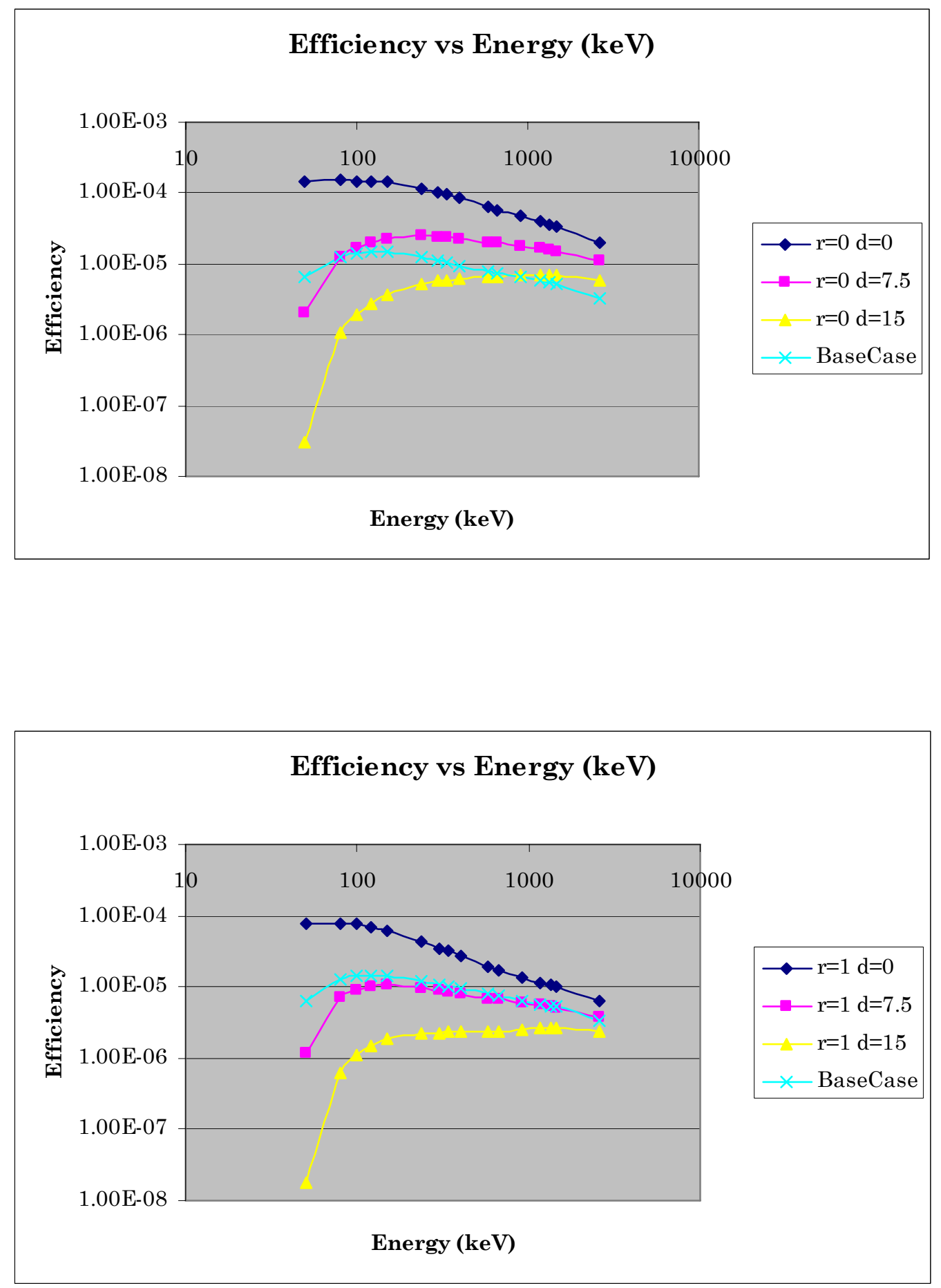
For $r=2$, which is outside the FOV by a factor of two, the efficiency function "breaks down" and should be used cautiously. There are probably mathematical artifacts (blurring) and incomplete convergence in the point-kernel model that are not well accounted for because the device is being asked to determine a fictional quantity beyond intended purpose. The same can be said for $\mathrm{r}=3 \mathrm{~m}$.
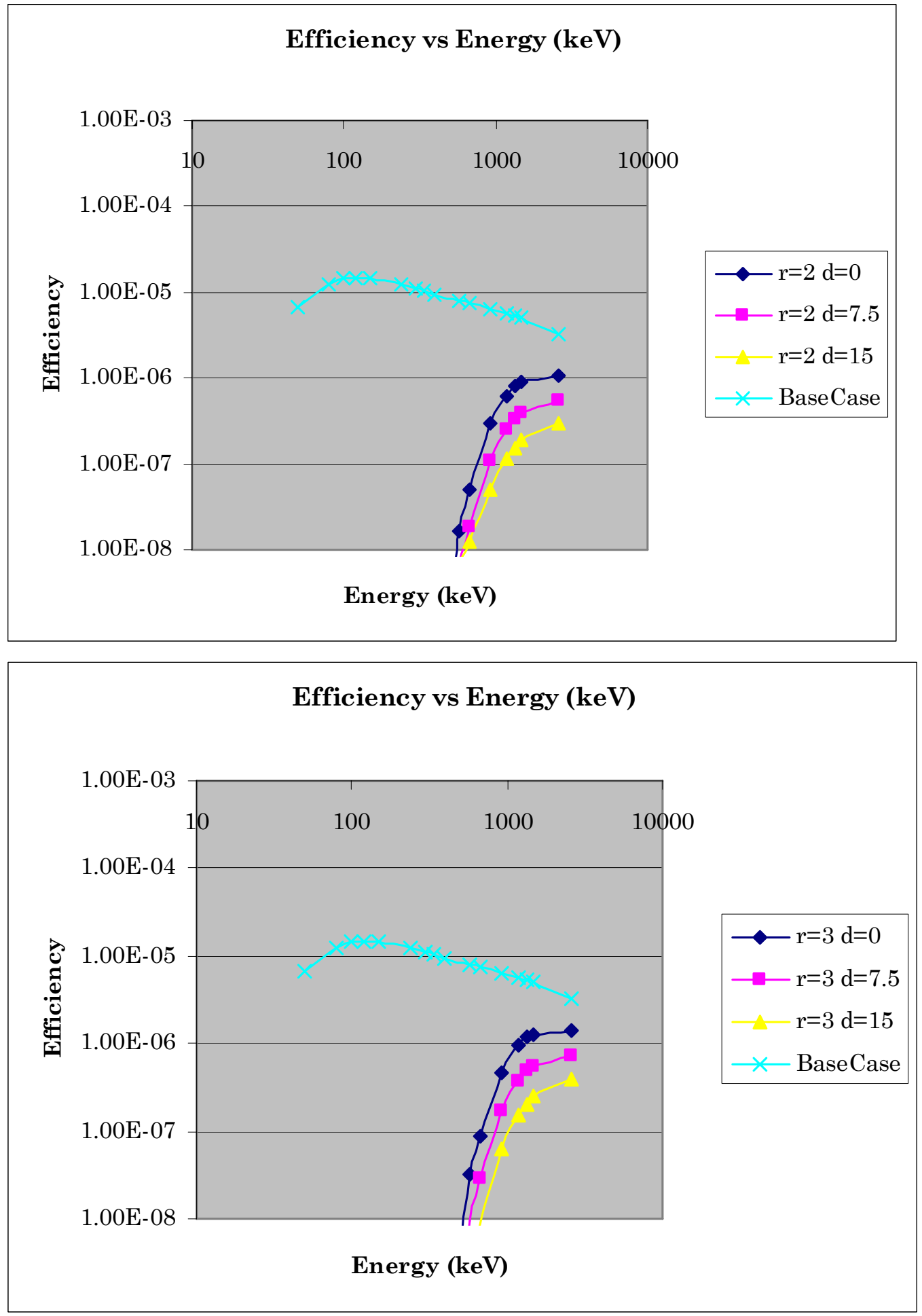
Now plotting the efficiency functions for the radii and holding the source depth constant:
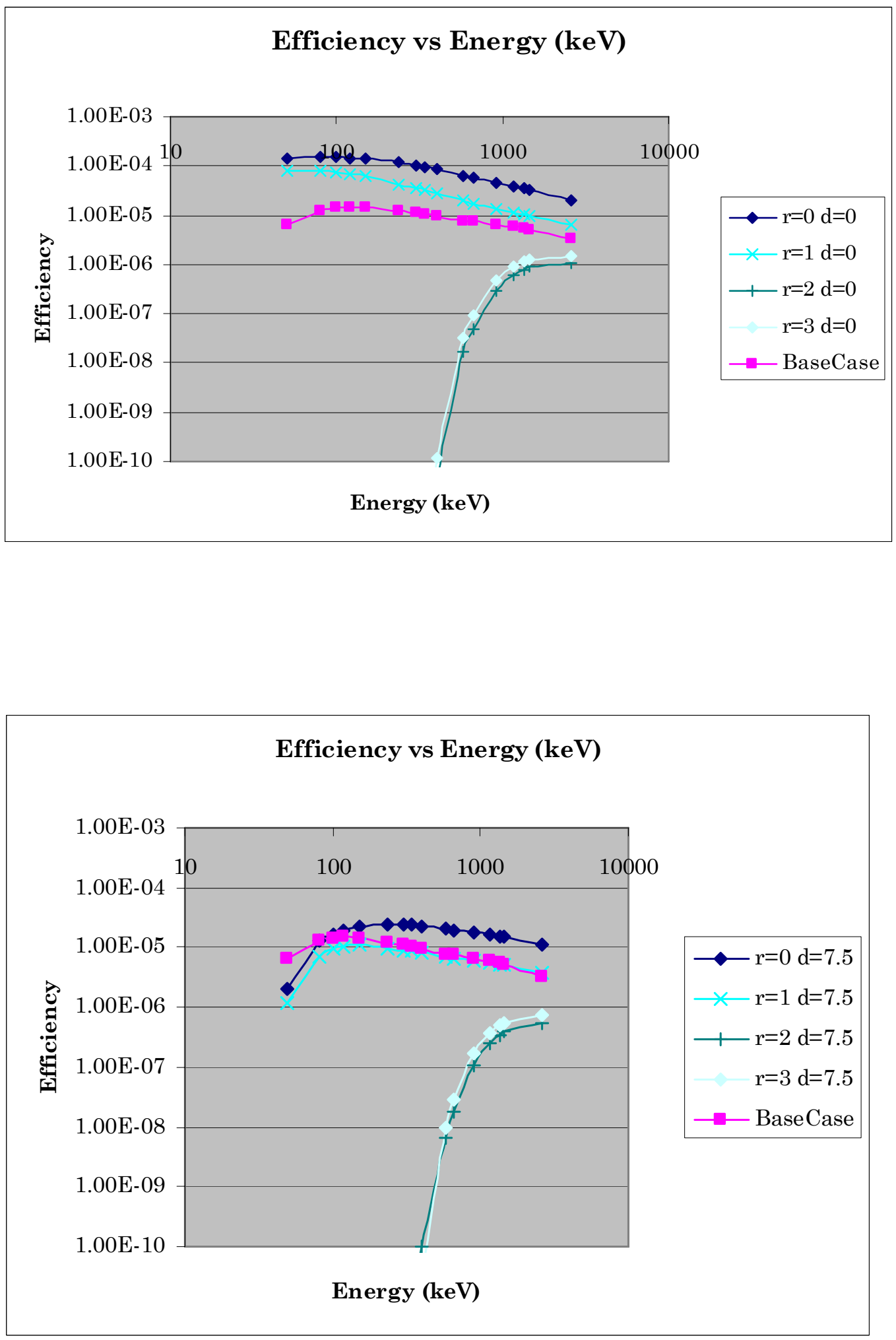


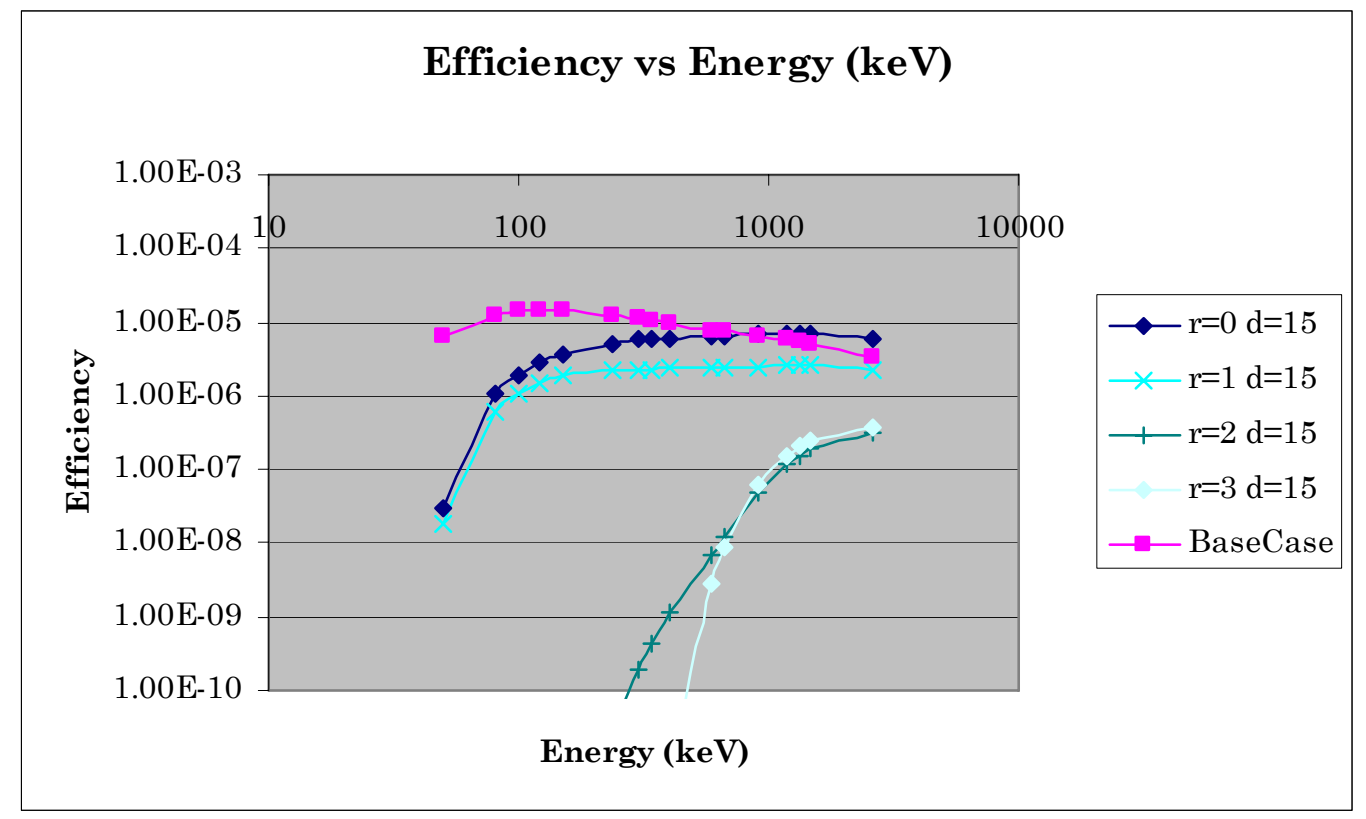

The ratio of the efficiency of the "actual" test measurement to the "Base Case" efficiency function, that is:

$$
\frac{\varepsilon(E)_{\text {actual }}}{\varepsilon(E)_{\text {base case }}}
$$

is shown in Table 10 .

Table 10. Efficiency Ratios (Actual to Base Case)

\begin{tabular}{|c|c|c|c|c|c|c|c|c|c|c|c|c|}
\hline Energy (keV) & $\begin{array}{l}r=0 \\
d=0\end{array}$ & $\begin{array}{l}\mathrm{r}=0 \\
\mathrm{~d}=7.5\end{array}$ & $\begin{array}{l}\mathrm{r}=0 \\
\mathrm{~d}=15\end{array}$ & $\begin{array}{l}r=1 \\
d=0\end{array}$ & $\begin{array}{l}\mathrm{r}=1 \\
\mathrm{~d}=7.5\end{array}$ & $\begin{array}{l}r=1 \\
d=15\end{array}$ & $\begin{array}{l}r=2 \\
d=0\end{array}$ & $\begin{array}{l}\mathrm{r}=2 \\
\mathrm{~d}=7.5\end{array}$ & $\begin{array}{l}r=2 \\
d=15\end{array}$ & $\begin{array}{l}r=3 \\
d=0\end{array}$ & $\begin{array}{l}\mathrm{r}=3 \\
\mathrm{~d}=7.5\end{array}$ & $\begin{array}{l}r=3 \\
d=15\end{array}$ \\
\hline 50 & 22.27 & 0.32 & 0.00 & 11.78 & 0.18 & 0.00 & $0.00 \mathrm{E}+00$ & $0.00 \mathrm{E}+00$ & $5.10 \mathrm{E}-20$ & $0.00 \mathrm{E}+00$ & $0.00 \mathrm{E}+00$ & $0.00 \mathrm{E}+00$ \\
\hline 80 & 12.24 & 1.01 & 0.08 & 6.28 & 0.56 & 0.05 & $4.44 \mathrm{E}-40$ & $2.99 \mathrm{E}-25$ & 7.96E-10 & $0.00 E+00$ & $0.00 \mathrm{E}+00$ & $0.00 E+00$ \\
\hline 100 & 10.49 & 1.19 & 0.14 & 5.30 & 0.65 & 0.08 & $0.00 \mathrm{E}+00$ & $0.00 \mathrm{E}+00$ & $6.32 \mathrm{E}-16$ & $0.00 \mathrm{E}+00$ & $0.00 \mathrm{E}+00$ & $0.00 \mathrm{E}+00$ \\
\hline 120 & 9.99 & 1.35 & 0.19 & 4.79 & 0.70 & 0.10 & $0.00 \mathrm{E}+00$ & $1.61 \mathrm{E}-38$ & $2.09 \mathrm{E}-12$ & $0.00 \mathrm{E}+00$ & $0.00 \mathrm{E}+00$ & $0.00 \mathrm{E}+00$ \\
\hline 150 & 9.81 & 1.56 & 0.25 & 4.34 & 0.75 & 0.13 & $3.71 \mathrm{E}-38$ & $3.74 \mathrm{E}-24$ & 1.35E-09 & $0.00 \mathrm{E}+00$ & $0.00 \mathrm{E}+00$ & $0.00 \mathrm{E}+00$ \\
\hline 238.6 & 9.65 & 2.00 & 0.42 & 3.52 & 0.80 & 0.18 & $8.91 \mathrm{E}-15$ & $1.09 \mathrm{E}-10$ & $2.04 \mathrm{E}-06$ & $1.40 \mathrm{E}-16$ & $2.08 \mathrm{E}-17$ & $3.04 \mathrm{E}-18$ \\
\hline 300 & 9.51 & 2.22 & 0.52 & 3.22 & 0.83 & 0.21 & 5.63E-10 & 7.82E-08 & 1.70E-05 & 5.99E-10 & $1.13 \mathrm{E}-10$ & $2.12 \mathrm{E}-11$ \\
\hline 338.3 & 9.26 & 2.30 & 0.58 & 3.08 & 0.84 & 0.22 & $4.02 \mathrm{E}-08$ & 8.32E-07 & $4.21 \mathrm{E}-05$ & $9.12 \mathrm{E}-08$ & $1.90 \mathrm{E}-08$ & $3.95 \mathrm{E}-09$ \\
\hline 400 & 8.92 & 2.40 & 0.65 & 2.89 & 0.86 & 0.25 & 4.80E-06 & 1.06E-05 & 1.23E-04 & $1.20 \mathrm{E}-05$ & $2.83 \mathrm{E}-06$ & $6.67 \mathrm{E}-07$ \\
\hline 583.2 & 8.04 & 2.57 & 0.83 & 2.46 & 0.88 & 0.31 & $2.13 \mathrm{E}-03$ & $8.24 \mathrm{E}-04$ & $8.81 \mathrm{E}-04$ & $4.12 \mathrm{E}-03$ & $1.21 \mathrm{E}-03$ & $3.55 \mathrm{E}-04$ \\
\hline 661.66 & 7.76 & 2.62 & 0.89 & 2.33 & 0.88 & 0.33 & $6.69 \mathrm{E}-03$ & 2.43E-03 & 1.69E-03 & $1.21 \mathrm{E}-02$ & $3.78 \mathrm{E}-03$ & 1.19E-03 \\
\hline 911.2 & 7.22 & 2.77 & 1.07 & 2.08 & 0.91 & 0.39 & 4.48E-02 & 1.67E-02 & 7.79E-03 & 7.29E-02 & $2.63 \mathrm{E}-02$ & 9.49E-03 \\
\hline 1173.24 & 6.80 & 2.87 & 1.22 & 1.98 & 0.95 & 0.45 & $1.07 \mathrm{E}-01$ & $4.32 \mathrm{E}-02$ & $1.98 \mathrm{E}-02$ & $1.62 \mathrm{E}-01$ & $6.44 \mathrm{E}-02$ & $2.58 \mathrm{E}-02$ \\
\hline 1332.5 & 6.50 & 2.87 & 1.28 & 1.94 & 0.98 & 0.48 & $1.46 \mathrm{E}-01$ & $6.16 \mathrm{E}-02$ & $2.86 \mathrm{E}-02$ & $2.15 \mathrm{E}-01$ & 9.03E-02 & $3.80 \mathrm{E}-02$ \\
\hline 1460 & 6.39 & 2.91 & 1.34 & 1.90 & 0.99 & 0.51 & $1.74 \mathrm{E}-01$ & $7.61 \mathrm{E}-02$ & $3.61 \mathrm{E}-02$ & $2.49 \mathrm{E}-01$ & $1.08 \mathrm{E}-01$ & $4.72 \mathrm{E}-02$ \\
\hline 2614.5 & 6.18 & 3.32 & 1.81 & 1.90 & 1.17 & 0.71 & $3.27 \mathrm{E}-01$ & $1.70 \mathrm{E}-01$ & $9.28 \mathrm{E}-02$ & $4.34 \mathrm{E}-01$ & $2.24 \mathrm{E}-01$ & 1.17E-01 \\
\hline
\end{tabular}

The only meaningful ratios are for the cases when the source is within the field of view (FOV). That is the ratios for $r=2$ and $r=3$ are too small to be meaningful (as expected).

Looking at the first case for $\mathrm{r}=0, \mathrm{~d}=0$, for $50-\mathrm{keV}$ gamma-rays the ratio is 22.27 . This means that a discrete source of radioactivity the size of a Marinelli beaker placed on the surface of the earth $1 \mathrm{~m}$ directly below the detector (38\% efficient detector, 90-degree collimator) would yield a response that is 22.27 times that of the same amount of total radioactivity 
uniformly distributed throughout a volume element with radius of $100 \mathrm{~cm}$, thickness of 15 $\mathrm{cm}$, density $1.7 \mathrm{~g} / \mathrm{cm}^{3}$, with a total weight of about $800 \mathrm{~kg}$, given that the radioactive material emits $50-\mathrm{keV}$ gamma rays. What is most interesting is to look at the ratios at the periphery of the FOV. When the discrete source is on the periphery $(r=1)$ and placed on the surface, the efficiency is at least a factor of two greater than the efficiency for the same activity in the base case disc source, over all gamma-ray energies. When the source is buried at $7.5 \mathrm{~cm}$ at $\mathrm{r}=1$, the efficiency is about the same as the base case distributed source. When the source is buried at $15 \mathrm{~cm}, \mathrm{r}=1 \mathrm{~m}$, the ratio (as expected) increases with energy - the more penetrating gamma-rays survive collisions in the $15 \mathrm{~cm}$ of soil. The chance of detecting a buried Am241 source on the periphery is very small, on a per unit activity basis.

All of the reported MDAs for the Base Case are equivalent to a discrete source buried 7.5 $\mathrm{cm}$ below grade, and placed on the periphery for the field of view, $\mathrm{r}=1 \mathrm{~m}$. By calculating ratios accordingly, benchmarks for MDAs for discrete sources on the periphery and positioned anywhere within the FOV are determined.

Table 11 below shows in fact that the MDAs for discrete sources of Co-60, Cs-137, and Ac228 placed on the periphery of the FOV $(\mathrm{r}=1 \mathrm{~m})$ and buried $7.5 \mathrm{~cm}$ are about the same as for the Base Case efficiency function for a distributed source. The values in the table show for discrete sources placed at either $r=0, d=0,7.5$, or 15 ; or $r=1, d=0,7.5$, or 15 the MDAs for the uniformly distributed source or for a discrete particle source placed at that corresponding position. It is important to note that the MDAs calculated (Currie Method) for the distributed source were calculated with the actual test sources in the ground; otherwise, the MDAs for all measurement conditions would be statistically the same (with the same background spectrum). The MDAs for the discrete source case should worsen as the source is moved out to the periphery or beneath the ground, and looking at the table, they do in most cases where counting statistics are favorable.

Table 11. MDAs for Discrete Sources compared to the Base Case Model for a Distributed Source (1 meter measurement)

\begin{tabular}{|c|c|c|c|c|c|c|}
\hline & \multicolumn{3}{|c|}{ Distributed Source } & \multicolumn{3}{|c|}{ Discrete Source } \\
\hline & Co-60 & Cs-137 & Ac-228 & Co-60 & Cs-137 & Ac-228 \\
\hline Spectrum ID & MDA (uCi) & MDA (uCi) & MDA (uCi) & MDA (uCi) & MDA (uCi) & MDA (uCi) \\
\hline$r=0, d=0$ & 0.18 & 0.37 & 0.62 & 0.03 & 0.14 & 0.58 \\
\hline$r=1, d=0$ & 0.13 & 0.3 & 0.39 & 0.07 & 0.13 & 0.19 \\
\hline$r=0, d=7.5$ & 0.19 & 0.31 & 0.71 & 0.07 & 0.12 & 0.66 \\
\hline$r=1, d=7.5$ & 0.12 & 0.24 & 0.38 & 0.13 & 0.27 & 0.42 \\
\hline$r=0, d=15$ & 0.19 & 0.31 & 0.60 & 0.16 & 0.16 & 0.63 \\
\hline$r=1, d=15$ & 0.11 & 0.17 & 0.49 & 0.24 & 0.52 & 1.27 \\
\hline
\end{tabular}

Similar relative results can be expected for the $2 \mathrm{~m}$ high measurements. 